Universidade de São Paulo

Instituto de Física

\title{
Fabricação e caracterização de filmes semicondutores de InN depositados com o método de deposição assistida por feixe de íons
}

\author{
Karina Carvalho Lopes
}

Orientador: Prof. Dr. Masao Matsuoka

Dissertação de mestrado apresentada ao Instituto de Física para a obtenção do título de Mestre em Ciências

Comissão Examinadora:

Prof. Dr. Masao Matsuoka - Universidade de São Paulo

Profa. Dra. Luisa Maria Scolfaro Leite - Universidade de São Paulo

Profa. Dra. Ivette Frida Cymbaum Oppenheim - Universidade de São Paulo 


\section{FICHA CATALOGRÁFICA}

Preparada pelo Serviço de Biblioteca e Informação do Instituto de Física da Universidade de São Paulo

Lopes, Karina Carvalho

Fabricação e caracterização de filmes semicondutores de $\ln \mathrm{N}$ depositados com o método de deposição assistida por feixe de elétrons - São Paulo - 2008

Dissertação (Mestrado) - Universidade de São Paulo. Instituto de Física - Depto. de Física Nuclear

Orientador: Prof. Dr. Masao Matsuoka

Área de Concentração: Física

Unitermos: 1. Física da Matéria Condensada;

2. Filmes finos; 3. Semicondutores; 4 . Nitreto de índio. 
"Ensina-nos a contar os nossos dias, para que alcancemos coração sábio."

(s| 90:12) 


\section{Agradecimentos}

Primeiramente, quero agradecer ao Prof. Masao, que me orientou de forma incansável e também por sua amizade. Aos professores que muito contribuíram para a realização deste trabalho: prof. Pedro Kiohara, prof. Pedro Nascente, prof. Chubaci, prof. Jaime, profa. Roseli e prof. Luis. À parte técnica, que ajudou a montar o laboratório: colaboradores da oficina mecânica, Celso e Tromba. Em especial, sou grata ao Prof. José Roberto Leite por introduzir este fascinante tema.

Aos amigos: Anne, Bahia, Elisa, Fla, Le e So, do IFUSP; aos queridos da LUZ-EF; Deinha, Isabella e a todos os outros que não coloquei os nomes. Ao Henady.

À minha família, que me apoiou em todos os momentos.

À FAPESP e Naval Research Laboratory por financiarem este projeto.

Obrigada . 


\section{ÍNDICE}

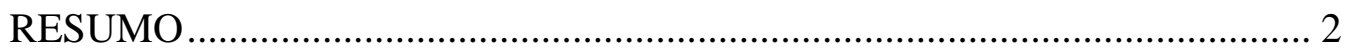

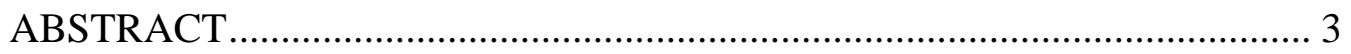

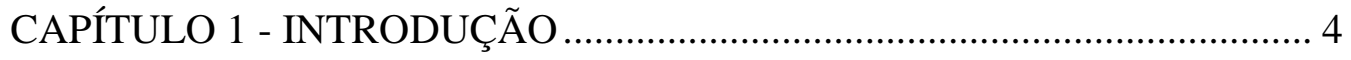

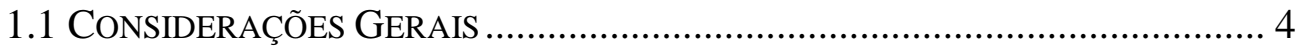

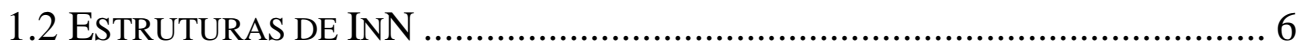

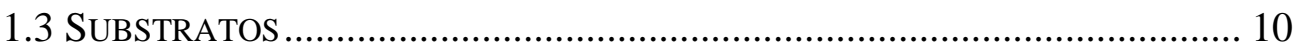

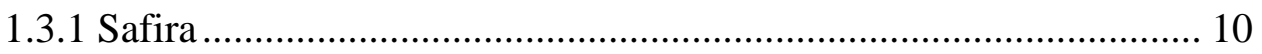

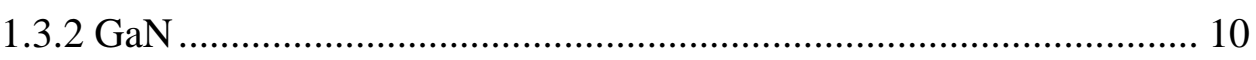

1.3.3 Silício ........................................................................................ 11

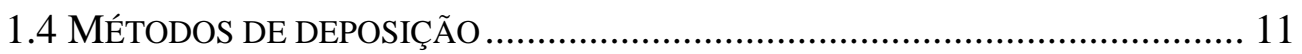

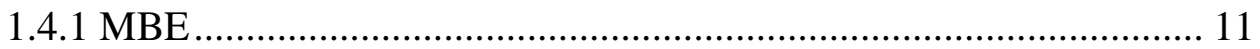

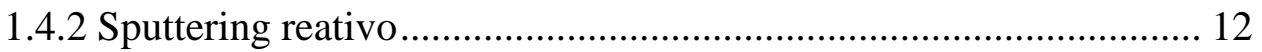

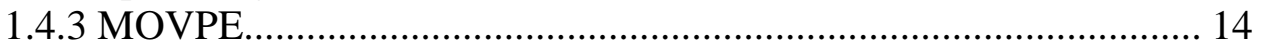

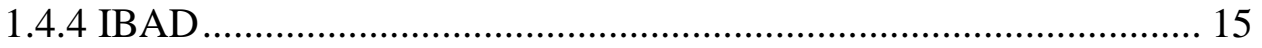

1.5 MOTIVAÇÕES E OBJETIVOS DO TRABALHO .............................................. 16

CAPÍTULO 2 - MÉTODO EXPERIMENTAL .............................................. 18

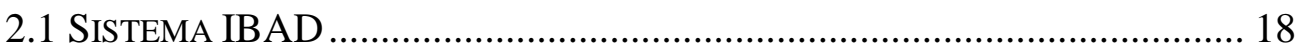

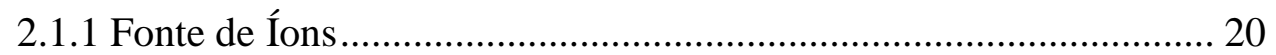

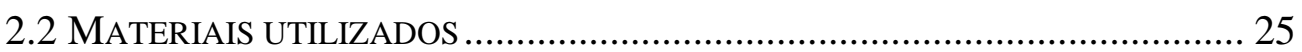

2.3 TÉCNICAS DE CARACTERIZAÇÃO ......................................................... 32

2.3.1 Difração de Raios-X ...................................................................... 32

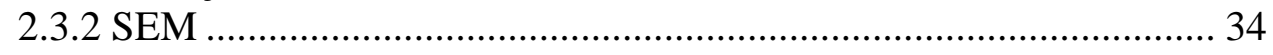

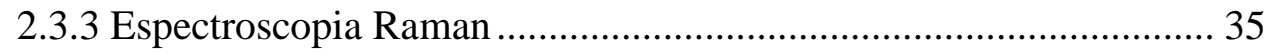

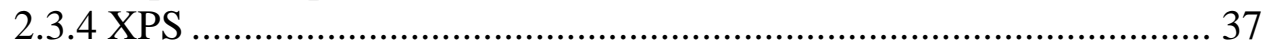

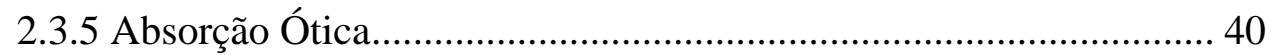

CAPÍTULO 3 - RESULTADOS E DISCUSSÃO ......................................... 42

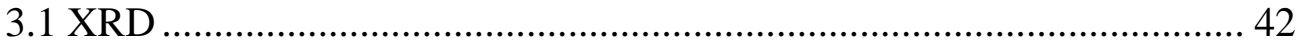

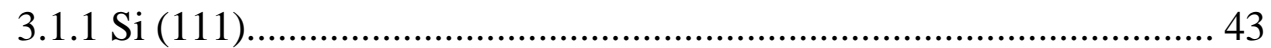

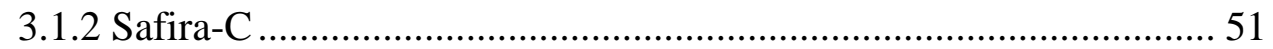

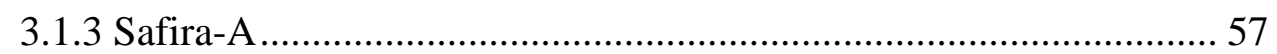

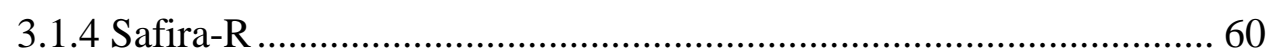

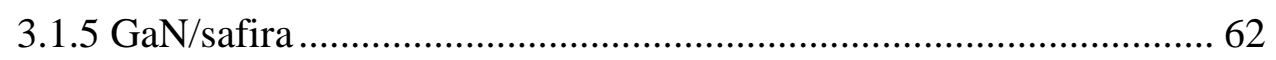

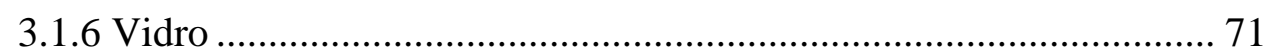

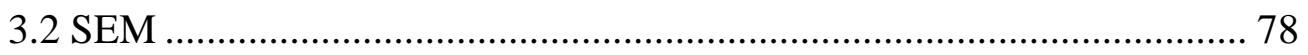

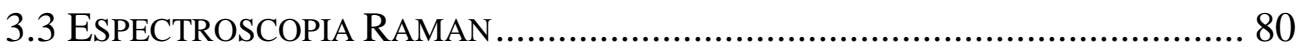

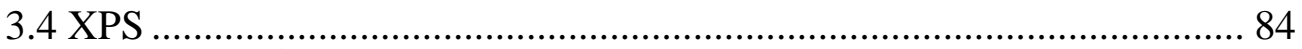

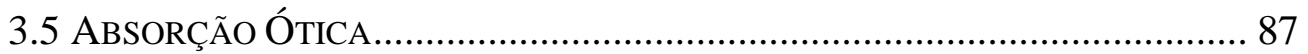

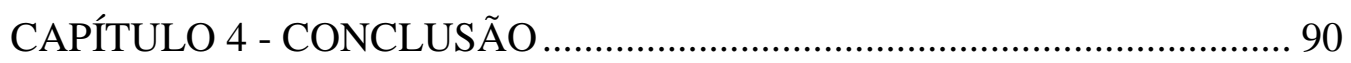

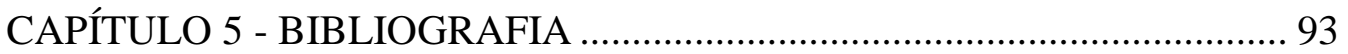




\section{Resumo}

Neste trabalho, analisamos as propriedades estruturais, morfológicas e óticas de filmes finos de nitreto de índio, depositados em diferentes tipos de substratos ( $\mathrm{Si}$, safira-C, safira-A, safira-R, GaN/safira e vidro) pelo método de deposição assistida por feixe de elétrons com energia de íons entre 100 e $1180 \mathrm{eV}$. A temperatura de substrato durante o processo de deposição variou da temperatura ambiente (TA) à $450^{\circ} \mathrm{C}$, e ARR(I/A), que é a razão do fluxo de íons incidentes no feixe de íons relativa ao fluxo de átomos de In evaporados, de 0,8 até 4,5. O crescimento de $\operatorname{InN}$ cristalino foi fortemente influenciado pela orientação cristalográfica do substrato e os filmes sobre safira-C, safira-A e GaN/safira foram os que apresentaram maior cristalinidade. O melhor valor de energia de íons foi de 100 eV para a formação de $\mathrm{InN}$ cristalino e sua cristalinidade aumentou com o aumento da temperatura do substrato. Não observamos influências de ARR(I/A) sobre a cristalinidade de InN e os filmes preparados em TA sobre $\mathrm{GaN} /$ safira apresentaram InN amorfo. 


\section{Abstract}

In this work, we analyzed the structural, morphological and optical properties of thin indium nitride films grown on some types of substrate ( $\mathrm{Si}$, c-plane sapphire, a-plane sapphire, r-plane sapphire, GaN/sapphire and glass) by the ion beam assisted deposition method with ion energy of 100-1180 eV. The substrate temperature during deposition ranged from room temperature (RT) to $450^{\circ} \mathrm{C}$ and $\mathrm{ARR}(\mathrm{I} / \mathrm{A})$, from 0.8 to 4.5 . The growth of crystalline InN was strongly influenced by the crystallographic orientation of substrate and the films on cplane sapphire, a-plane sapphire and GaN/sapphire provided more favorable results. The best value of ion energy was found to be $100 \mathrm{eV}$ for the formation of crystalline InN and this crystallization increased with increasing the substrate temperature. We found that influence of ARR(I/A) on the crystallization of InN was imperceptible and that the film prepared at $\mathrm{RT}$ on the GaN/sapphire was amorphous of $\mathrm{InN}$. 


\section{Capítulo 1}

\section{Introdução}

\subsection{Considerações Gerais}

Na última década, semicondutores de nitreto do grupo III (AlN, GaN e InN) e suas ligas ternárias tornaram-se promissores materiais para dispositivos ópticos e eletrônicos, em conseqüência da extensão de seus band gaps de 0,9 a 6,2 eV, cobrindo a região infravermelha, toda a região do visível e ultravioleta (UV) [1-4]. Atualmente, filmes finos de GaN, $\mathrm{In}_{\mathrm{x}} \mathrm{Ga}_{1-\mathrm{x}} \mathrm{N}$ e $\mathrm{Al}_{\mathrm{x}} \mathrm{Ga}_{1-\mathrm{x}} \mathrm{N}$, ricos em Ga, são usados em dispositivos opto-eletrônicos comerciais, tais como diodos emissores de luz (LEDs) e lasers [5,6]. Também são utilizados em LEDs de UV baseados em GaN, sendo combinados com materiais fosforescentes, que são usados como emissores de luz branca com alta eficiência.

É conhecido que o InN possui a menor massa efetiva de elétrons de todos os semicondutores de nitretos do grupo III e, portanto, a mais alta mobilidade, fornecendo uma oportunidade significativa de avanço nos dispositivos de alta freqüência [7].

Entretanto, o crescimento de InN é o mais difícil entre estes nitretos porque a pressão de vapor de equilíbrio do nitrogênio sobre InN é algumas ordens de grandeza maior que sobre AlN e GaN. A quantidade de estudos sobre InN é relativamente pequena, devido à sua baixa temperatura de 
decomposição e falta de substratos adequados, cujas constantes de rede e coeficiente de dilatação térmica igualam-se àqueles de $\operatorname{InN}[4]$.

Com o avanço de técnicas de crescimento, filmes finos de InN têm sido depositados com sucesso sobre substratos de safira $\left(\mathrm{Al}_{2} \mathrm{O}_{3}\right), \mathrm{GaAs}, \mathrm{GaP}, \mathrm{Si}$ e vidro, por epitaxia por feixe molecular (Molecular Beam Epitaxy - MBE) [8] e epitaxia de fase de vapor organometálico (Metalorganic Vapor Phase Epitaxy - MOVPE) [9]. Porém, algumas propriedades ópticas e eletrônicas importantes ainda não são entendidas, tal como o band gap Eg; a maioria dos valores experimentais é cerca de 1,9-2,0 eV, mas recentemente, foi relatado o Eg no intervalo de 0,7-1,1 eV para filme finos de alta qualidade formados por MBE e MOVPE.

A primeira tentativa de sintetizar InN foi feita por Juza e Hahn em 1938 a partir de $\operatorname{InF}_{6}\left(\mathrm{NH}_{4}\right)_{3}$ e a estrutura cristalina de InN obtida foi wurtzita [10]. Após isso, outras tentativas foram feitas por Juza e Rabenua em 1956 [11], Renner em 1958 [12], Pastrnak e Souckova em 1963 [13] e Samsonov em 1969 [14]. McChesney et al. relataram que a pressão de dissociação de $\operatorname{In} N$ é extremamente alta e que InN não é formado pela reação direta de moléculas de $\mathrm{N}_{2}$ e In de maneira não ativa [15]. Os métodos usados até então utilizavam-se da reação de um composto de In com amônia ou da decomposição térmica de compostos complexos contendo In e N, sendo o InN obtido em forma de pó ou cristal pequeno. Os primeiros sucessos no crescimento de filmes de InN foram obtidos por Hovel e Cuomo em 1972 utilizando o método sputtering reativo de radiofreqüência (RF) [16]. Em 1974, Trainor e Rose relataram algumas propriedades óticas e elétricas de filmes de InN crescidos sobre substrato de safira através de evaporação reativa e discutiram a estabilidade térmica de InN [17]. No mesmo período, o crescimento de InN foi obtido por Andreeyva e Eliseejva através de sputtering e por Osamura et al. através do método de plasma de feixe de elétrons $[18,19]$. 
Marasina et al. cresceram camadas epitaxiais de $\operatorname{InN}$ sobre substratos de quartzo e safira pelo método MOVPE utilizando a interação entre $\mathrm{InCl}_{3}$ e $\mathrm{NH}_{3}$ [20]. Eles verificaram que a temperatura do substrato é um dos parâmetros mais importante para determinar as melhores condições de crescimento do filme, devido à rápida dissociação do InN ocorrendo acima de $600^{\circ} \mathrm{C}$; não há nenhuma deposição de $\operatorname{InN}$ em $670^{\circ} \mathrm{C}$.

$\mathrm{Na}$ década de 80, alguns importantes trabalhos sobre crescimento de InN através do método sputtering reativo foram produzidos [21-25]. Muitas propriedades de filmes de InN foram estudadas neste período no qual o trabalho de Tansley e Foley foi proeminente [21-23]. Filmes monocristalinos de InN foram crescidos sobre substratos de safira em 1989 por Matsuoka et al. e por Wakahara et al. através do método MOVPE reagindo trimetil-índio (trimethylindium - TMI), $\left(\mathrm{CH}_{3}\right)_{3} \mathrm{In}$ com $\mathrm{NH}_{3}$ e ou $\mathrm{N}_{2}$ ativado por microonda, respectivamente.

$\mathrm{O}$ crescimento epitaxial de filmes de InN monocristalinos e de boa qualidade é amplamente feito desde a década de 90 sobre diferentes substratos e camadas intermediárias com diferentes condições de crescimento, com os métodos MOVPE e $\operatorname{MBE}[26,27]$.

\subsection{Estruturas de InN}

Apesar de haver uma grande variedade de fatores que influenciam o empacotamento dos átomos em cristais, eles geralmente procuram o empacotamento periódico mais eficiente possível a fim de maximizar atrações inter-atômicas. Os átomos podem ser aproximados por esferas rígidas e uniformes. Imaginemos uma camada hipoteticamente infinita de átomos do tipo A sobre um plano cartesiano $\theta$. Consideremos agora apenas 
um destes átomos $\mathrm{A}$ rodeado por mais outros seis átomos deste mesmo tipo A. Estes sete átomos-esfera terão seus respectivos centros em posições geométricas bem definidas quando projetados no plano $\theta$. Acima desta camada A haverá uma outra camada inteiramente composta por átomos, digamos, do tipo B. Estes átomos B acomodar-se-ão nos vãos (depressões) entre os átomos da camada $\mathrm{A}$. Os centros geométricos destes átomosesfera $B$, quando projetados no plano $\theta$, claramente não coincidirão com as coordenadas dos centros dos átomos A, conforme observado na figura1.1.

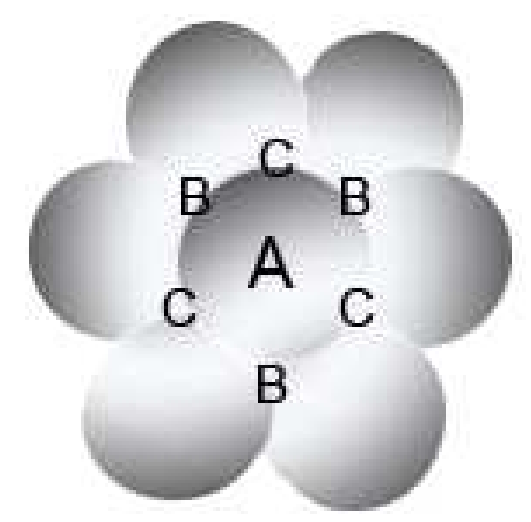

Figura 1.1: vista por cima da camada A, as posições no plano $\theta$ dos centros dos átomosesferas das camadas $B$ e C (em branco), acomodadas nos vãos da camada $A$.

Sendo assim, temos uma primeira camada A sobreposta por uma outra camada $B$, ambas sobre o plano $\theta$. Olhando de cima, estas duas camadas apresentarão seus centros A e B em diferentes posições no plano $\theta$. Podemos colocar ainda uma terceira camada de átomos do tipo $\mathrm{C}$ por cima destas duas outras camadas, A e B. Por abuso de linguagem, podemos nos referir tanto às camadas por $\mathrm{C}$, quanto aos átomos, quanto às 
esferas, quanto às coordenadas dos centros projetadas no plano $\theta$.

Com base nisso, podemos discutir o empacotamento atômico que nos interessa. Pode-se colocar uma terceira camada de esferas empacotadas compactamente tanto sobre as posições B como sobre as posições C. Uma forma bastante comum de empacotamento compacto corresponde a camadas empilhadas do tipo $\mathrm{ABAB}$ ou ACAC (são equivalentes). Esta estrutura é chamada hexagonal compacta (hc). Existe uma segunda forma correspondente a uma pilha de camadas do tipo ABCABC que representa a estrutura atômica cúbica de empacotamento compacto, isto é, átomos estão colocados nos vértices de um cubo, com átomos adicionais nos centros de cada face do cubo. Esta estrutura é conhecida por cúbica de faces centradas (cfc). A competição entre hc e cfc é determinada pelas forças de longo alcance existentes entre os átomos. O InN possui duas estruturas possíveis: wurtzita hexagonal ( $h$-InN) e cúbica zinc blende $(c-\operatorname{InN})$, como a figura 1.2 mostra. A tabela 1.1 indica os parâmetros de rede para as duas estruturas. A maior parte das pesquisas feitas é concentrada na estrutura hexagonal por ser uma fase estável termodinamicamente, enquanto a estrutura cúbica é uma fase metaestável. 


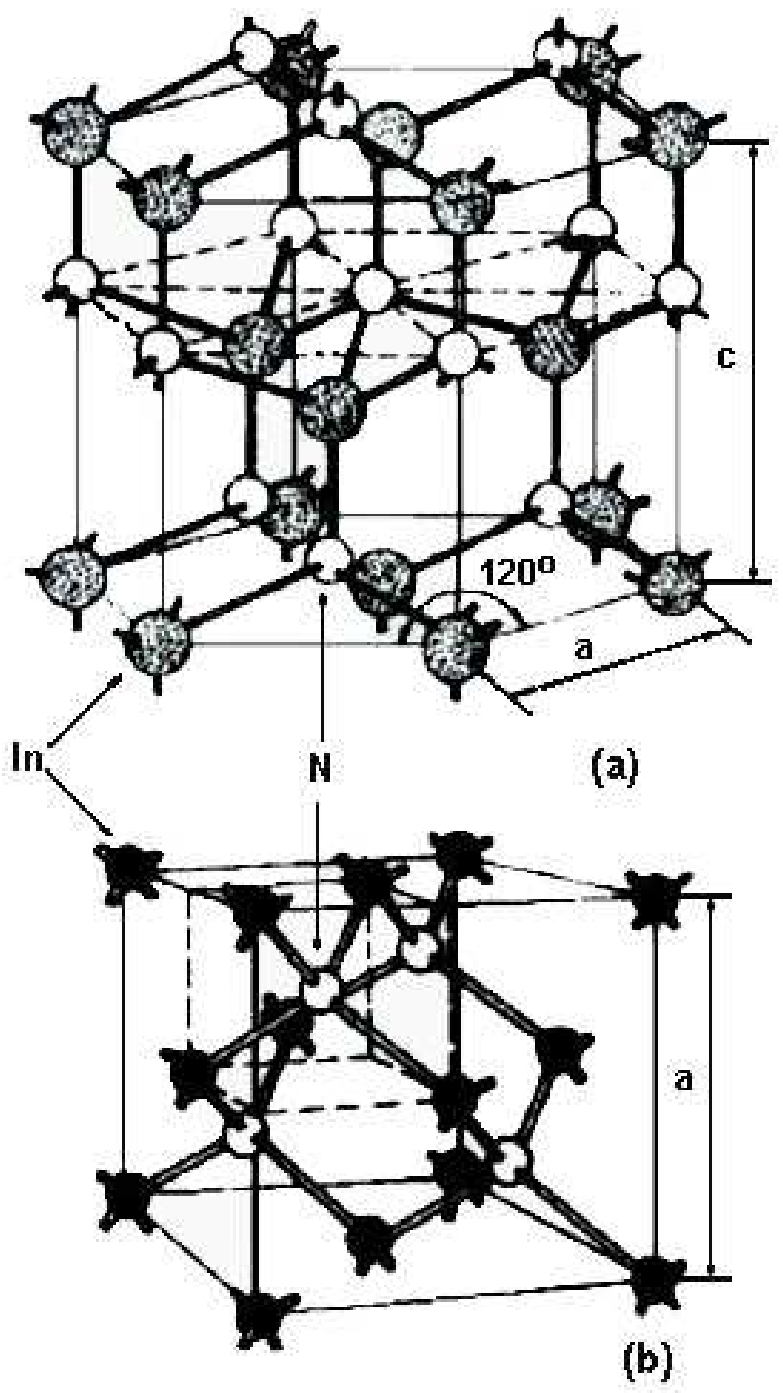

Figura 1.2. Estruras de InN: (a) wurtzita hexagonal ( $h$-InN) e (b) cúbica zinc blende $(c-\operatorname{InN})[28]$.

Tabela 1.1: Parâmetros de rede de $h-\operatorname{InN}$ e $c-\operatorname{InN}$ [28].

\begin{tabular}{ccc}
\hline \hline Estrutura & $\mathbf{a}(\AA)$ & $\mathbf{c}(\AA)$ \\
\hline$h-\operatorname{InN}$ & $3,501-3,536$ & $5,540-7,709$ \\
$c-\operatorname{InN}$ & $4,92-4,98$ & \\
\hline \hline
\end{tabular}




\subsection{Substratos}

Estudos indicam a importância dos substratos na formação do filme de InN. Os substratos de safira, nitreto de gálio (GaN) e silício ( $\mathrm{Si}$ ) são comumente utilizados para a deposição de In $\mathrm{N}$.

\subsubsection{Safira}

Os substratos de safiras são os mais utilizados no crescimento epitaxial de InN por serem transparentes e estáveis em alta temperatura. Porém, há um desacordo relativamente grande entre o parâmetro $a$ de h-InN e o de safira, hInN(001)/safira(001), igual a cerca de $25 \%$. Esse desacordo e a diferença entre o coeficiente da expansão térmica de InN e o de safira podem resultar em uma concentração de defeitos estruturais extremamente alta. Alguns pesquisadores têm demonstrado que o preparo do substrato e a introdução de uma camada intermediária entre o substrato e o filme podem melhorar significativamente a qualidade do filme, reduzindo a concentração de defeitos estruturais. A forma mais encontrada de InN crescido sobre safira é $h-I n N$, no entanto, Chen et al. relataram formação mista de $h$-InN e $c-\operatorname{InN}$ em temperatura de crescimento entre 345 e $450^{\circ} \mathrm{C}$ [29].

\subsubsection{GaN}

Devido a sua orientação cristalográfica ser a mesma de $h$ InN, e o desacordo entre $h$-InN(001)/GaN(001) ser de 10\%, pesquisadores empregam como camada intermediária sobre substratos de safira e GaAs [30]. 


\subsubsection{Silício}

O silício seria o material mais apropriado como substrato para a formação de InN por ter o menor desacordo entre $h$ InN(001)/Si(111), cerca de $8 \%$, e foi largamente utilizado como substrato, mas a qualidade dos filmes era muito pobre. Evidenciou-se que o insucesso era causado pela formação de uma camada de $\mathrm{SiN}_{x}$ em sua superfície, como resultado de uma nitridação não intencional da superfície do substrato durante o crescimento [31]. Entretanto, Yodo et al. relatam formação de filmes de InN sobre substratos de Si (001) e Si (111) em temperatura ambiente pelo método MBE de ressonância de cíclotron eletrônica (Electron Cyclotron Ressonance - ECRMBE), os quais exibiram uma forte emissão foto-luminescente em 1,814 eV para Si (001) e 1,880, 2,081 e 2,156 eV para Si (111) [32].

\subsection{Métodos de deposição}

Serão apresentados os três métodos mais utilizados na formação de InN: MBE, sputtering reativo, MOPVE e, por último, o nosso método de deposição assistida por feixe de íons (Ion Beam Assisted Deposition - IBAD).

\subsubsection{MBE}

O princípio de funcionamento do método MBE é a evaporação térmica no ambiente de ultra-alto vácuo (pressão de fundo de $10^{-10}-10^{-11}$ Torr) no qual acontece a deposição, na pureza e no controle extremamente precisos dos fluxos de materiais. 
Em um sistema MBE, os materiais a serem evaporados são colocados em células de efusão e evaporados através de um sistema de filamentos resistivos. Controladores eletrônicos de potência e sensores (termopares) são usados para manter constante a temperatura de cada célula de modo a gerar um fluxo estável de material. Na frente dessa célula está localizado o obturador mecânico que permite que o feixe seja interrompido quando necessário, permitindo o crescimento de camadas alternadas de diferentes materiais com interfaces abruptas. A disposição geométrica das células na câmara de ultra-alto vácuo é feita de forma que todos os feixes se cruzem na posição em que o substrato é colocado. Na superfície do substrato ocorrem todos os processos químicos e físicos relacionados ao crescimento, dos quais podemos citar a adsorção dos átomos ou moléculas, a migração superficial (difusão), dissociação de moléculas, incorporação dos átomos na rede cristalina e dessorção térmica das espécies não incorporadas [33].

Como a energia de dissociação de moléculas de $\mathrm{N}_{2}$ é em torno de 9,5 eV, o fornecimento de $\mathrm{N}_{2}$ gasoso à superfície do substrato não poderá introduzir qualquer crescimento de nitreto. Para se obter nitrogênio atômico reativo, as moléculas de $\mathrm{N}_{2}$ são dissociadas pelo plasma de radiofreqüência (RF-MBE) ou pela ECR-MBE. Às vezes, os feixes de compostos organometálicos são usados como fontes dos elementos requeridos (MOMBE).

\subsubsection{Sputtering reativo}

O principal do processo de deposição é transferir átomos removidos através de impacto de íons gasosos da superfície de um alvo sólido para um substrato onde serão realizadas a deposição e a formação do filme. O processo de sputtering é feito em gás inerte (usualmente argônio) para depositar um 
filme de alvo e no gás reativo apropriado adicional (tais como $\mathrm{N}_{2}$ e $\mathrm{O}_{2}$ ) para preparar um filme do composto requerido (por exemplo $\mathrm{InN}$ e $\mathrm{SiO}_{2}$ ).

O processo sputtering é dividido em três categorias: (1) DC, (2) RF e (3) magnetron.

\section{Sputtering DC}

O sputtering DC é o mais simples de todos. O alvo é situado no catodo e o substrato é colocado no anodo. Quando a pressão de gás dentro da câmara de sputtering chega a uma faixa 1 mTorr a 100 mTorr, é aplicada entre o catodo e o anodo uma tensão de alguns kV para criar um plasma. Os íons positivos criados neste plasma são acelerados em direção ao catodo, atacando o material do alvo; átomos assim removidos da superfície do alvo são depositados sobre o substrato. Uma desvantagem do método é a impossibilidade de se fazer sputtering nos materiais isolantes.

\section{Sputtering RF}

Foi criado com o propósito de fazer deposição de materiais isolantes. O mecanismo de deposição é igual ao método sputtering DC e a única diferença entre os dois métodos está na fonte de potência; uma fonte DC no sputtering DC e uma de RF no sputtering RF. A freqüência geralmente usada é de 13,56 MHz. O alvo será bombardeado alternadamente por íons e por elétrons e, assim, a carga média no alvo será exatamente nula, tornando-se possível a deposição de material isolante. 


\section{Magnetron sputtering}

Em magnetrons, elétrons não só chegam ao anodo, como estão aprisionados próximo ao alvo (catodo), prolongando o tempo de permanência dos elétrons no plasma e aumentando a eficiência de ionização. Este será feito com a presença de um campo magnético orientado paralelo à superfície do alvo e perpendicular ao campo elétrico. Na prática, utilizam-se ímãs permanentes embutidos no catodo para induzir esse campo magnético. Elétrons emitidos do catodo são inicialmente acelerados em direção ao anodo e, quando eles se encontram com a região do campo magnético, eles fazem movimentos espirais sob a força de Lorentz.

\subsubsection{MOVPE}

É um método de deposição química de vapor com o crescimento epitaxial de materiais, a partir de reação de compostos orgânicos ou organometálicos com os elementos requeridos. Um nome alternativo para este processo é deposição química de vapor organometálico (Metalorganic Chemical Vapor Deposition - MOCVD).

O crescimento de filme neste método é pela reação química, não pela deposição física usada nos outros métodos (MBE, sputttering reativo e IBAD). A reação química e a formação da camada epitaxial ocorrem na superfície do substrato a vácuo modesto. O filme de $\mathrm{InN}$ pode ser crescido sobre um substrato em um reator, geralmente usando TMI $\left[\left(\mathrm{CH}_{3}\right)_{3} \mathrm{In}\right]$ como uma fonte de In e o gás de amônia $\left(\mathrm{NH}_{3}\right)$, que é às vezes diluída com $\mathrm{N}_{2}$, como uma fonte de nitrogênio. $\mathrm{O}$ crescimento em baixas temperaturas, menores que $400^{\circ} \mathrm{C}$, é dominado pela formação de agregados de In metálico, devido à baixa taxa de decomposição de $\mathrm{NH}_{3}$ e à migração reduzida dos 
materiais depositados. Por outro lado, altas temperaturas de crescimento, apesar de ser esperado que a taxa de decomposição de $\mathrm{NH}_{3}$ seja alta, conduzem a decomposição térmica de InN. Portanto, a região de temperatura adequada para a deposição de In $\mathrm{N}$ é relativamente estreita.

\subsubsection{IBAD}

Na década de 80 foi desenvolvido um novo método de deposição por evaporação chamado IBAD. Neste método, a deposição de índio a vácuo sobre um substrato é combinada com a irradiação simultânea por íons de nitrogênio. Os íons, com energia de centenas de eV até dezenas de keV penetram em um substrato e chocam-se com átomos depositados sobre este, impelindo-os da superfície para dentro; a seguir é formada uma nova fase intermediária mista de elementos do substrato, íons incidentes e átomos (figura 1.3). A formação dessa nova fase intermediária aumenta, conseqüentemente, a aderência do filme depositado. Com este método, os parâmetros de deposição, tais como a taxa de deposição do índio, a energia de íons e a densidade de corrente de íons de nitrogênio são controlados independentemente e a razão do fluxo de íons incidentes (nitrogênio) no feixe de íons relativa ao fluxo de átomos de In evaporados e transportados ao substrato, ARR(I/A) pode ser facilmente variada. 


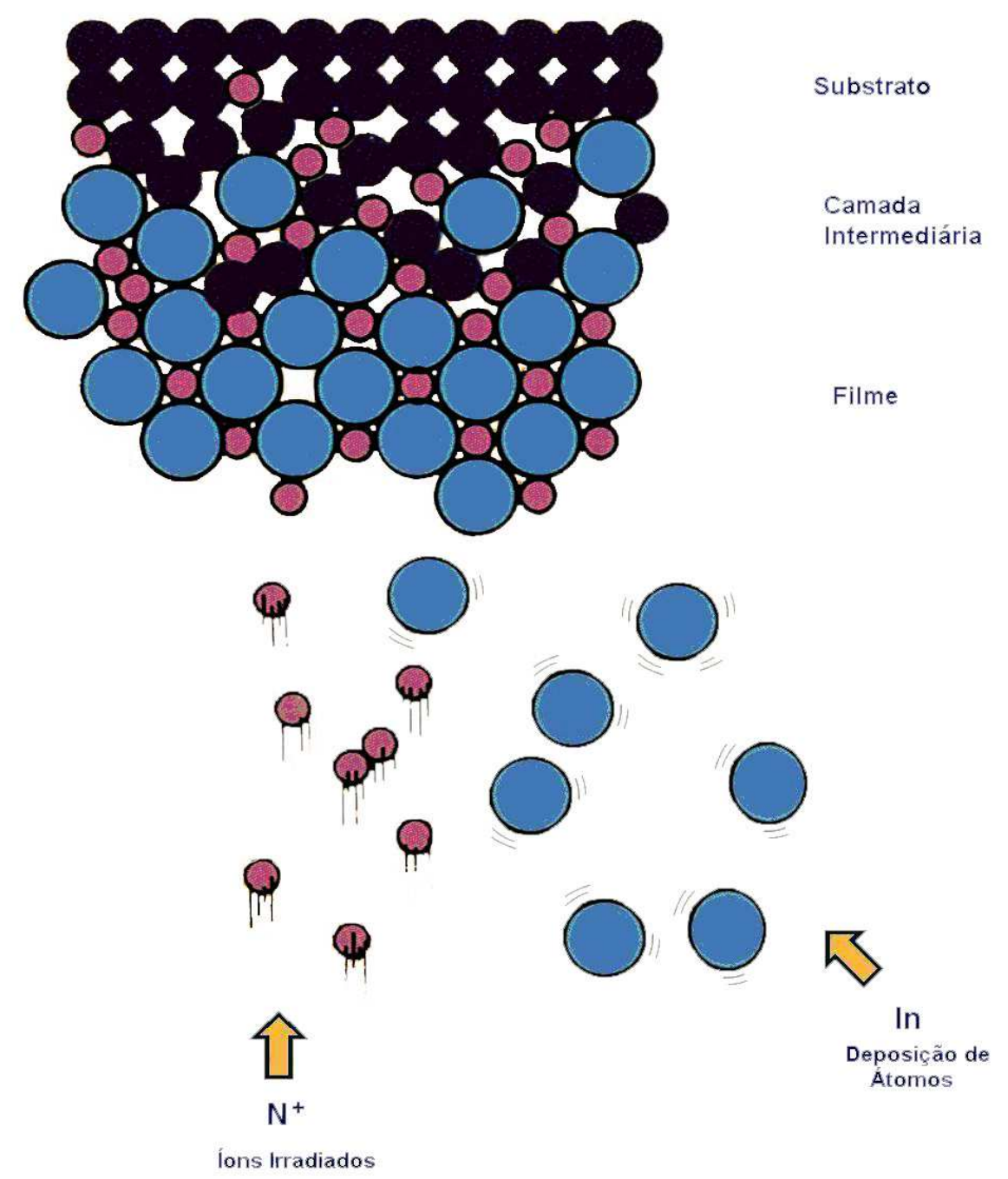

Figura 1.3. Esquema de formação de filme com o processo IB A D [34].

\subsection{Motivações e objetivos do trabalho}

O presente trabalho está orientado a contribuir no entendimento do processo de formação dos filmes de InN com o método IBAD e, dessa forma, auxiliar a formação de InN dopado com um elemento dos metais de transição. Para isso, pretende-se alcançar os seguintes objetivos: 
(i) usando seis tipos de substratos: Si(111), safira-C, safira-A, safira-R, GaN/safira-A e vidro, produzir os filmes finos de InN com o método IBAD, variando-se os seguintes parâmetros de deposição: energia de íons, ARR(I/A) e temperatura de substrato durante a deposição;

(ii) analisar os filmes de $\mathrm{InN}$ com as técnicas de caracterização de: difração de raios-X (XRD), microscopia eletrônica de varredura (SEM), espectroscopia Raman, espectroscopia de fotoelétrons excitados por raios-X (XPS) e absorção ótica.
A presente dissertação consiste de quatro capítulos. No próximo, apresentar-se-ão os métodos experimentais, descrevendo o sistema IBAD, os materiais utilizados e as técnicas de caracterização. O capítulo 3 descreverá os resultados experimentais obtidos. E esses resultados serão concluídos no capítulo 4. 


\section{Capítulo 2}

\section{Método Experimental}

Neste capítulo, será descrito o sistema IBAD, o qual foi montado e instalado no Instituto de Física da Universidade de São Paulo, bem como seu funcionamento. Os materiais utilizados, as condições de deposição e as técnicas de caracterização também serão apresentados.

\subsection{Sistema IBAD}

O sistema IBAD, como as figuras 2.1 e 2.2 mostram, consiste basicamente de: (1) Uma fonte de íons tipo Kaufman (MPS-3000, Ion Tech) com diâmetro de feixe de $5 \mathrm{~cm}$ na saída, energia de íons de 50 a $1200 \mathrm{eV}$, corrente de feixe máxima de $200 \mathrm{~mA}$ (densidade de corrente máxima de $10 \mathrm{~mA} / \mathrm{cm}^{2}$ na saída da fonte de íons) e fluxo normal ao substrato. Foram acopladas à fonte de íons duas linhas de gás para $\mathrm{N}_{2}$ e $\mathrm{Ar}$ com os respectivos controladores de fluxo de massa [mass flow controller (MFC) 1179A, MKS]; (2) Um evaporador por feixe de elétrons (EB3, Edwards) com um porta amostra para quatro cadinhos de 4 cc cada, potência de $3 \mathrm{~kW}$ ( $5 \mathrm{kV}$ e $600 \mathrm{~mA}$ ), o ângulo de incidência do fluxo de átomos evaporados sobre a superfície do substrato é aproximadamente de $45^{\circ}$; (3) Uma câmara de vácuo de aço inoxidável com diâmetro de $60 \mathrm{~cm}$ e 
altura de $70 \mathrm{~cm}$, em que estão instalados, além da fonte de íons e do evaporador por feixe de elétrons acima mencionados, dois sensores de pressão de gás (um pirani e um penning), um monitor de deposição (XTC/2, Leybold) e um suporte de substrato com aquecedor elétrico de até $550^{\circ} \mathrm{C}$ e termopar tipo $\mathrm{K}$, sobre o qual pode ser fixado um substrato de $2,5 \times 2,5 \mathrm{~cm}^{2}$ de área máxima, e um copo de Faraday feito de aço inoxidável com diâmetro de 2". Durante a deposição, o substrato é exposto perpendicularmente ao feixe de íons. A câmara de vácuo é evacuada por uma bomba mecânica (taxa de bombeamento de 40 $\left.\mathrm{m}^{3} / \mathrm{h}\right)$ ou por uma criogênica $(1500 \mathrm{l} / \mathrm{s})$. A pressão de fundo e a pressão de trabalho foram, respectivamente, de $1,2 \times 10^{-7}-6,0 \times$ $10^{-6}$ e de $1,0 \times 10^{-4}$ Torr.

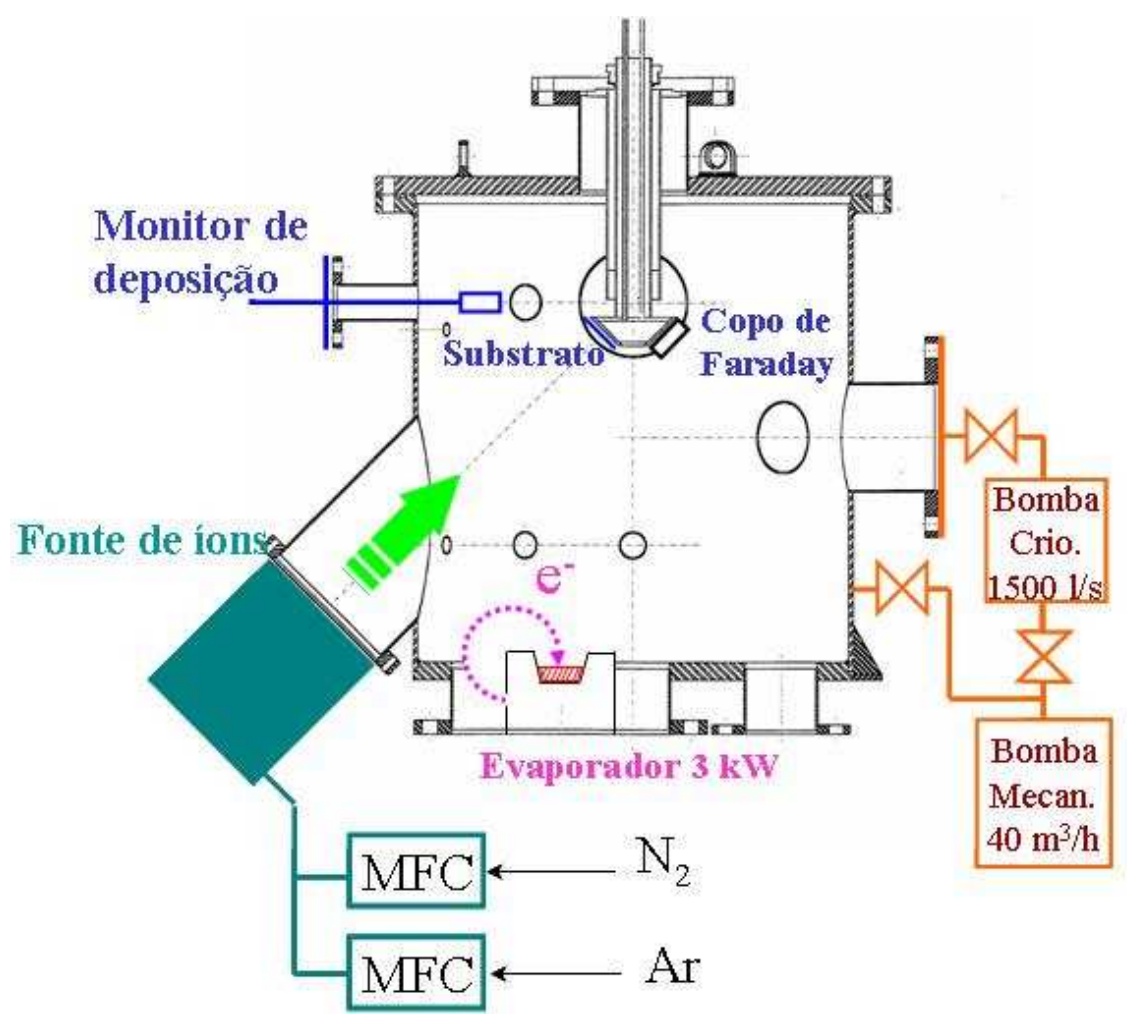

Figura 2.1. Esquema do sistema IBAD. 


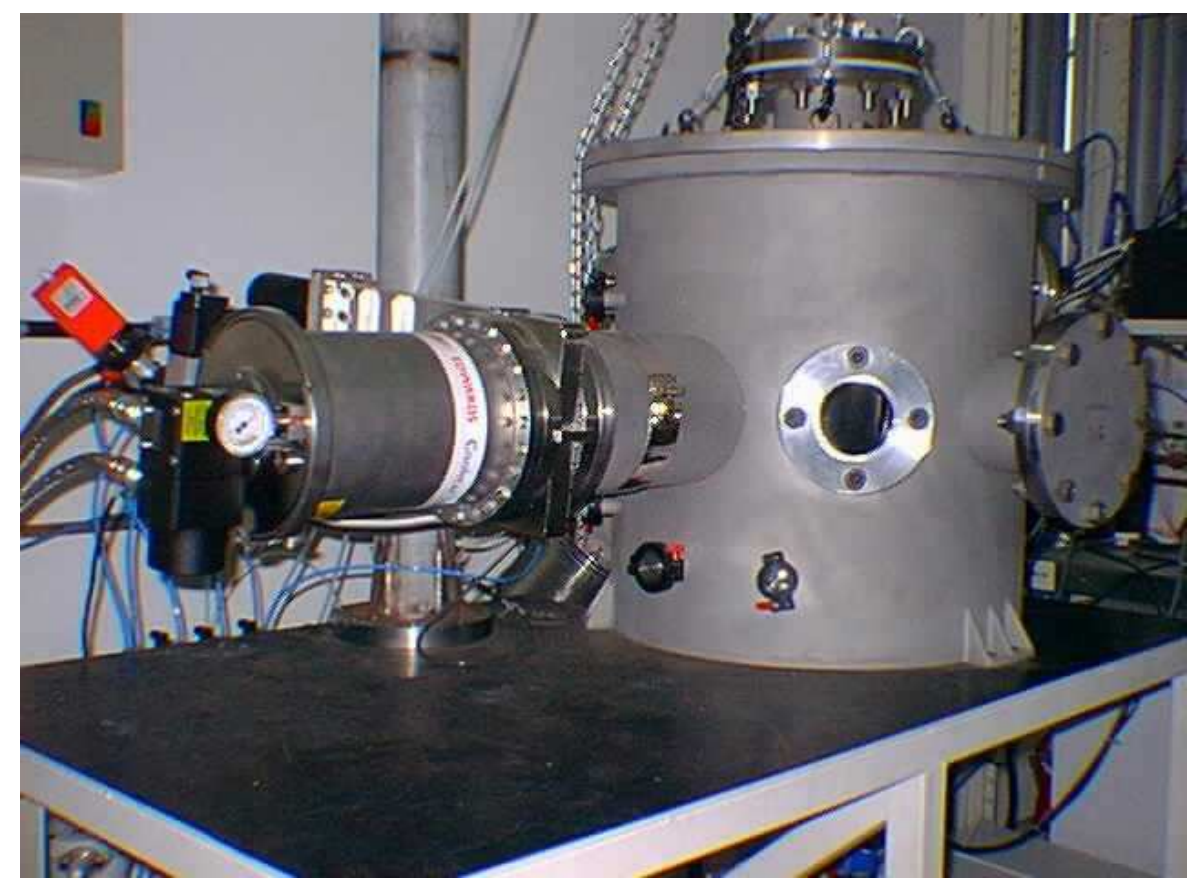

Figura 2.2. Fotografia do sistema IBAD.

\subsubsection{Fonte de Íons}

A fonte de íons foi testada variando os parâmetros de operação: corrente de catodo, tensão de feixe, tensão de aceleração e fluxo de gás. A tensão de feixe é aplicada ao anodo positivamente em relação à terra e a tensão de aceleração, à grade de aceleração negativamente em relação à terra. Portanto, a tensão de feixe determina a energia de íons e a tensão de aceleração fornece uma barreira a elétrons no plasma. Serão mostradas a seguir algumas características da fonte de íons obtidas neste teste. 


\section{Características da fonte de íons fluxo de gás}

A pressão de gás no interior da câmara de descarga da fonte de íons é um dos parâmetros fundamentais. Esta pressão é controlada pelo fluxo de gás conduzido à fonte de íons e pela velocidade de bombeamento na câmara de vácuo. Se a pressão na câmara de descarga for reduzida, a descarga cessará. A figura 2.3 indica a corrente de feixe, que passa pela unidade de potência para tensão de feixe e representa toda a corrente de íons, em função do fluxo de gás de nitrogênio. O fluxo mínimo é de $2,3 \mathrm{sccm}$ (standard cubic centimeters per minute: unidade da taxa de vazão de gases nas condições normais de temperatura e pressão) e o fluxo ótimo é considerado em torno de $2,5 \mathrm{sccm}$.

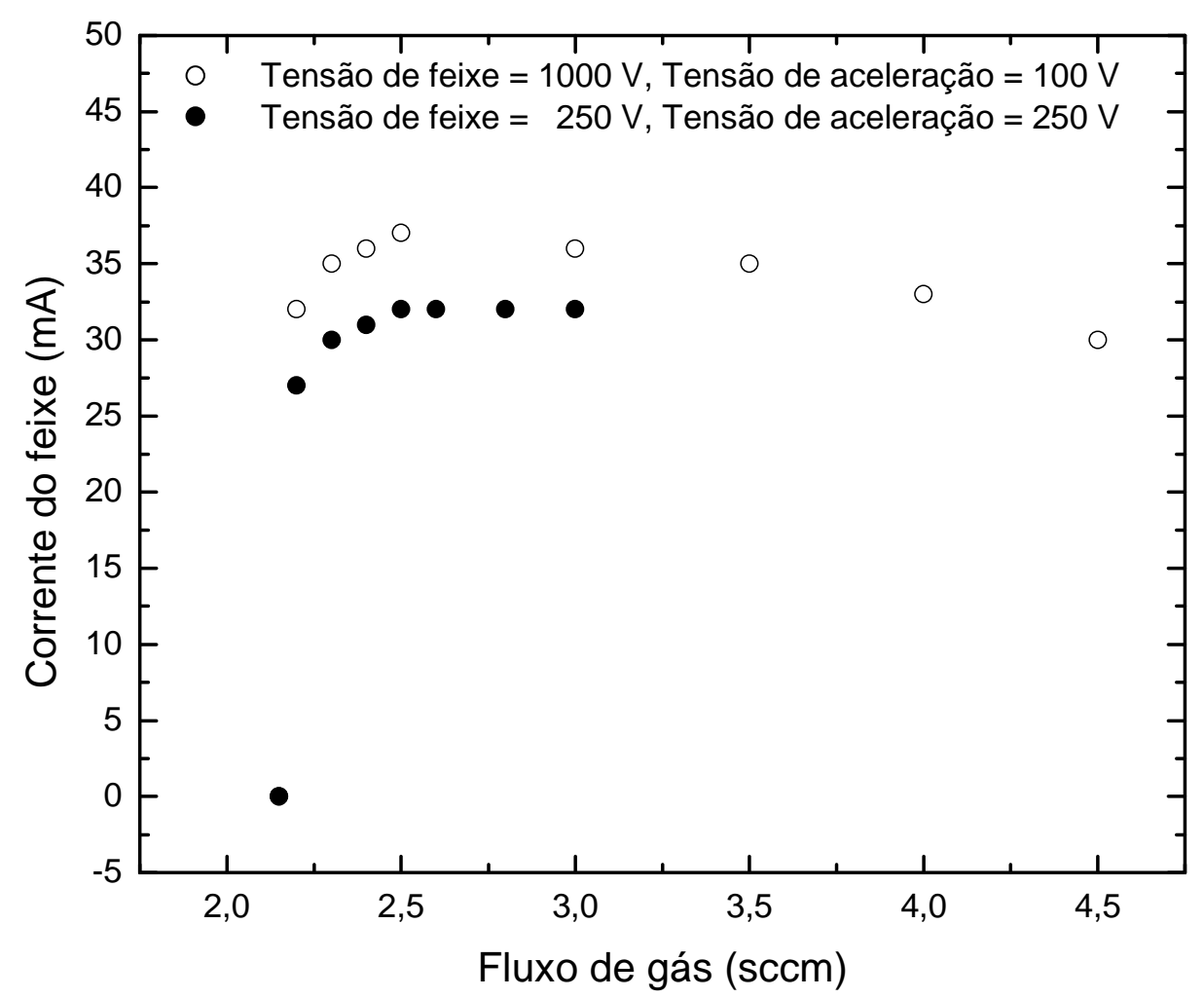

Figura 2.3. Variação da corrente de feixe com o fluxo de gás de nitrogênio. 


\section{Limite de carga espacial de catodo}

Os elétrons emitidos pelo catodo passam pelo plasma de descarga na maioria das condições de operação. Porém, em condições de pressão baixa e da tensão de descarga (aplicada ao anodo positivamente em relação ao catodo) baixa, a carga espacial dos elétrons próxima ao catodo tende a impedir elétrons de saírem do catodo e chegarem ao plasma de descarga. Quando este fenômeno ocorre, o catodo estará operando na condição do limite de carga espacial. A partir da figura 2.4, é claro que a corrente de catodo acima de 3,6 A está com esse limite de carga espacial.

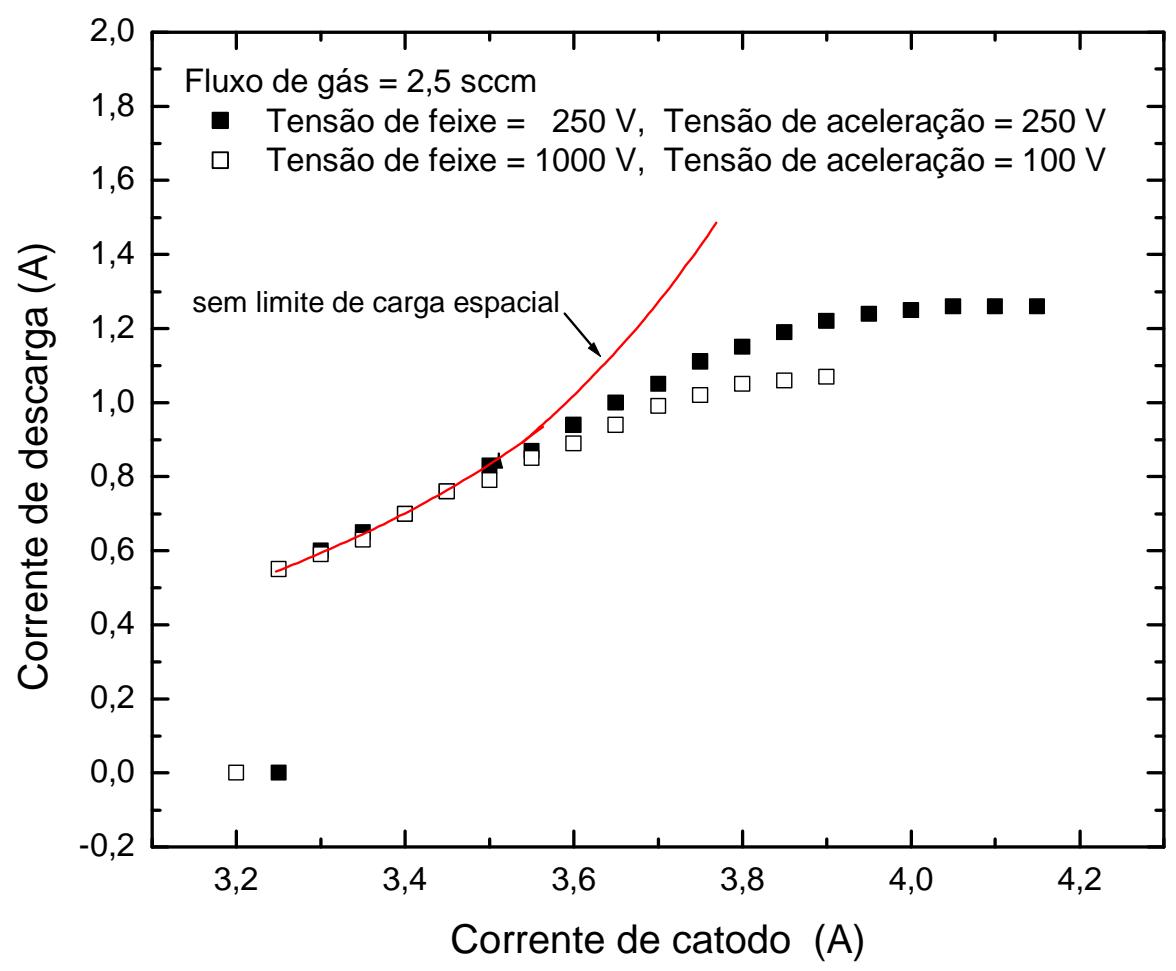

Figura 2.4. Corrente de descarga em função da corrente de catodo. 


\section{Contracorrente de elétrons}

Se elétrons fora da fonte de íons entram ao plasma de descarga através da ótica geométrica de íons, a unidade de potência para a tensão de feixe não conseguirá distinguir dos íons acelerados no feixe essa contracorrente de elétrons. Em outras palavras, a observação da corrente de feixe não permite o operador dizer se essa corrente é devida a íons. A figura 2.5 exibe a corrente de feixe em função da tensão de aceleração para três valores da tensão de feixe $(250,500$ e $1000 \mathrm{~V})$. Esta figura indica aparentemente a ausência da contracorrente de elétrons para a tensão de aceleração acima de $100 \mathrm{~V}$.

A variação na corrente de feixe, quando a tensão de aceleração é variada, é atribuída à variação da tensão total, igual à soma da tensão de feixe e da tensão de aceleração, da qual a extração de íons do plasma de descarga depende. Portanto, a região da tensão de aceleração de 100 a 600 V está livre da contracorrente de elétrons.

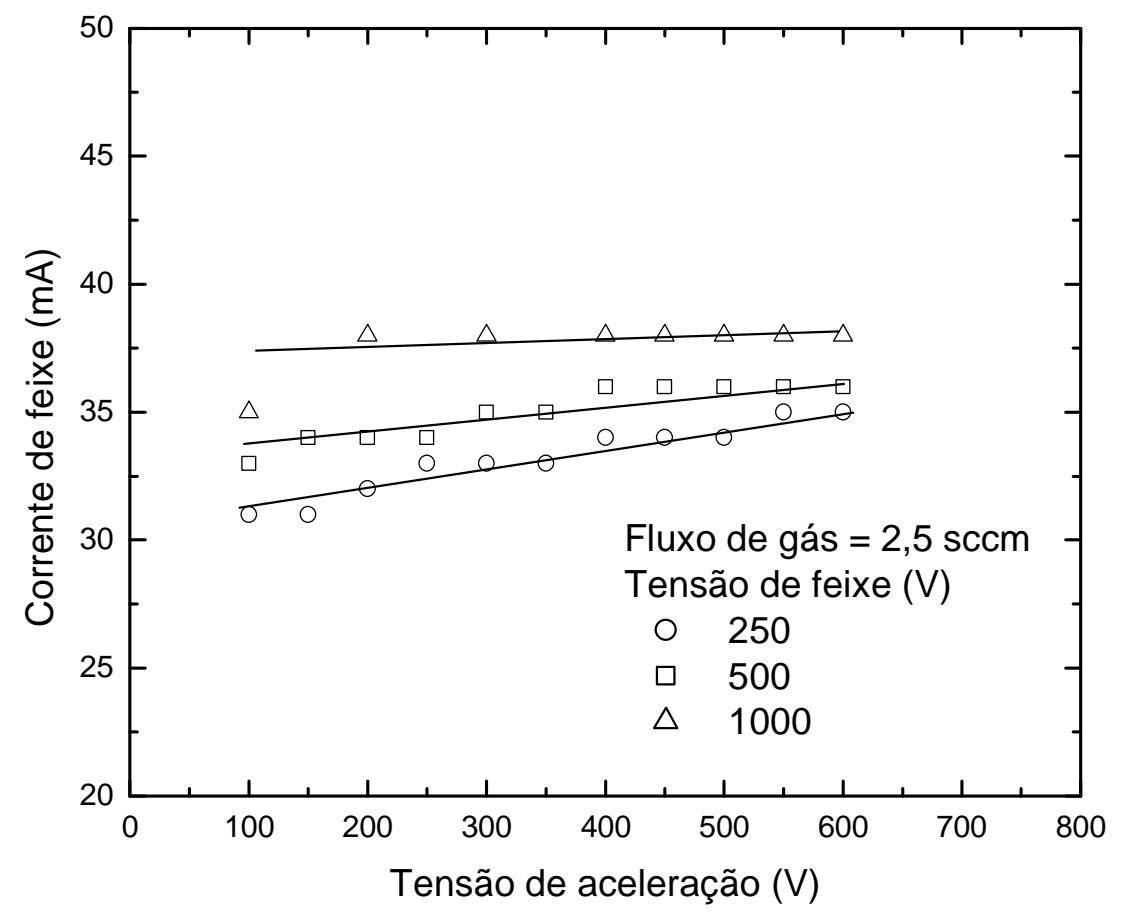

Figura 2.5. Corrente de feixe em função da tensão de aceleração. 


\section{Corrente de íons medida pelo copo de Faraday}

Os parâmetros de deposição mais importantes e fundamentais no método IBAD são a energia de íons relacionada à tensão de feixe e a arrival rate ratio, ARR(I/A), definida como o fluxo de íons de nitrogênio incidente no substrato, relativo ao fluxo de átomos de um material evaporados e transportados ao substrato. A figura 2.6 mostra a corrente de íons medida pelo copo de Faraday em função da corrente de catodo para cinco valores da tensão de feixe. A corrente de íons mínima obtida nesta figura é de 0,93 mA para tensão de feixe de $250 \mathrm{~V}$. Essa corrente está relacionada com o número de íons de nitrogênio que chegam à superfície de substrato por unidade de área e por unidade de tempo. A ARR(I/A) é calculada a partir dessa corrente, como será mencionado mais adiante.

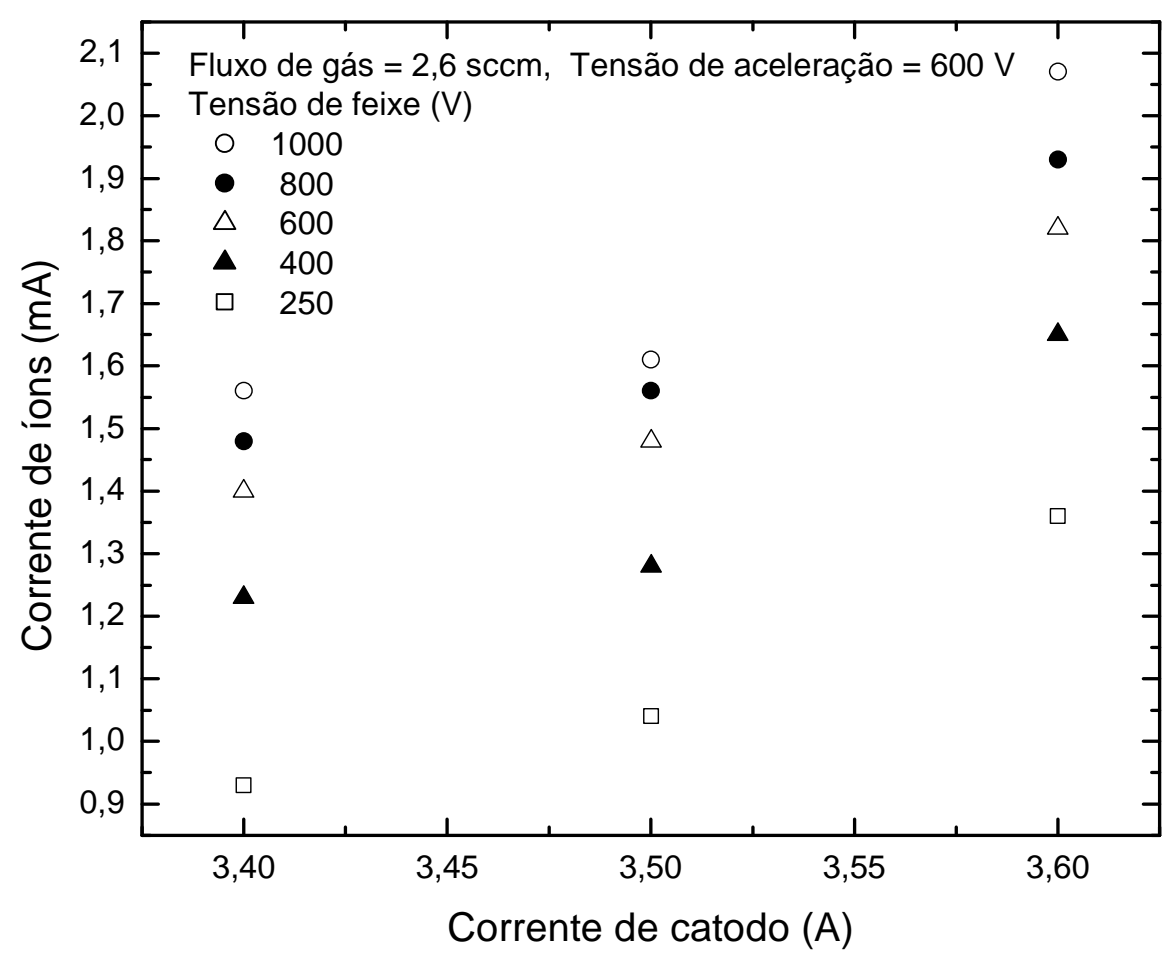

Figura 2.6. Corrente de íons em função da corrente de catodo. 


\subsection{Materiais utilizados}

O índio metálico usado para a evaporação era de alta pureza (99,99\%). O gás de nitrogênio, também de alta pureza (99,999\%), foi conduzido à fonte de íons para a produção do feixe de íons.

Os filmes de nitreto de índio foram depositados sobre substratos de:

- silício com plano de orientação (111);

- vidro borosilicato de bário CORNING 7059;

- safira com plano de orientação (001);

- safira com plano de orientação (110);

- safira com plano de orientação $(1 \overline{1} 2)$;

- uma camada de GaN com plano de orientação de (001) depositada sobre safira com plano de orientação (110).

Chamados nessa dissertação como Si (111), vidro, safiraC, safira-A, safira-R e GaN/safira, respectivamente. Todos os substratos foram cortados com ponta de diamante. Para a limpeza desses substratos, foram necessárias preparações específicas. O substrato de Si (111) foi lavado primeiramente em HF $10 \%$ durante 10 min. e depois enxaguado em água destilada. Os demais foram submetidos a um processo de limpeza no qual ficavam submersos em tricloroetileno, depois colocados em acetona e finalmente lavados com metanol. Em cada etapa desse processo foi utilizado banho ultra-sônico durante $3 \mathrm{~min}$.

O cálculo do parâmetro ARR(I/A) foi baseado na densidade da corrente de íons incidentes ao substrato e na taxa de deposição de índio. A densidade da corrente de íons é 
determinada a partir do valor da corrente de íons que passa pelo copo de Faraday medido por um amperímetro e dividido pela área do copo de Faraday. Como um analisador de massa não está disponível na câmara de vácuo, supomos que a distribuição de estados de carga dos íons seja de $11 \%$ de $\mathrm{N}^{+}$e $89 \%$ de $\mathrm{N}_{2}^{+}$, segundo a literatura [35].

Espera-se que uma parte desses íons sofra colisões de transferência de carga com o gás de nitrogênio ao longo da trajetória de $41 \mathrm{~cm}$ a partir da saída da fonte de íons até o substrato, assim tornando-se partículas neutras retendo a energia inicial. Conseqüentemente, foi necessário corrigir o valor medido da corrente de íons coletada pelo copo de Faraday usando a seguinte equação:

$$
I=I_{0} \exp \left[-p_{0} P_{c}(\mathrm{v}) l\right]
$$

onde $I_{0}$ é a corrente de íons inicial na saída da fonte de íons, I a corrente de íons final na posição do copo de Faraday, que é equivalente à posição do substrato, depois da passagem através da distância $l(\mathrm{~cm}), p_{0}=273 p / T$ ( $p$ e $T$ são, respectiamente, a pressão e temperatura absoluta do gás) e $P_{c}(\mathrm{v})$ é a probabilidade de colisão dependente da velocidade de íons v [36].

A concentração de moléculas de gás por $\mathrm{cm}^{3}$ é dada por $N / V=3,53 \times 10^{16} p_{0}$. A $P_{c}(v)$ é também chamada de seção de colisão efetiva $Q_{c}$. A seção de colisão efetiva para um íon, $q$, é dada por:

$$
q=\frac{Q_{c}}{N / V}
$$


Substituindo a equação (2.2) na equação (2.1), a corrente de íons é dada por:

$$
I=I_{0} \exp \left(-3,53 \times 10^{16} p_{0} q l\right)
$$

A leitura da corrente de íons, $I_{t}$, medida pelo amperímetro, é a soma das correntes de $I\left(N^{+}\right)$e $I\left(N_{2}^{+}\right)$, isto é:

$$
I_{t}=I\left(N^{+}\right)+I\left(N_{2}^{+}\right)
$$

As correntes são dadas por:

$$
I\left(N^{+}\right)=I_{0}\left(N^{+}\right) \exp \left(-3,53 \times 10^{16} p q_{1} l\right)
$$

$\mathrm{e}$

$$
I\left(N_{2}^{+}\right)=I_{0}\left(N_{2}^{+}\right) \exp \left(-3,53 \times 10^{16} p q_{2} l\right)
$$

onde $q_{1}$ e $q_{2}$ são seções de colisão efetiva para $N^{+}$e $N_{2}^{+}$, respectivamente.

A relação entre as correntes iniciais $I_{0}\left(N^{+}\right)$e $I_{0}\left(N_{2}^{+}\right)$é dada pela expressão [35]:

$$
I_{0}\left(N_{2}^{+}\right)=8 I_{0}\left(N^{+}\right)
$$

Substituindo as equações (2.5), (2.6) e (2.7) na equação (2.4), resulta:

$$
I_{0}\left(N^{+}\right)=\frac{I_{t}}{\exp \left(-3,53 \times 10^{16} p q_{1} l\right)+8 \exp \left(-3,53 \times 10^{16} p q_{2} l\right)}
$$

Então, a corrente de íons corrigida para nitrogênio $I_{c}$ é dada por: 


$$
\begin{gathered}
I_{c}=I_{0}\left(N_{2}^{+}\right)+I_{0}\left(N^{+}\right)=9 I_{0}\left(N^{+}\right) \\
I_{c}=\frac{9 I_{t}}{\exp \left(-3,53 \times 10^{16} p q_{1} l\right)+8 \exp \left(-3,53 \times 10^{16} p q_{2} l\right)}
\end{gathered}
$$

A referência [36] fornece os gráficos de $q_{1}$ e $q_{2}$ para a energia de 0 a $2000 \mathrm{eV}$.

A densidade de corrente é dada por $I_{c} /\left[\pi(2,5)^{2}\right] \mathrm{mA} / \mathrm{cm}^{2}$, onde a $I_{c}$ é medida em $\mathrm{mA}$.

Então, o fluxo de íons de nitrogênio, Y , é dado por:

$$
Y_{I}=\frac{I_{c} \times 10^{-3}}{\pi(2,5)^{2} \times 1,602 \times 10^{-19}}=3,18 \times 10^{14} \times I_{c} \quad \text { íns } /\left(\mathrm{cm}^{2} \cdot s\right)
$$

Por outro lado, o fluxo de átomos de índio evaporados, $\mathrm{Y}_{\mathrm{A}}$, pode ser calculado a partir da taxa de deposição $T_{d}(\AA / \mathrm{A} / \mathrm{s})$, sendo que: Massa atômica do índio: $M=114,82 \mathrm{~g} / \mathrm{mol}$; Densidade do índio: $\rho=7,3 \mathrm{~g} / \mathrm{cm}^{3}$ e Número de Avogadro: $N_{a}=6,022 \times 10^{23}$ átomos $/ \mathrm{mol}$.

$\mathrm{O} \mathrm{Y}_{\mathrm{A}}$ é dado pela seguinte expressão:

$$
Y_{A}=\frac{T_{d} \times 10^{-8} \times \rho}{M} N_{a}=3,83 \times 10^{14} T_{d} \text { átomos } /\left(\mathrm{cm}^{2} \cdot \mathrm{s}\right)
$$

A ARR(I/A) é dada pelo $Y_{I}$ dividido pelo $Y_{A}$, isto é:

$$
\operatorname{ARR}(\mathrm{I} / \mathrm{A})=\frac{\mathrm{Y}_{\mathrm{I}}}{\mathrm{Y}_{\mathrm{A}}}=0,83 \frac{I_{c}}{T_{d}}
$$


Usando a Ic mínima igual a $0,93 \mathrm{~mA}$ anteriormente obtida na figura 2.6 e supondo a Td mínima igual a $0,3 \AA / s$, a ARR(I/A) é de 2,6. Como a Td pode aumentar a $3 \AA / s$, a ARR(I/A) pode variar ao menos de 0,3 a 2,6.

A temperatura de cada substrato foi mantida em temperatura ambiente (TA), 200, 250,300, 420, 470 ou $520^{\circ} \mathrm{C}$, durante a deposição de filme. Mantendo a taxa de deposição e a densidade da corrente de íons constantes durante a deposição, o processo de deposição foi terminado quando a espessura do filme medida pelo monitor de deposição (espessura nominal) chegou a 400,500, 1500 ou $4500 \AA$ A. As condições de deposição utilizadas, assim como a ARR(I/A), são mostradas nas Tabelas $2.1-2.6$. 
Tabela 2.1: Condição de deposição dos filmes para substrato de Si (111).

\begin{tabular}{cccccc}
\hline \hline Amostra & Energia $(\mathbf{e V})$ & Td (A/s) & ARR(I/A) & $\begin{array}{c}\text { Espessura } \\
\text { nominal }(\mathbf{\AA})\end{array}$ & T $\left(\mathbf{~}^{\mathbf{O}} \mathbf{C}\right)$ \\
\hline si01 & 800 & 0,7 & 3,2 & 1500 & 200 \\
si02 & 800 & 0,7 & 3,2 & 500 & 300 \\
si03 & 800 & 0,7 & 3,2 & 400 & 300 \\
si04 & 800 & 0,7 & 3,2 & 400 & 250 \\
si05 & 800 & 0,7 & 3,2 & 400 & 200 \\
si06 & 200 & 0,7 & 3,3 & 500 & 300 \\
si07 & 200 & 0,7 & 3,2 & 400 & 300 \\
si08 & 200 & 0,7 & 3,3 & 400 & 200 \\
si09 & 100 & 0,3 & 5,5 & 500 & 200 \\
si10 & 100 & 0,3 & 0,8 & 500 & 200 \\
si11 & 100 & 0,3 & 0,8 & 500 & 20 \\
\hline *si12 & 800 & 0,7 & 3,2 & 300 \\
\hline * amostra crescida com feixe de íons derivado de $17 \%$ de gás Ar e $83 \%$
\end{tabular}

Tabela 2.2: Condição de deposição dos filmes para substrato de Safira-A.

\begin{tabular}{cccccc}
\hline \hline Amostra & Energia (eV) & Td (A/s) & ARR(I/A) & $\begin{array}{c}\text { Espessura } \\
\text { nominal }(\stackrel{\AA}{\mathbf{A}})\end{array}$ & $\mathbf{T}\left({ }^{\circ} \mathbf{C}\right)$ \\
\hline safA01 & 100 & 0,3 & 5,5 & 500 & 200 \\
safA02 & 100 & 0,3 & 0,8 & 500 & 200 \\
safA03 & 100 & 0,3 & 0,8 & 500 & 20 \\
\hline \hline
\end{tabular}

Tabela 2.3: Condição de deposição dos filmes para substrato de GaN/safira.

\begin{tabular}{cccccc}
\hline \hline Amostra & Energia (eV) & Td (A/s) & ARR (I/A) & $\begin{array}{c}\text { Espessura } \\
\text { nominal }(\mathbf{A})\end{array}$ & T $\left({ }^{\mathbf{o}} \mathbf{C}\right)$ \\
\hline gan01 & 1190 & 0,7 & 4,2 & 500 & 300 \\
gan02 & 1190 & 0,7 & 3,3 & 500 & 300 \\
gan03 & 800 & 0,7 & 4,4 & 500 & 300 \\
gan04 & 800 & 0,7 & 3,2 & 500 & 300 \\
gan05 & 800 & 0,7 & 3,2 & 400 & 200 \\
gan06 & 500 & 0,7 & 4,3 & 500 & 300 \\
gan07 & 500 & 0,7 & 3,0 & 500 & 300 \\
gan08 & 200 & 0,7 & 4,4 & 500 & 300 \\
gan09 & 200 & 0,7 & 3,3 & 500 & 300 \\
gan10 & 100 & 0,3 & 0,8 & 500 & 450 \\
gan11 & 100 & 0,3 & 5,6 & 500 & 300 \\
gan12 & 100 & 0,3 & 0,8 & 500 & 300 \\
gan13 & 100 & 0,3 & 5,5 & 500 & 200 \\
gan14 & 100 & 0,3 & 0,8 & 500 & 200 \\
gan15 & 100 & 0,3 & 0,8 & 500 & 100 \\
gan16 & 100 & 0,3 & 0,8 & 500 & 20 \\
\hline *gan17 & 800 & 0,7 & 3,2 & 500 & 300 \\
\hline \hline
\end{tabular}

$$
\text { de gás } \mathrm{N}_{2} \text {. }
$$


Tabela 2.4: Condição de deposição dos filmes para substrato de Safira-C.

\begin{tabular}{cccccc}
\hline \hline Amostra & Energia $(\mathbf{e V})$ & Td (A/s) & ARR (I/A) & $\begin{array}{c}\text { Espessura } \\
\text { nominal }(\AA)\end{array}$ & T $\left({ }^{\circ} \mathbf{C}\right)$ \\
\hline safC01 & 800 & 0,3 & 4,0 & 500 & 300 \\
safC02 & 100 & 0,3 & 0,8 & 500 & 450 \\
safC03 & 100 & 0,3 & 5,5 & 500 & 300 \\
safC04 & 100 & 0,3 & 0,8 & 500 & 300 \\
safC05 & 100 & 0,3 & 5,5 & 500 & 200 \\
safC06 & 100 & 0,3 & 0,8 & 500 & 200 \\
safC07 & 100 & 0,3 & 0,8 & 500 & 20 \\
\hline \hline
\end{tabular}

Tabela 2.5: Condição de deposição dos filmes para substrato de Safira-R.

\begin{tabular}{cccccc}
\hline \hline Amostra & Energia (eV) & Td (A/s) & ARR (I/A) & $\begin{array}{c}\text { Espessura } \\
\text { nominal }(\AA)\end{array}$ & T $\left({ }^{\mathbf{o}} \mathbf{C}\right)$ \\
\hline safR01 & 100 & 0,3 & 0,8 & 500 & 450 \\
safR02 & 100 & 0,3 & 5,5 & 500 & 300 \\
safR03 & 100 & 0,3 & 0,8 & 500 & 300 \\
safR04 & 100 & 0,3 & 5,5 & 500 & 200 \\
safR05 & 100 & 0,3 & 0,8 & 500 & 200 \\
safR06 & 100 & 0,3 & 0,8 & 500 & 20 \\
\hline \hline
\end{tabular}

Tabela 2.6: Condição de deposição dos filmes para substrato de vidro.

\begin{tabular}{cccccc}
\hline \hline Amostra & Energia $(\mathbf{e V})$ & Td (A/s) & ARR $(\mathbf{I} / \mathbf{A})$ & $\begin{array}{c}\text { Espessura } \\
\text { nominal }(\mathbf{A})\end{array}$ & $\mathbf{T}\left({ }^{\circ} \mathbf{C}\right)$ \\
\hline vidro01 & 800 & 0,3 & 4,0 & 500 & 300 \\
vidro02 & 100 & 0,3 & 0,8 & 500 & 450 \\
vidro03 & 100 & 0,3 & 5,5 & 500 & 300 \\
vidro04 & 100 & 0,3 & 0,8 & 500 & 300 \\
vidro05 & 100 & 0,3 & 5,5 & 500 & 200 \\
vidro06 & 100 & 0,3 & 0,8 & 500 & 200 \\
vidro07 & 100 & 0,3 & 0,8 & 500 & 20 \\
vidro08 & 100 & 0,3 & 0,8 & 3000 & 20 \\
\hline \hline
\end{tabular}




\title{
2.3 Técnicas de Caracterização
}

\author{
Nesta seção, serão apresentadas as técnicas de \\ caracterização utilizadas para estudar as propriedades \\ cristalina, morfológica, vibracional, química e ótica dos filmes \\ depositados. São respectivamente elas: difração de raios-X, \\ microscopia eletrônica de varredura, espectroscopia Raman, \\ espectroscopia de fotoelétrons excitados por raios-X e absorção \\ ótica.
}

A espessura real de alguns filmes foi medida por um profilômetro modelo DEKTAK3030 no Laboratório de Sistemas Integráveis (LSI) da Escola Politécnica da USP. Este instrumento mede a altura do degrau formado de uma área do substrato mascarada por uma chapa metálica antes da deposição e do filme depositado na outra área do substrato através do movimento horizontal de uma agulha sobre a superfície.

\subsubsection{Difração de Raios-X}

A difração de raios-X (XRD - X-Ray Diffraction) é uma técnica de caracterização importante para o estudo das propriedades estruturais dos cristais. Através dela, é possível a identificação de compostos cristalinos e a determinação dos parâmetros de rede cristalina, orientação do plano e grau de cristalinidade dos materiais.

O fenômeno da difração ocorre devido ao encontro de uma onda com centros espalhadores, cuja distância entre eles tem a mesma ordem de grandeza do comprimento de onda, sendo da ordem de Angström. Os primeiros estudos sobre difração de raios-X em cristais foram feitas pelo físico alemão 
Max von Laue, sendo laureado com o prêmio Nobel de Física em 1912.

Num cristal, os centros espalhadores são formados por átomos contidos nos planos virtuais, os quais são denominados planos cristalográficos e indexados através dos índices de Miller, $h k l$, separados por uma distância $d[37]$. W.L. Bragg formulou uma equação na qual é possível obter a distância interplanar, sabendo-se o ângulo de incidência e o comprimento de onda do feixe incidente através de relações geométricas entre o feixe incidente e o feixe difratado pelos planos. Esta relação é conhecida como Lei de Bragg [38], e dada por:

$$
2 d_{h k l} \operatorname{sen} \theta=n \lambda
$$

onde $\theta$ é o ângulo entre a direção do feixe incidente e o plano cristalográfico, $\lambda$ o comprimento de onda da radiação e $n$ um número inteiro referente à ordem da difração (usualmente considera-se $n=1)$. $d_{h k l}$ é a distância interplanar.

A Fig. 2.7 mostra a interação entre a radiação e os planos cristalográficos. O ângulo entre a direção do feixe incidente e a do refletido é de $2 \theta$.

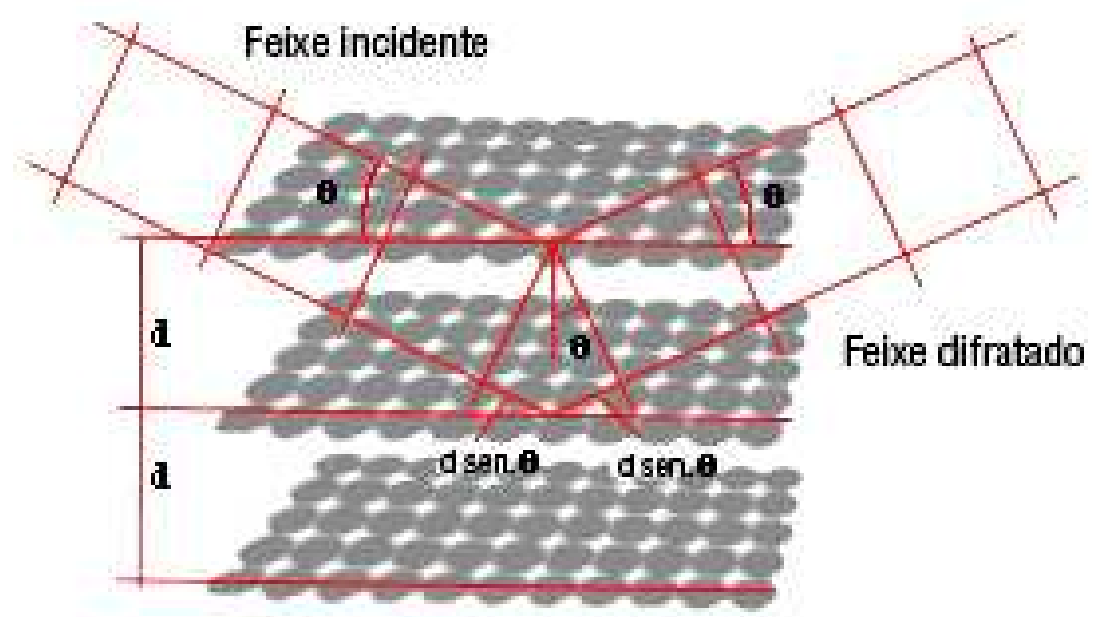

Figura 2.7. Difração de raios-X por um cristal. 
Os parâmetros de rede e os três ângulos da célula unitária para os diversos tipos de estrutura cristalina são obtidos a partir do conhecimento das distâncias entre os planos e dos índices de Miller.

Os valores de $d$, intensidades relativas e os índices de Miller para os compostos padrões estão tabelados e disponíveis em microfichas ou CD-ROM no sistema ICDD (JCPDS) da International Union of Crystallography[39].

As medidas de XRD foram feitas com o método $\theta-2 \theta$, utilizando-se uma varredura por passo de $0,05^{\circ}$ e um tempo de contagem de 5 s em cada passo para a obtenção de uma melhor estatística dos difratogramas na região de $2 \theta$ de $25^{\circ}-70^{\circ}$, onde se encontram os sinais mais intensos de reflexões de $\operatorname{InN}$ e In metálico.

As medidas de difração de raios-X foram realizadas usando difratômetro (Rint 2100, Rigaku) com radiação $\mathrm{CuK}_{\alpha}(\lambda=1,5418 \AA ̊ \AA)$ no Laboratório de Cristalografia do Instituto de Física da USP - IFUSP.

\subsubsection{SEM}

Em um equipamento de microscópio eletrônico de varredura (SEM - Scanning Electron Microscope) é utilizada uma sonda para percorrer a superfície da amostra ponto-aponto, constituindo assim a imagem desta. Tal sonda é formada por um feixe colimado de elétrons. Vários tipos de sinais são gerados pela incidência da sonda sobre a amostra: elétrons secundários; elétrons primários retro-espalhados; elétrons Auger; luminescência catódica; raios-X característicos; elétrons transmitidos[40]. Vários sinais são emitidos de diferentes profundidades da amostra. Todos estes sinais podem ser coletados e usados para produzir imagens, porém o modo mais 
comum de se produzir imagens de SEM envolve a coleta de elétrons secundários, que fornecem a morfologia de superfície da amostra.

As imagens de SEM sobre a morfologia das amostras depositadas foram obtidas usando um equipamento (2010, $J E O L)$ com a resolução de $100 \AA$ (tensão do canhão de $25 \mathrm{kV}$ ) no Laboratório de Microscopia Eletrônica do Instituto de Física da USP - IFUSP.

\subsubsection{Espectroscopia Raman}

O espectro Raman é baseado no efeito Raman, que é devido ao espalhamento inelástico de uma radiação monocromática que incide numa molécula. Este efeito foi descoberto pelo físico indiano Chandrasekhara Venkata Raman em 1928. No efeito Raman, a atividade está ligada ao momento de dipolo induzido na molécula pelo campo elétrico da radiação e consiste de uma pequena fração dos fótons incidentes (cerca de 1 em $10^{7}$ ) [41].

Tanto moléculas diatômicas heteronucleares como homonucleares apresentam atividade, pois em ambos os casos ocorre variação da polarizabilidade com a vibração, que é a condição necessária para observação de radiações espalhadas. No espectro em escala de energia teremos simetricamente em relação à linha Rayleigh uma banda do lado de freqüências mais baixas, a Stokes, e uma do lado de freqüências mais altas, a anti-Stokes. Classicamente, as duas deveriam ter mesma intensidade, mas observa-se que a Stokes é mais intensa do que a anti-Stokes, como será mencionado adiante.

No espalhamento Raman Stokes, a molécula no estado fundamental sofre colisão com o fóton de energia $h v_{0}$, passa para um estado intermediário (ou virtual), que não precisa ser 
um estado estacionário da molécula, e decai em seguida para um estado vibracionalmente excitado, de energia $e_{v}$; o fóton espalhado, terá energia $\left(h v_{0}-e_{v},\right)$ menor do que a do incidente. No espalhamento Rayleigh, após a interação do fóton com a molécula, esta volta ao mesmo nível de energia inicial e o fóton é espalhado sem modificação de freqüência. No espalhamento Raman anti-Stokes, o fóton encontra a molécula já num estado excitado e, após a interação, a molécula decai para o estado fundamental. Esta diferença é cedida ao fóton, que é espalhado com energia $h v_{0}+e_{v}$. Os mecanismos de espalhamento podem ser representados pelos esquemas da figura 2.8.

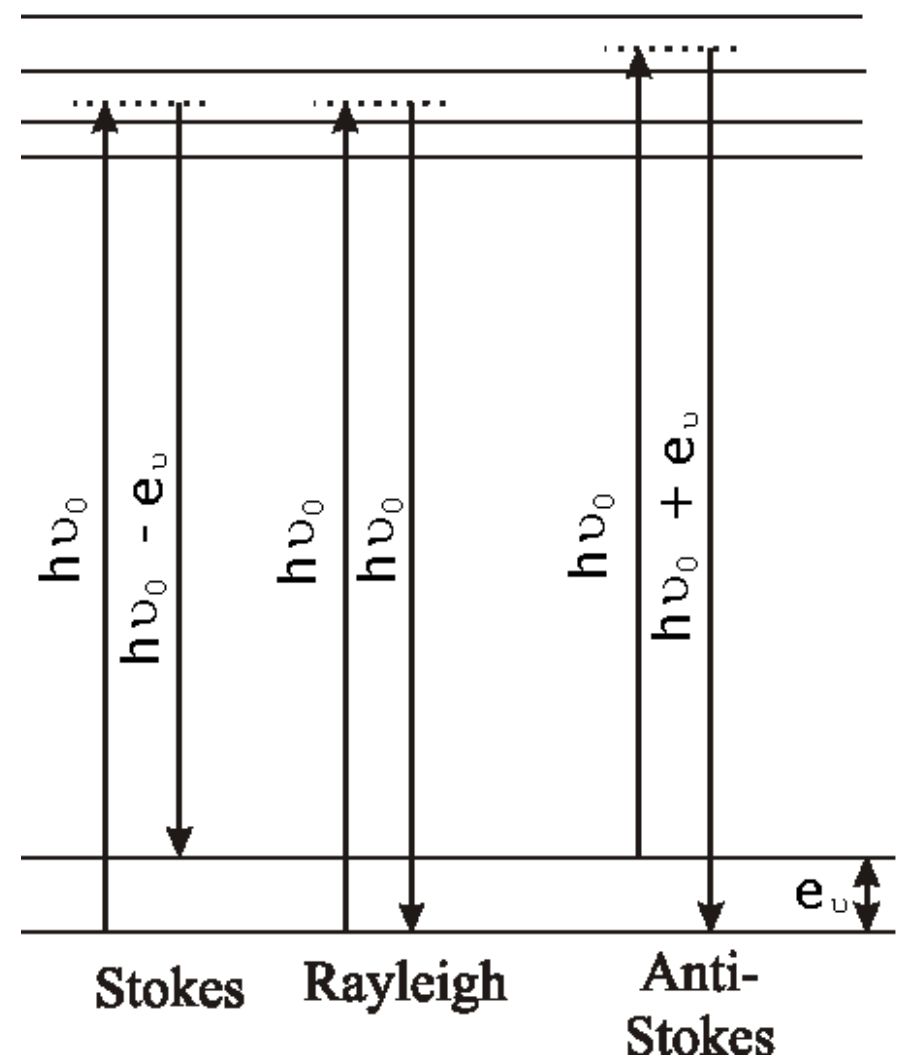

Figura 2.8: Esquemas dos mecanismos de espalhamento.

Este esquema é útil para visualizar o espalhamento Raman, mostrando que além do estado inicial e do final da molécula, também comparece o estado intermediário. 
Como a população dos estados excitados segue a distribuição de Boltzmann, deve-se esperar para as bandas antiStokes menor intensidade do que para as Stokes. Isto se verifica experimentalmente e a relação entre as intensidades da banda anti-Stokes $I_{A}$ e da Stokes $I_{S}$ é dada por:

$$
\frac{I_{A}}{I_{S}}=\left(\frac{v_{0}+v_{V}}{v_{0}-v_{V}}\right)^{4} e^{-\frac{e_{V}}{k T}}
$$

onde $k$ é a constante de Boltzmann, $v_{V}$ é a freqüência da radiação espalhada e $T$ é a temperatura absoluta.

Conseqüentemente, para freqüências vibracionais baixas, as intensidades da banda Stokes e da anti-Stokes são comparáveis, mas para freqüências vibracionais muito altas torna-se difícil a observação das bandas anti-Stokes [42].

As medidas de espectroscopia Raman foram realizadas usando um equipamento modelo Raman 2000, Renishaw, operado com a linha de excitação do raio laser em $5148 \AA$ no Laboratório do Instituto Nacional de Pesquisas Espaciais, Inpe, em São José dos Campos.

\subsubsection{XPS}

A Espectroscopia de Fotoelétrons Excitados por Raios-X (XPS - X-Ray Photoelectron Spectroscopy) utiliza raios-X moles (geralmente $h \boldsymbol{v}=1486,6$ e $1253,6 \mathrm{eV}$ para as linhas $K_{\alpha}$ de Al e Mg, respectivamente) como fonte de fótons.

A figura 2.9 mostra um diagrama dos níveis de energia eletrônicos do átomo do material excitado no processo de fotoemissão. Como os níveis de energia são quantizados, os fotoelétrons possuem uma distibuição de energia cinética que 
consiste de picos discretos, associados às camadas eletrônicas do átomo fotoionizado. A energia cinética do fotoelétron $E_{K}$ é dada por:

$$
E_{K}=h v-E_{B}
$$

onde $E_{B}$ é a energia de ligação deste elétron em relação ao ambiente de vácuo e $h V$ é a energia do fóton incidente. A identificação dos elementos presentes na superfície (profundidade de $10 \AA$ ) é feita diretamente pela determinação das energias de ligação para os picos dos fotoelétrons de caroço. A intensidade de cada pico é proporcional ao número de átomos no volume detectado, permitindo, portanto, obter-se informações sobre a composição da superfície.

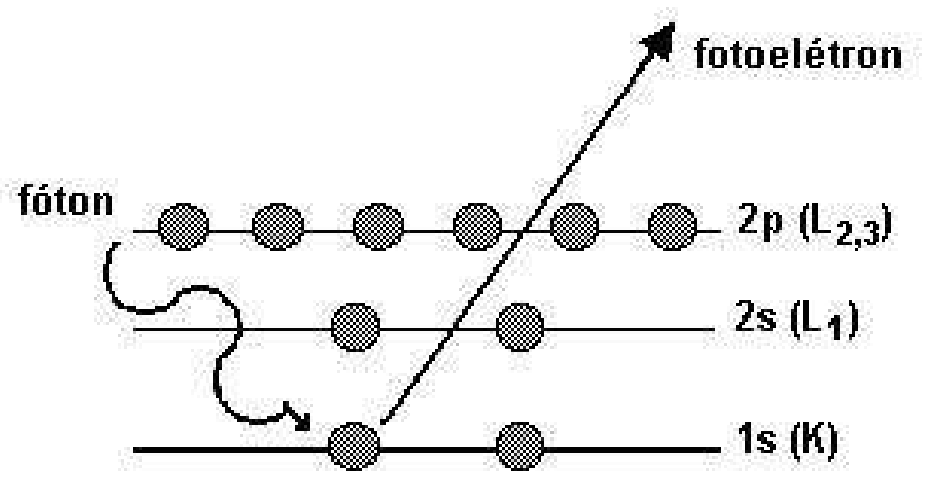

Figura 2.9. Diagrama dos níveis de energia.

Na XPS, há que se levar em conta a separação spin-órbita em dubletos: um elétron desemparelhado em um orbital degenerado ( $p, d, f$, etc.), o momento angular de spin, $\vec{S}$, e o momento angular orbital, $\vec{L}$, podem combinar-se de várias maneiras, e produzir novos estados que são caracterizados pelo momento angular total do elétron, $\vec{J}$, e seu módulo é dado por: 


$$
J=|L \pm S|
$$

onde $L=0,1,2, \ldots ; \quad S=1 / 2 ; \quad J=1 / 2,3 / 2,5 / 2, \ldots$ As energias dos novos estados são diferentes porque os momentos magnéticos devidos ao spin do elétron e ao movimento orbital podem oporse ou reforçar-se mutuamente. As degenerescências desses estados são $2 J+1$ e as intensidades relativas desse picos separados são dadas pela razão das degenerescências.

A posição exata de um pico fotoelétrico indica o estado químico do átomo emissor. As energias de ligação dos níveis de caroço dos átomos são suficientemente afetadas pelo seu ambiente químico (ou seja, estado de oxidação, sítios da rede, estrutura molecular, etc.) que provocam um deslocamento de 0,1 à $10 \mathrm{eV}$ nas energias dos fotoelétrons. Estes deslocamentos químicos devem-se às variações na blindagem eletrostática sofridas pelos elétrons de caroço quando os elétrons de valência do átomo de interesse são atraídos ou repelidos. Considerandose o mesmo elemento em dois estados químicos, a diferença entre as energias de ligação é dada pela diferença entre as energias cinéticas. Entretanto, vários efeitos influenciam o deslocamento das energias dos fotoelétrons medidos, como o carregamento nas superfícies isolantes, e ainda não há uma única teoria que explica completamente os deslocamentos químicos, de forma que a interpretação destes deslocamentos é feita comparando-se as energias de ligação de um material analisado com seu padrão.

Os picos fotoelétricos aparecem no espectro sobre um fundo de elétrons secundários e a presença de um buraco de caroço após a ionização afeta a distribuição dos elétrons emitidos, levando a deslocamentos, separação dos picos e o surgimento de picos sátelites [43].

As medidas de XPS das amostras depositadas foram realizadas usando um equipamento (XSAM HS, Kratos) a 
radiação $\mathrm{AlK}_{\alpha}$ de 1486,6 eV e potência de $65 \mathrm{~W}$, no Centro de Caracterização e Desenvolvimento de Materiais (CCDM) da Universidade Federal de São Carlos.

\subsubsection{Absorção Ótica}

Como uma ferramenta de análise de propriedades óticas, a absorção ótica em um material homogêneo pode ser compreendida em termos simplificados. A atenuação da luz atravessando um material de espessura $x$ é dada por:

$$
I=I_{0} e^{-\alpha x}
$$

onde $I$ é intensidade da luz transmitida, $I_{0}$ a intensidade da luz incidente e $\alpha$ o coeficiente de absorção linear. Este coeficiente é tipicamente dependente do comprimento de onda e da temperatura, e unicamente define o alcance da absorção ótica. Os espectrofotômetros registram a absorção como uma porcentagem da transmissão $\left(I / I_{0} \times 100\right)$, conhecida como Lei de Beer:

$$
T=\frac{I}{I_{0}}=e^{-\alpha x}
$$

sendo $T$ a transmitância do material. Outra forma de se registrar a absorção é através da Lei de Lambert-Beer:

$$
A=\log \left(\frac{1}{T}\right)
$$

onde $A$ é a absorbância ou densidade ótica [44]. 
As medidas de absorção ótica foram realizadas usando um espectrofotômetro (Carry 500 Scan, Varian) no Laboratório de Cristais Iônicos, Filmes Finos e Datação (LACIFID) do Instituto de Física da USP. 


\section{Capítulo 3}

\section{Resultados e Discussão}

Nas seções 3-1 a 3-5, são apresentados os resultados das medidas de XRD, SEM, Raman, XPS e absorção ótica, respectivamente.

\subsection{XRD}

Todas as amostras preparadas e apresentadas no capítulo anterior foram submetidas primeiro a essa medida de XRD no intuito de saber as melhores condições de deposição para a formação de InN.

Como a deposição de InN começou sobre o substrato de Si(111), que era o único disponível na época, serão apresentados na próxima seção os resultados obtidos das amostras depositadas nesses substratos. As identificações dos picos observados nos difratogramas de raios-X foram feitas através de comparações com os cartões JCPDS (InN 50-1239, In 05-0642, Safira 10-0173, Safira 11-0517 e Safira 12-0539).

A seguir serão apresentados os seguintes resultados dessas medidas:

(a) Dependência da temperatura de substrato TS;

(b) Dependência da energia de íons E; 
(c) Dependência da taxa de razão de chegada ARR(I/A);

(d) Dependência da espessura de amostra;

(e) Dependência da mistura com íons de argônio no feixe de íons de nitrogênio.

conforme os tipos de substratos [Si(111), safira-C, safira-A, safira-R GaN/safira e vidro], nas respectivas seções $3.1 .1-3.1 .6$.

\subsubsection{Amostras depositadas em substrato de $\mathrm{Si}(111)$}

\section{(a) Dependência da TS}

As figuras 3.1(a)-3.1(c) apresentam os difratogramas de raios-X obtidos para as amostras formadas em 300, 250 e $200^{\circ} \mathrm{C}$, respectivamente, com $\mathrm{E}=800 \mathrm{eV}$ e $\mathrm{ARR}(\mathrm{I} / \mathrm{A})=3,2$.

Um pico em $28,5^{\circ}$ é observado em todas as figuras e atribuído à reflexão do plano (111) de Si. Um pico observado em $31,3^{\circ}$ na figura 3.1(a) é devido à reflexão do plano (002) de h-InN e, dois picos em $32,9^{\circ}$ e $38,9^{\circ}$ nas figuras 3.1(a) e 3.1(b) são relacionados às reflexões dos planos (101) e (110) de In, respectivamente. Estes três picos de $\mathrm{InN}$ e In não são observados para a amostra preparada em $200^{\circ} \mathrm{C}$, porém foi observado em microscópio ótico, a formação de um filme sobre o substrato. 


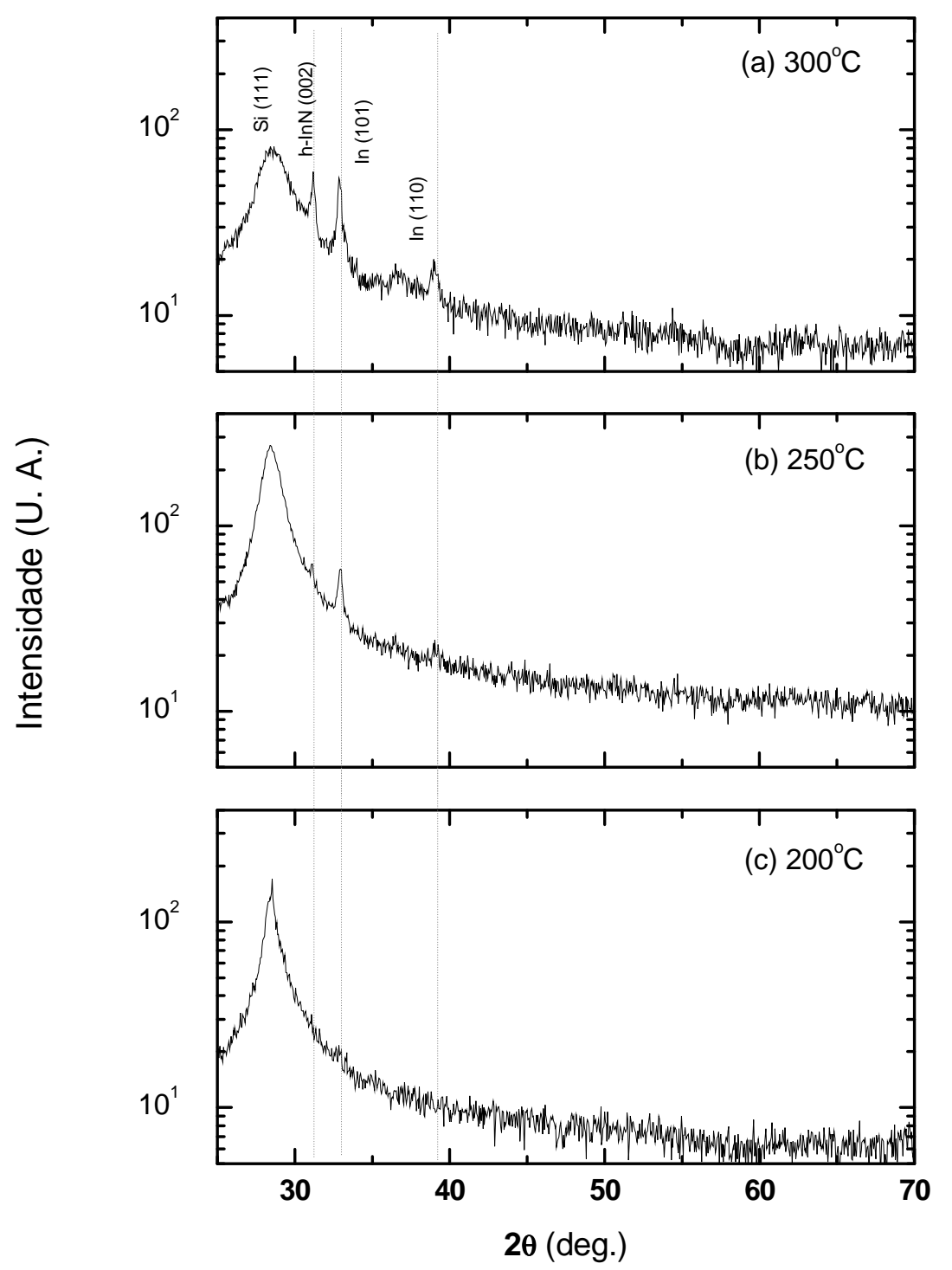

Figura 3.1. Difratogramas para amostras depositadas sobre substratos de Si (111) em: (a) $300^{\circ} \mathrm{C}$, (b) $250^{\circ} \mathrm{C}$ e (c) $200^{\circ} \mathrm{C}, \operatorname{com} \mathrm{E}=800$ eV e $\operatorname{ARR}(\mathbf{I} / \mathbf{A})=3,2$.

Foram depositadas duas amostras em 300 e $200^{\circ} \mathrm{C}$, com $\mathrm{E}=200 \mathrm{eV}$ e mantendo $\mathrm{ARR}(\mathrm{I} / \mathrm{A})=3,2$. O difratograma para a amostra depositada em $300^{\circ} \mathrm{C}$ [figura 3.2(a)] mostra os picos em $31,3,43,4,57,0$ e 54,4 ${ }^{\circ}$ devidos às reflexões dos planos (002), (102), (103) e (112) de h-InN, respectivamente, com a presença de diversos picos de In, enquanto a outra amostra apresenta somente os picos de In com suas intensidades reduzidas. Note que a segunda amostra não apresenta nenhum pico de InN. 


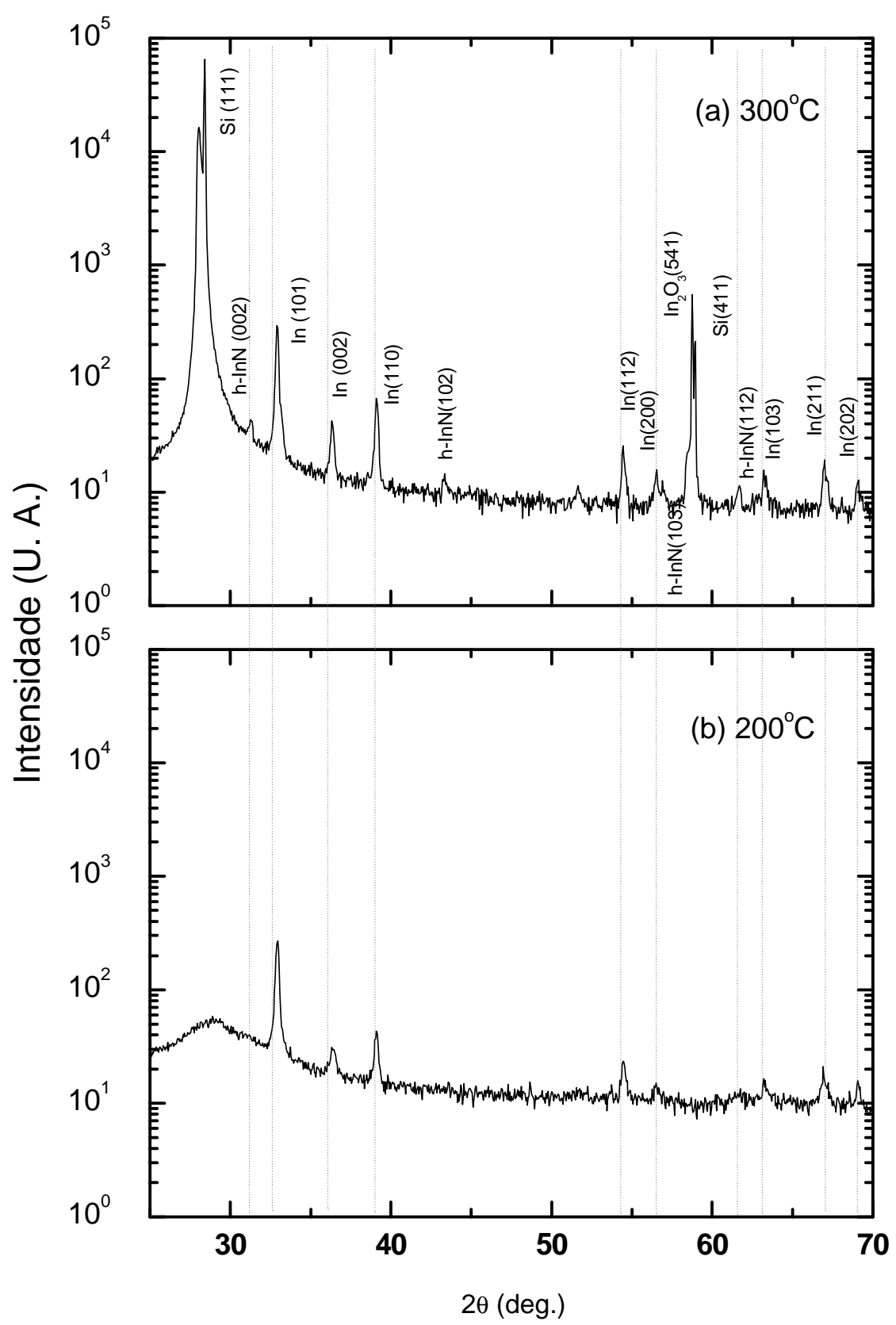

Figura 3.2. Difratogramas para amostras depositadas sobre substrato de $\mathrm{Si}$ (111) em: (a) $300^{\circ} \mathrm{C}$ e (b) $200^{\circ} \mathrm{C}, \operatorname{com} \mathrm{E}=200$ eV e $\operatorname{ARR}(\mathrm{I} / \mathrm{A})=$ 3,2 .

É verificado nas figuras 3.1 e 3.2 que, quanto mais alta TS, melhor é a cristalização da amostra. Este fato pode ser entendido da seguinte forma: a mobilidade dos átomos que chegaram à superfície do substrato é baixa em temperaturas baixas e, tal fato, pode levar a formação de microestrutura não cristalina ou amorfa. Por outro lado, considerando a segregação 
de In favorável durante a deposição, a formação de In torna-se mais nítida do que a de InN.

\section{(b) Dependência da $E$}

As figuras 3.3 (a) e 3.3 (b), que são iguais às respectivas figuras 3.1 (c) e 3.2 (b), mostram os difratogramas para duas amostras formadas a $200^{\circ} \mathrm{C} \operatorname{com} \mathrm{ARR}(\mathrm{I} / \mathrm{A})=3,2$ e $\mathrm{E}=800 \mathrm{e}$ $200 \mathrm{eV}$, respectivamente. A amostra depositada com $\mathrm{E}=200 \mathrm{eV}$ apresenta alguns picos de In, enquanto a outra não indica nenhum pico relacionado com InN e In. Esse fato significa que a energia de íons mais alta $(800 \mathrm{eV})$ inibe a cristalização. 


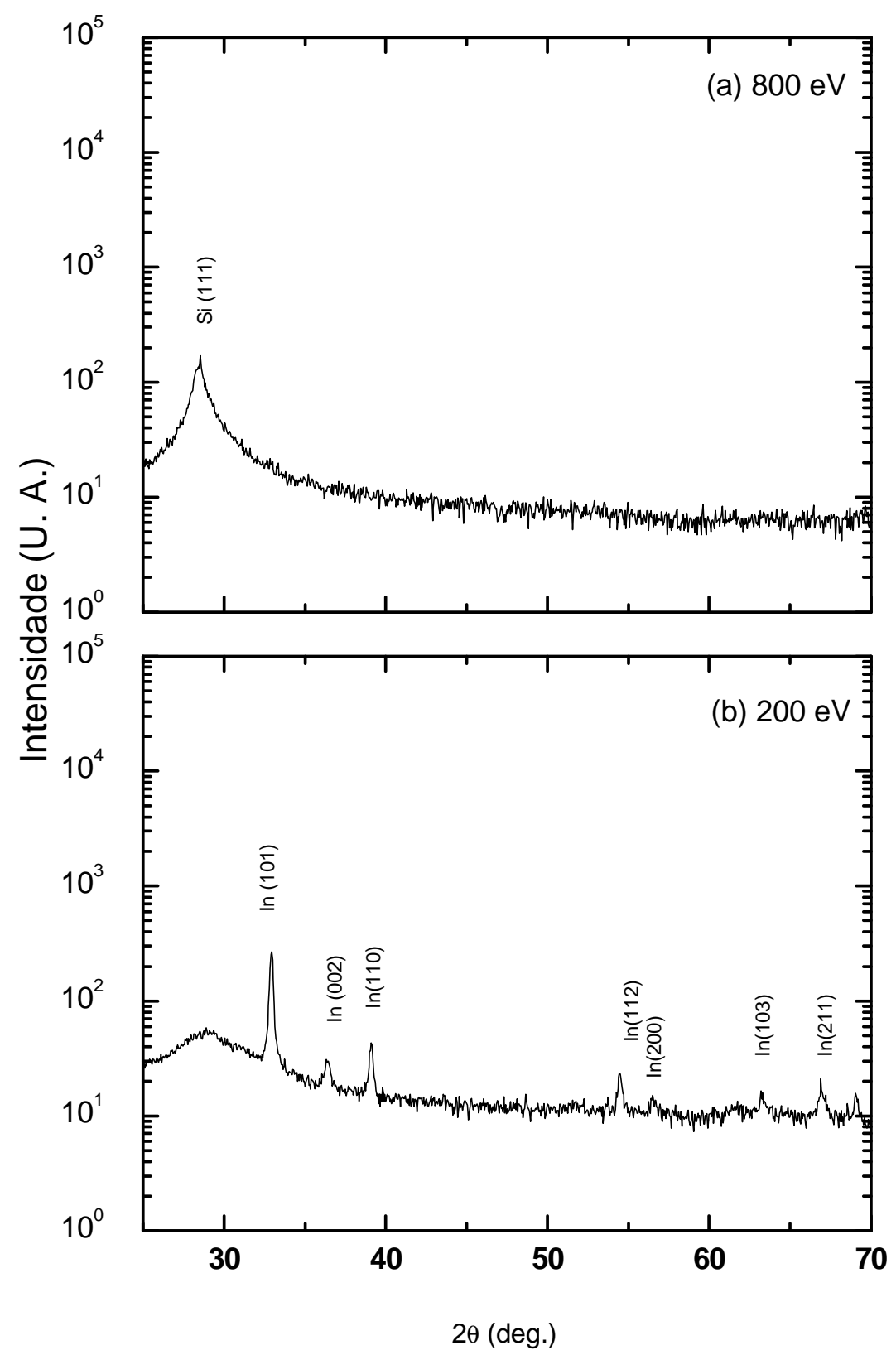

Figura 3.3. Difratogramas para amostras depositadas sobre substrato de $\mathrm{Si}$ (111) em 200 oC, ARR(I/A) de 3,2 e com $E=$ (a) 800 e (b) 200 eV.

\section{(c) Dependência da ARR(I/A)}

O estudo sobre o efeito da ARR(I/A) nas cristalizações foi feito para amostras crescidas em $200^{\circ} \mathrm{C}$ (figura 3.4 ) e com $\mathrm{E}=$ $100 \mathrm{eV}$. Tem-se o aumento da intensidade dos picos de In (101), e In (202) e a presença de In (110) em 39, ${ }^{\circ}$ quando se diminuiu 
a ARR(I/A) de 5,5 para 0,8. Não foi verificada a presença de In $\mathrm{N}$ nas amostras.

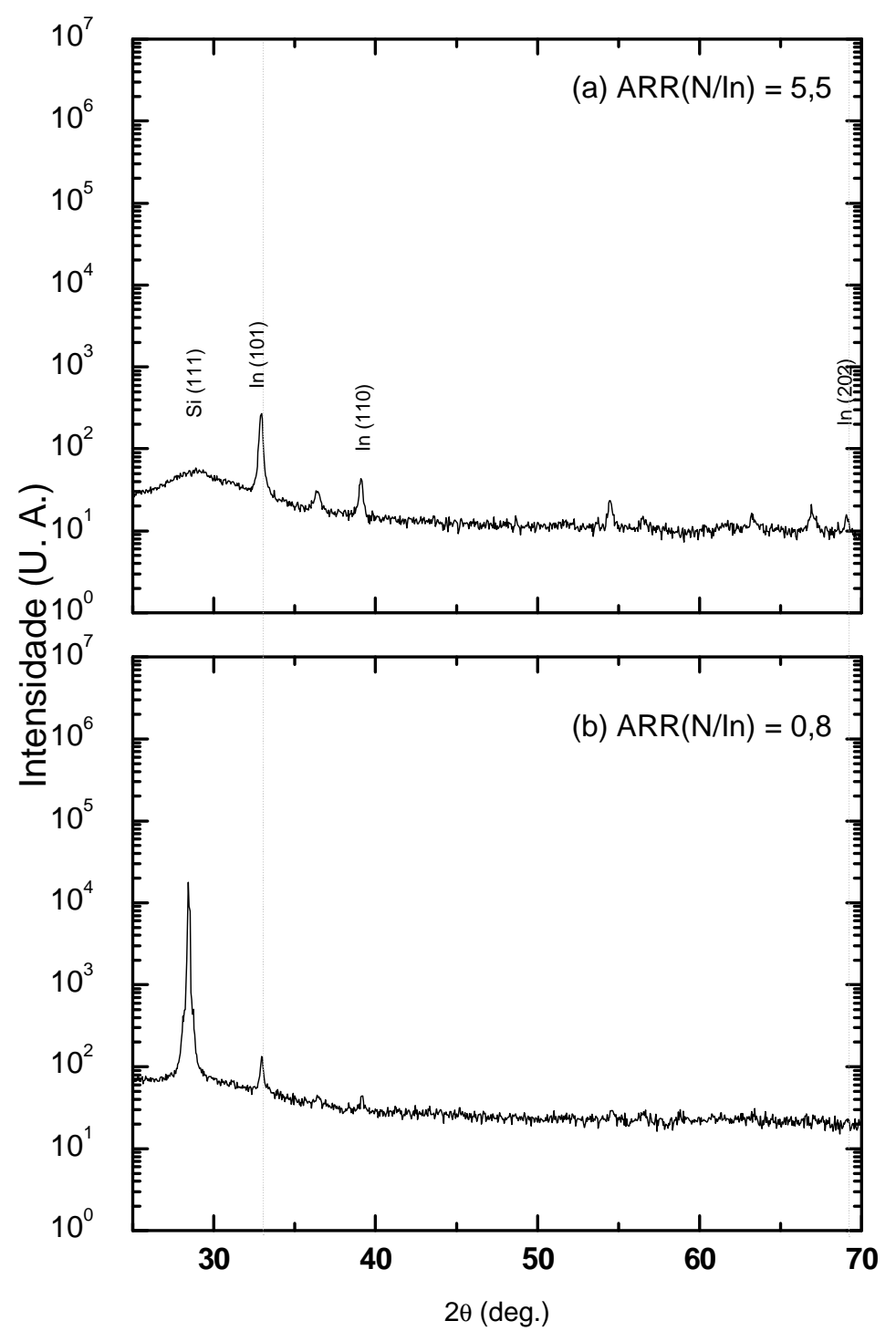

Figura 3.4. Difratogramas para amostras depositadas sobre Si (111) em $2000 \mathrm{C}, \operatorname{com} E=$ $100 \mathrm{eV}$ e $\operatorname{ARR}(\mathrm{I} / \mathrm{A})=$ (a) 5,5 e (b) 0,8 .

\section{(d) Dependência da espessura}

As figuras 3.5 (a) e 3.5 (b) mostram os difratogramas para as amostras depositadas em $200^{\circ} \mathrm{C} \operatorname{com} \mathrm{E}=800 \mathrm{eV}, \mathrm{ARR}(\mathrm{I} / \mathrm{A})=$ 3,2 e espessuras nominais de 1500 e $400 \AA$, respectivamente. A amostra mais espessa indica nitidamente dois picos devidos aos planos (101) e (110) de In. 


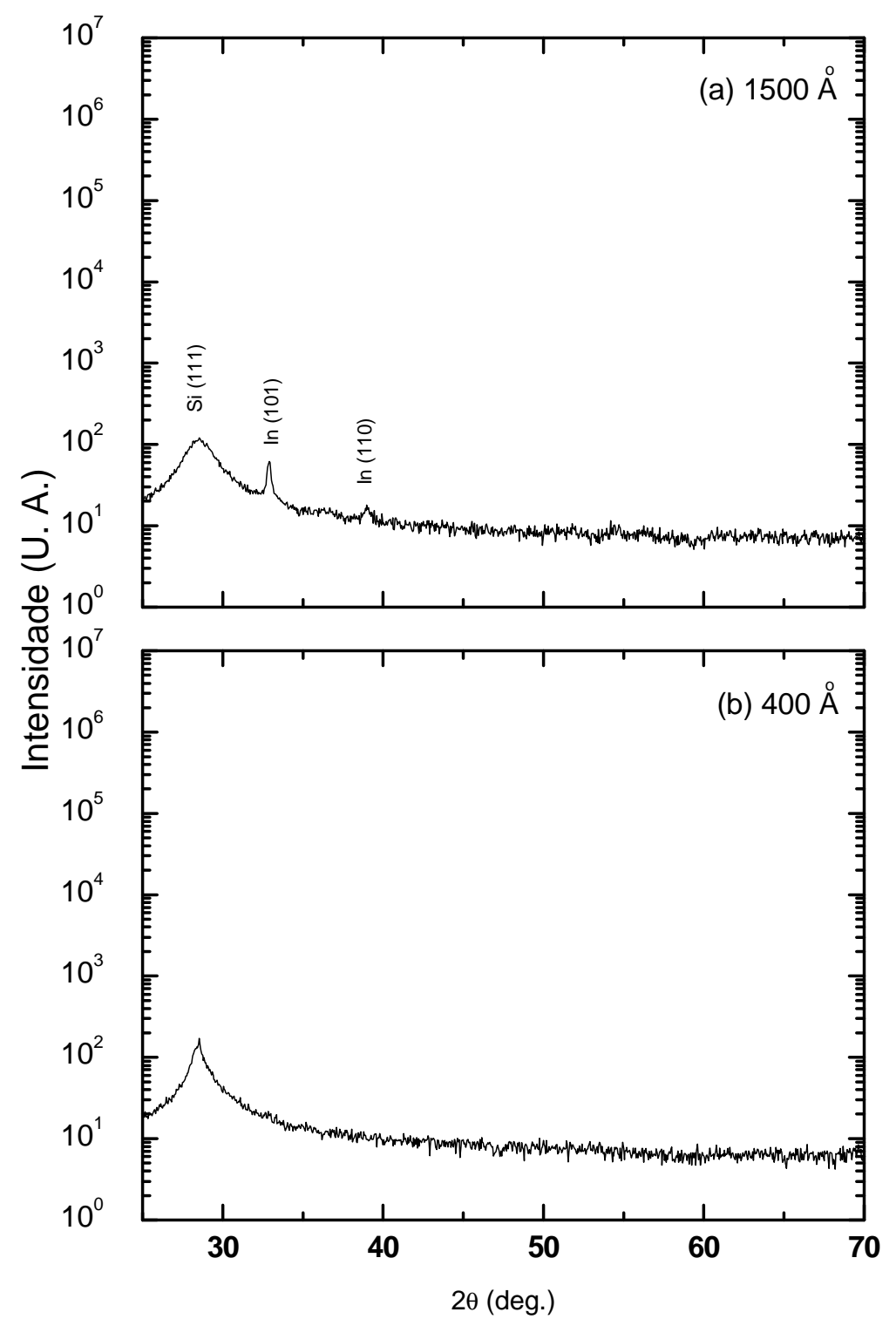

Figura 3.5. Difratogramas para amostras depositadas sobre substrato de Si (111) em $2000 \mathrm{C}, \operatorname{ARR}(\mathrm{I} / \mathrm{A})=3,2, \operatorname{com} \mathrm{E}=800 \mathrm{eV} \mathrm{e}$ espessura de: (a) 1500 e (b) $400 \AA$.

\section{(e) Dependência da mistura com íons de argônio}

É mostrado na figura 3.6(a), o difratograma para a amostra depositada a $300^{\circ} \mathrm{C}$ usando um feixe de íons produzido a partir de uma mistura de gases de nitrogênio $(83 \%$ de fluxo) e argônio (17\%), com $E=800$ eV e $\operatorname{ARR}(\mathrm{I} / \mathrm{A})=3,2$. A figura 3.6 (b), que é igual à 3.1 (a), mostra o difratograma para a amostra preparada usando o 
feixe de íons de nitrogênio (100\%) com as mesmas condições de deposição acima mencionadas.

Esta medida foi idealizada visto que a presença de íons de argônio no feixe de íons de nitrogênio ajude a formação da ligação entre o índio e o nitrogênio mais do que só a presença de íons de nitrogênio, pois, em uma mesma energia de íons, íons mais pesados transferem ao filme mais energia necessária para a formação da fase cristalina. Entretanto, a amostra produzida com o feixe de íons mistos não mostra nenhum pico de In nem de InN. Este fato significa que o bombardeamento por íons mistos pode destruir a fase cristalina já formada criando grande quantidade de danos de radiação.

A dificuldade da formação InN no substrato de silício, apresentada nesta seção, já é relatada na literatura [31], pois o composto de nitreto de silício formado na superfície do substrato impede essa formação, ainda que sua formação não pode ser observada por XRD em conseqüência de sua camada ser muito fina. Assim descartando a tentativa de formar InN no substrato de silício, começamos utilizar os outros tipos de substratos. 


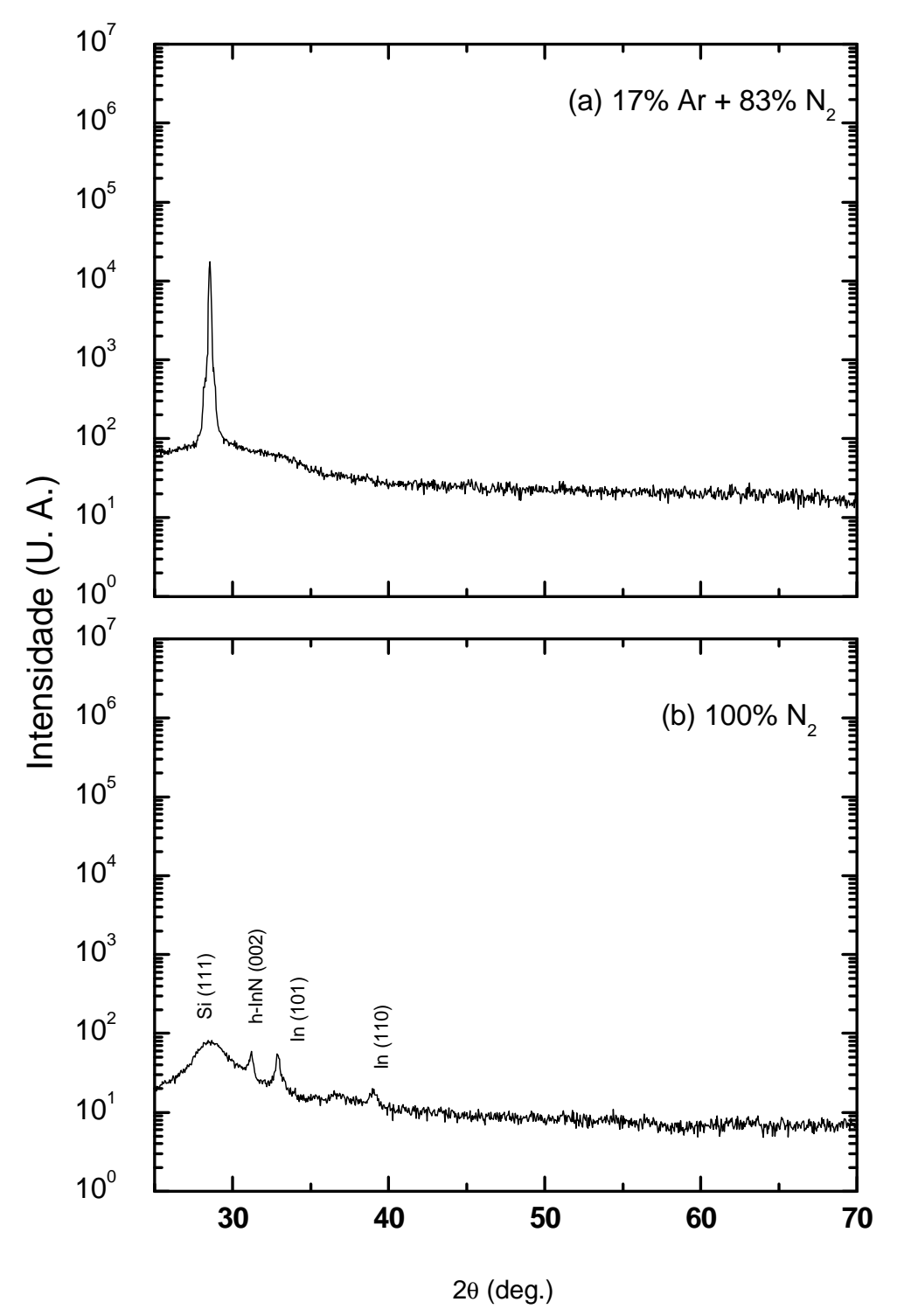

Figura 3.6. Difratograma para amostras depositadas sobre substrato de $S i$ (111) em $3000 \mathrm{C}$, com $E=800 \mathrm{eV}, \operatorname{ARR}(\mathrm{I} / \mathrm{A})=3,2$ e feixe de: (a) $17 \% \mathrm{Ar}+83 \% \mathrm{~N} 2$ e (b) $100 \% \mathrm{~N} 2$.

\subsubsection{Amostras depositadas em substrato de safira-C}

(a) Dependência da TS

As figuras 3.7(a) - 3.7(d) mostram os difratogramas para as amostras depositadas em 450, 300, $200^{\circ} \mathrm{C}$ e $\mathrm{TA}$, 
respectivamente, $\operatorname{com} \mathrm{E}=100 \mathrm{eV}$ e $\mathrm{ARR}(\mathrm{I} / \mathrm{A})=0,8$. Com o aumento de TS, o pico de h-InN (002) e o de In (101) aparecem e crescem juntos, sugerindo que o aumento da mobilidade dos átomos depositados na superfície do substrato facilita a formação e cristalização desses compostos. Em $450^{\circ} \mathrm{C}$, são observados mais dois picos em $65,3^{\circ}$ e $69,1^{\circ}$ referentes às reflexões do plano (004) de h-InN e do (202) de In. Os compostos cristalinos de h-InN e In são orientados preferencialmente nas respectivas direções [001] e [101] com respeito à normal à superfície da amostra. Infelizmente, a fase de In metálico sempre aparece com a de h-InN. 


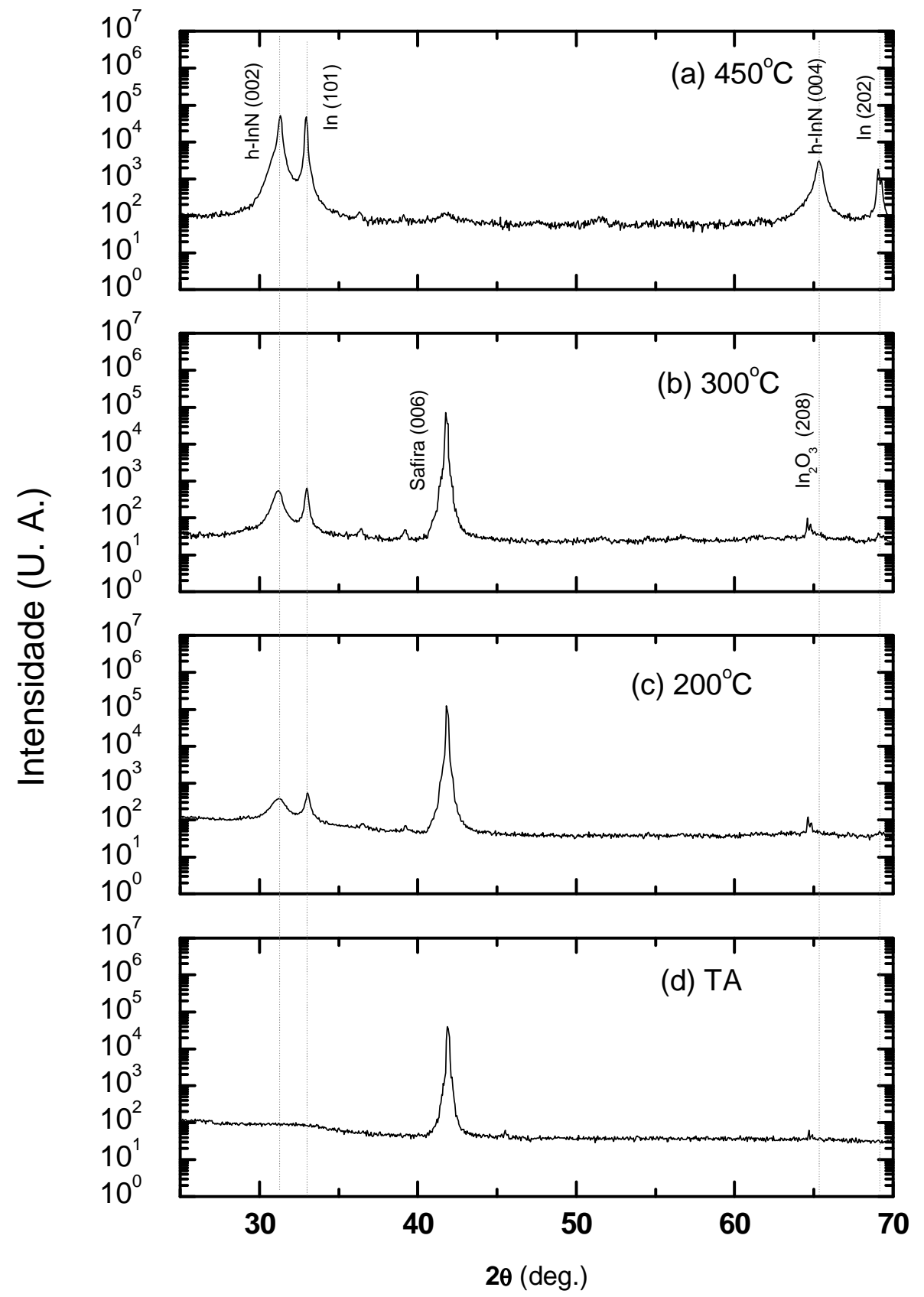

Figura 3.7. Difratogramas para amostras depositadas sobre safira-C em: (a) $4500 \mathrm{C}$, (b) $3000 \mathrm{C}$, (c) $2000 \mathrm{C}$ e (d) $\mathrm{TA} \operatorname{com} \mathrm{E}=100 \mathrm{eV}$ e $\operatorname{ARR}(\mathbf{I} / \mathbf{A})=\mathbf{0 , 8}$.

As figuras 3.8(a) e 3.8(b) indicam os difratogramas para as amostras preparadas em 300 e $200^{\circ} \mathrm{C}$, respectivamente, com $\mathrm{E}=100 \mathrm{eV}$ e $\operatorname{ARR}(\mathrm{I} / \mathrm{A})=5,5$. Neste caso também há tendência de as intensidades dos picos de h-InN (002) e In (101) aumentarem com o aumento de TS. 


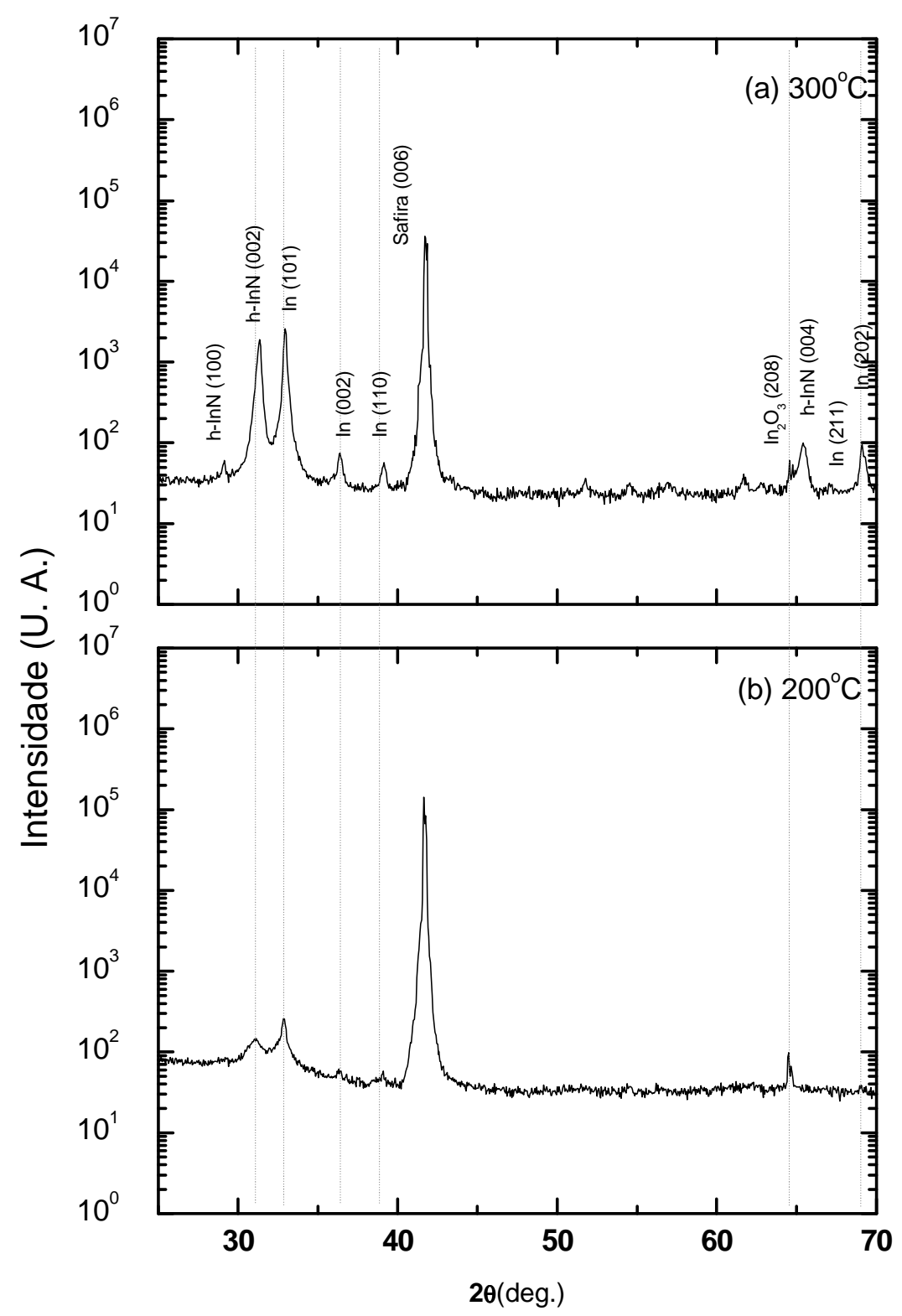

Figura 3.8. Difratogramas para amostras depositadas sobre safira-C em: (a) $3000 \mathrm{C}$ e (b) $2000 \mathrm{C} \operatorname{com} E=100$ eV e $\operatorname{ARR}(\mathrm{I} / \mathrm{A})=5,5$.

\section{(b) Dependência da $\mathbf{E}$}

Os difratogramas que aparecem nas figuras 3.9(a) e 3.9(b) referem-se às amostras formadas em $300^{\circ} \mathrm{C} \operatorname{com} \mathrm{E}=800 \mathrm{e}$ $100 \mathrm{eV}$, respectivamente, e $\operatorname{ARR}(\mathrm{I} / \mathrm{A})=0,8$. A partir dessas figuras, é verificado que a E mais alta inibe a cristalização de 
In $\mathrm{N}$ e In, como foi visto no caso de amostras depositadas sobre Si (111) [item (b) da seção 3.1.1].

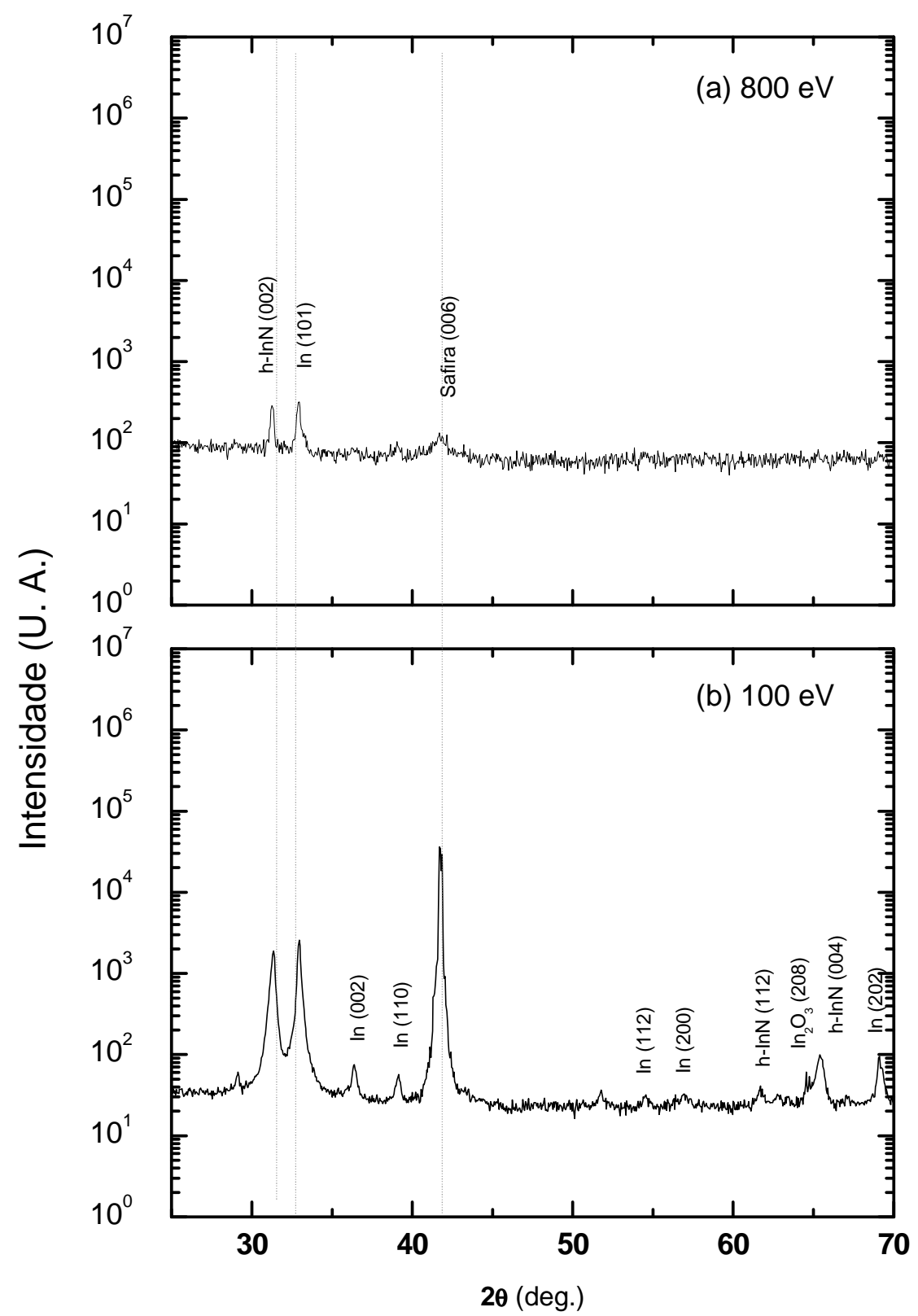

Figura 3.9. Difratogramas para amostras depositadas sobre safira-C em 300oC, com $\operatorname{ARR}(\mathrm{I} / \mathrm{A})=0,8$ e $E=$ (a) $800 \mathrm{eV}$ e (b) $100 \mathrm{eV}$.

\section{(c) Dependência da ARR(I/A)}

O estudo sobre o efeito da ARR(I/A) na formação do filme foi feito para amostras depositadas em 200 (figura 3.10) e $300^{\circ} \mathrm{C}$ (figura 3.11 ) $\mathrm{com} \mathrm{E}=100 \mathrm{eV}$. Na figura 3.10 , o aumento 
da intensidade dos picos de h-InN (002) e In (101) é verificado quando se diminuiu a ARR(I/A) de 5,5 para 0,8 [figuras 3.10(a) e $3.10(\mathrm{~b})$, respectivamente]. No entanto, o inverso ocorreu na figura 3.11: houve o aumento da intensidade dos picos à medida que aumentava a ARR(I/A) de 0,8 para 5,5 [figuras 3.11(b) e 3.11(a), respectivamente]. Este fato sugere que o processo de formação e crescimento dos compostos cristalinos é complexo; dependendo não só da ARR(I/A), mas também da TS.

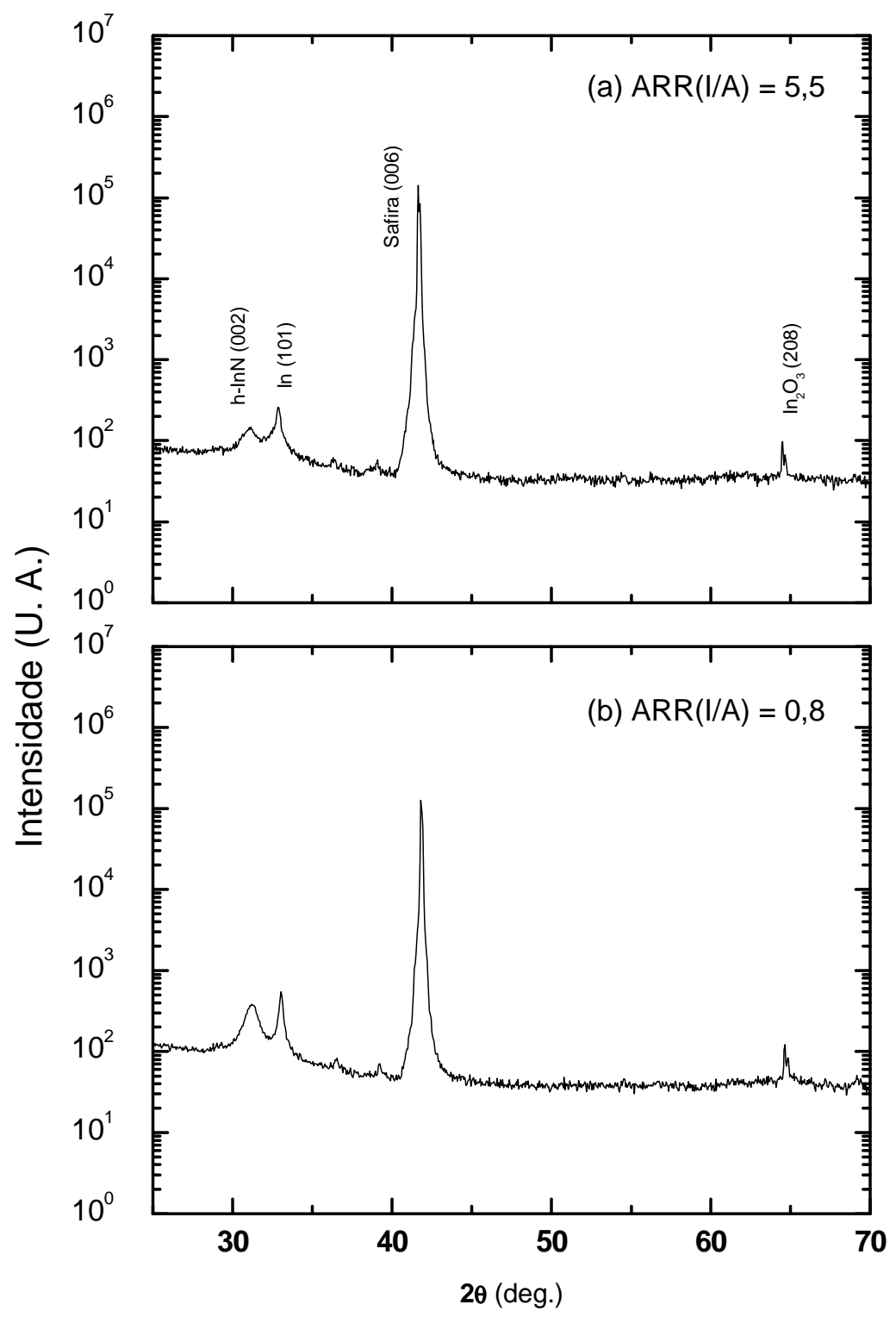

Figura 3.10. Difratogramas para amostras depositadas sobre safira-C em $2000 \mathrm{C}, \operatorname{com} E=$ $100 \mathrm{eV}$ e $\operatorname{ARR}(\mathrm{I} / \mathrm{A})=$ (a) 5,5 e (b) 0,8 . 


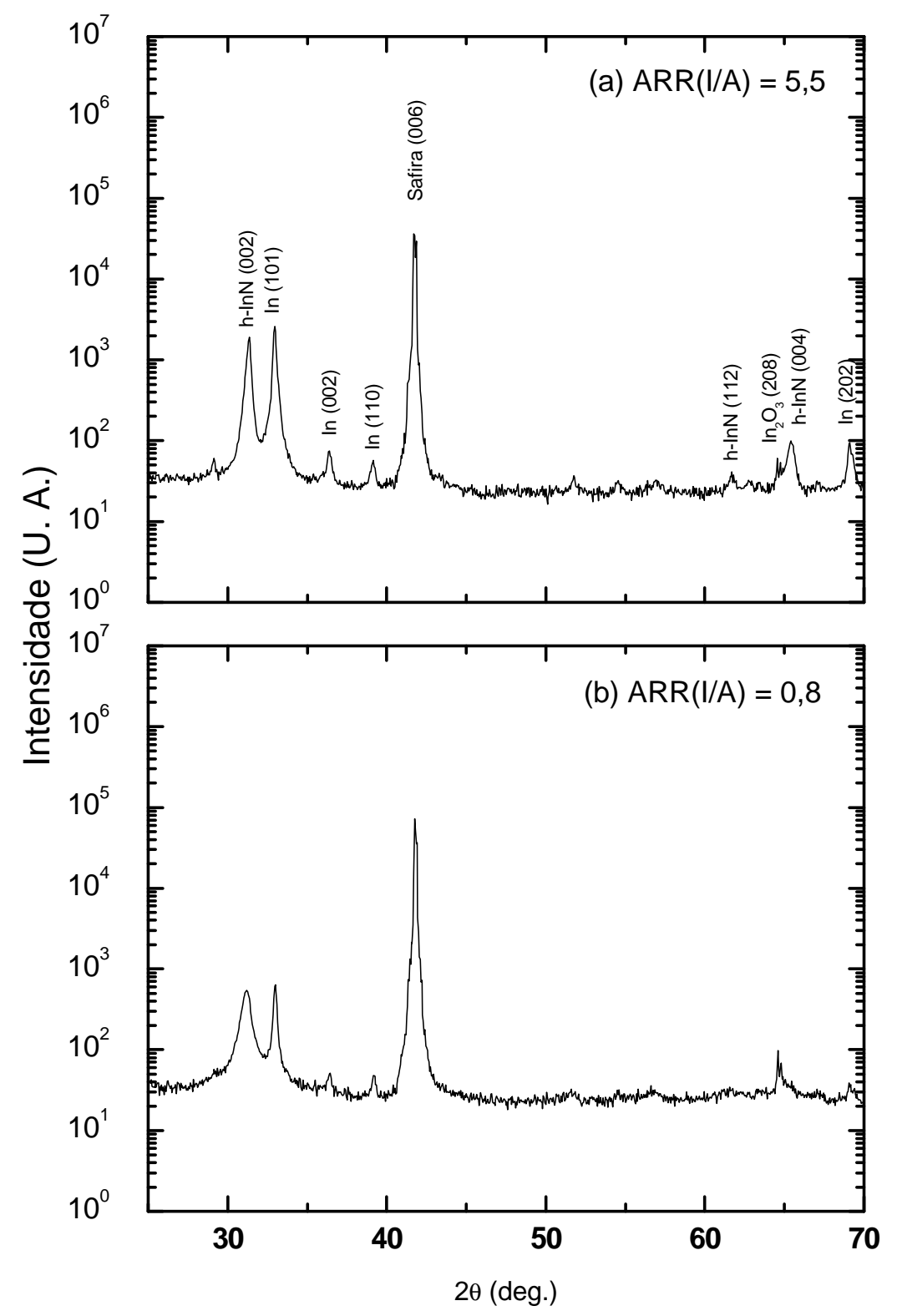

Figura 3.11. Difratogramas para amostras depositadas sobre safira-C em 300oC, $\operatorname{com} E=$ $100 \mathrm{eV}$ e $\operatorname{ARR}(\mathrm{I} / \mathrm{A})=$ (a) 5,5 e (b) 0,8 .

\subsubsection{Amostras depositadas em substrato de safira-A}

(a) Dependência da TS

As figuras 3.12(a) e 3.12(b) apresentam os difratogramas de raios-X obtidos para amostras preparadas em $200^{\circ} \mathrm{C}$ e $\mathrm{TA}$, 
respectivamente, $\operatorname{com} \mathrm{E}=100 \mathrm{eV}$ e $\mathrm{ARR}(\mathrm{I} / \mathrm{A})=0,8$. Observa-se o surgimento dos picos de h-InN(002) e In (101) e In (112) com o aumento da temperatura, mais uma vez indicando que a mobilidade dos átomos depositados na superfície do substrato facilita a formação e cristalização desses compostos com o aumento da TS.

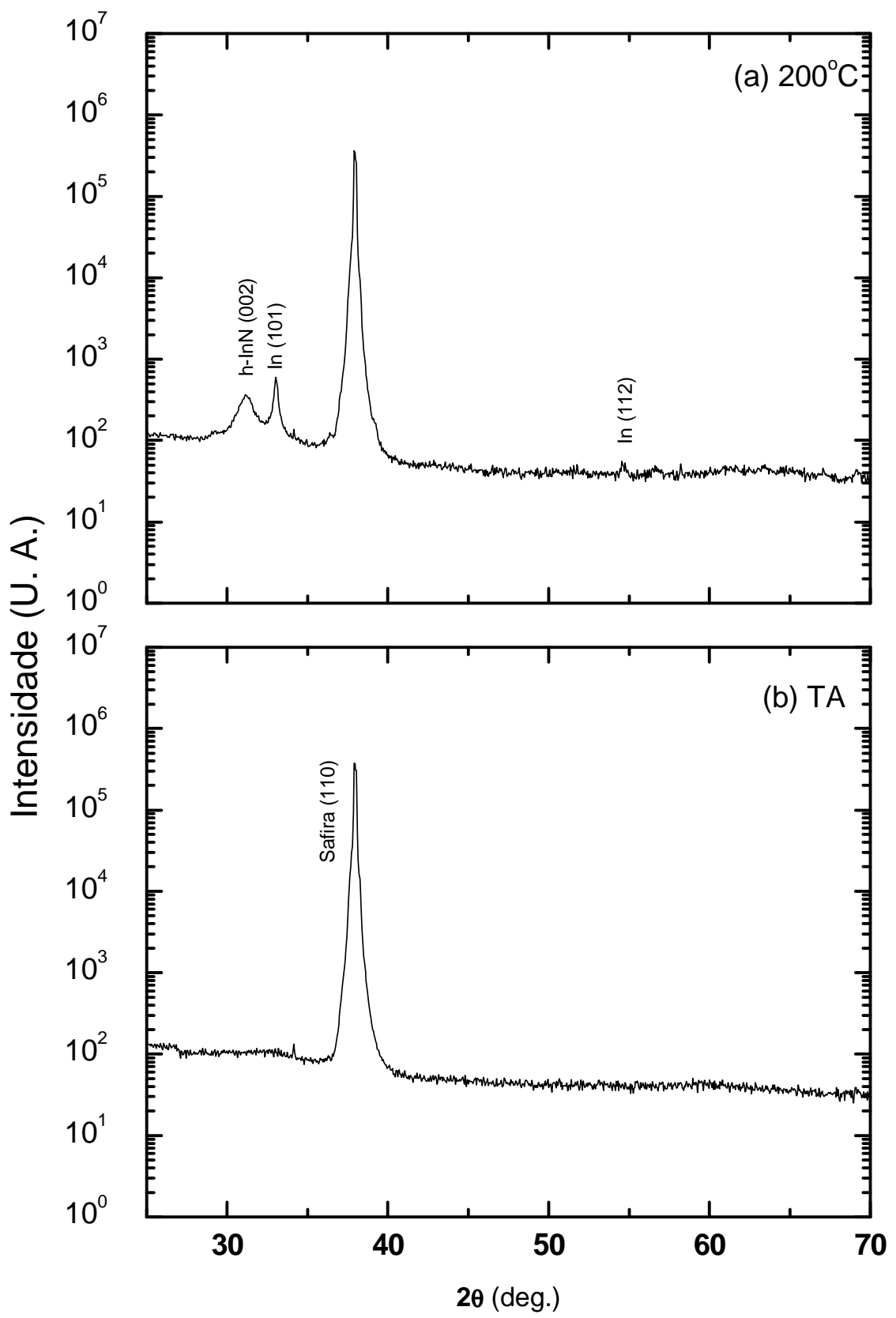

Figura 3.12. Difratogramas para amostras depositadas sobre safira-A em: (a) $2000 \mathrm{C}$ e (b) TA; com $E=100$ eV e ARR $(I / A)=0,8$. 


\section{(b) Dependência de ARR(I/A)}

As figuras 3.13(a) e 3.13(b) mostram difratogramas obtidos para amostras em $300{ }^{\circ} \mathrm{C}$, com $\mathrm{E}=100 \mathrm{eV}$ e ARR(I/A) $=5,5$ e 0,8 , respectivamente. Verifica-se que em ambas houve a formação de picos relacionados aos planos h-InN (002) e In (101), porém não houve mudanças significativas entre suas intensidades, como afirmado na seção 3.1.2.

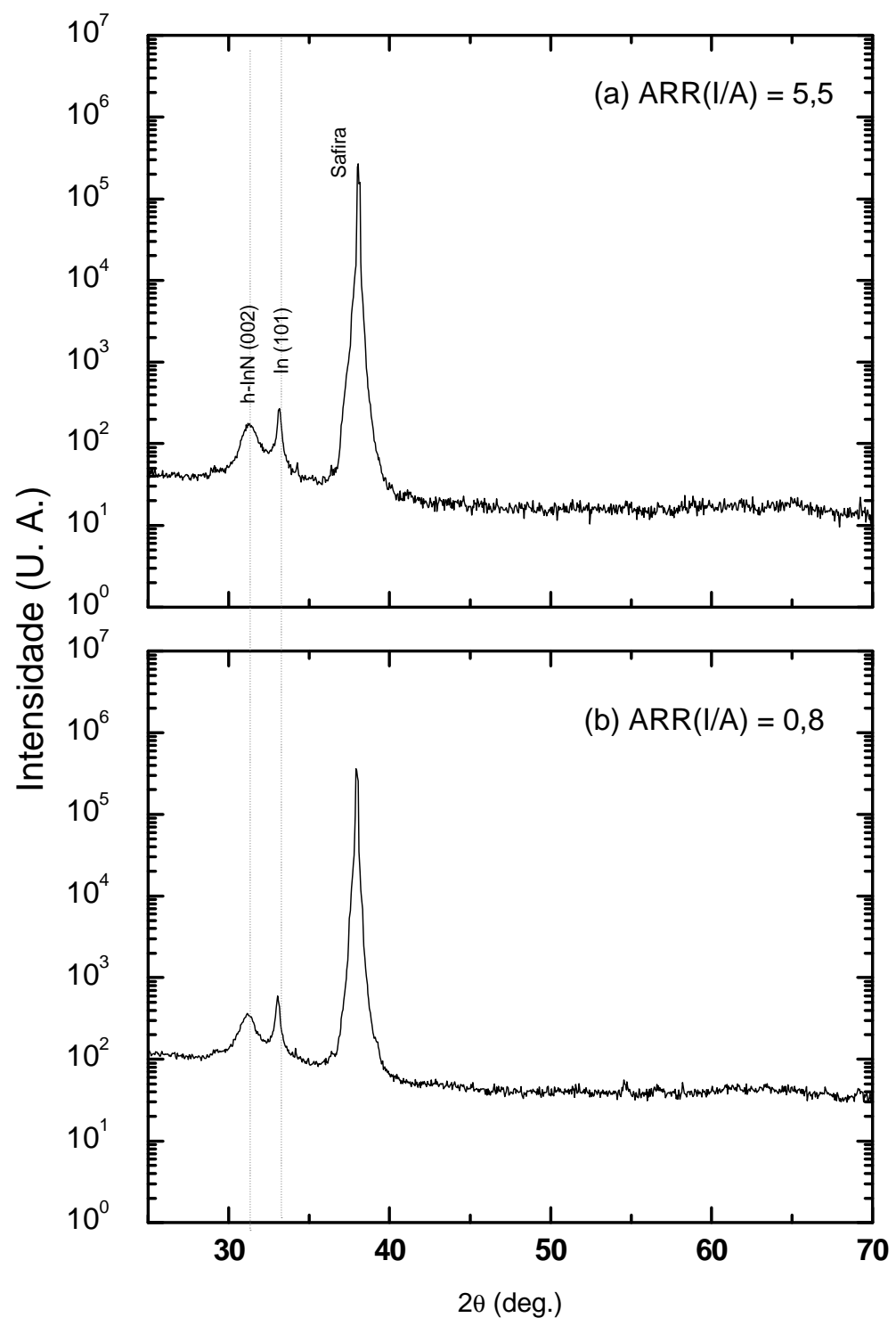

Figura 3.13. Difratogramas para amostras depositadas sobre safira-A em $3000 \mathrm{C}, \operatorname{com} \mathrm{E}=$ 100 eV e $\operatorname{ARR}(I / A)=($ a) 5,5 e (b) 0,8 . 


\subsubsection{Amostras depositadas em substrato de safira-R}

(a) Dependência da TS

As figuras 3.14(a) - 3.14(d) apresentam os resultados dos difratogramas das amostras crescidos em $450^{\circ} \mathrm{C}, 300^{\circ} \mathrm{C}, 200^{\circ} \mathrm{C}$ e $\mathrm{TA}$, respectivamente, $\operatorname{com} \mathrm{E}=100 \mathrm{eV}, \mathrm{ARR}(\mathrm{I} / \mathrm{A})=0,8$. Uma tendência ao aumento da formação de policristalinos e na intensidade dos picos de h-InN (002), (102) e (004) e In metálico é evidenciada nas amostras apresentadas, conforme aumenta-se a TS. 


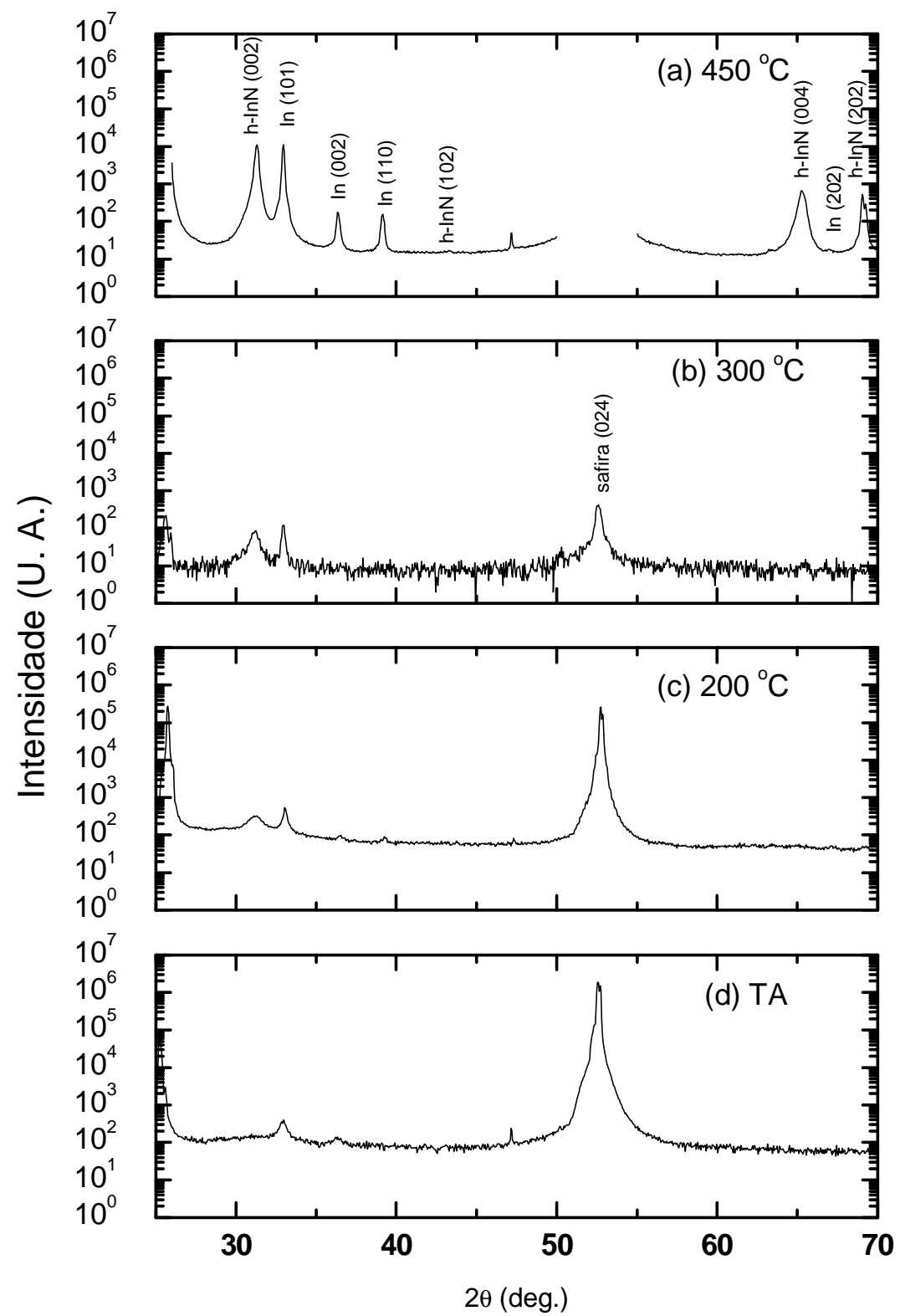

Figura 3.14. Difratogramas para amostras depositadas sobre safira-R em: (a) 450oC, (b) $3000 \mathrm{C}$, (c) $2000 \mathrm{C}$ e (d) TA, com $\mathrm{E}=100$ eV e $\operatorname{ARR}(\mathbf{I} / \mathbf{A})=0,8$.

(b) Dependência de $\operatorname{ARR}(\mathrm{I} / \mathrm{A})$

As figuras 3.15(a) e 3.15(b) mostram difratogramas obtidos para amostras em $300{ }^{\circ} \mathrm{C}$, com $\mathrm{E}=100 \mathrm{eV}$ e ARR(I/A) $=5,5$ e 0,8 , respectivamente. Verifica-se que em ambas houve a formação de picos relacionados aos planos h-InN (002) e In (101), porém não houve mudanças significativas entre suas intensidades. 


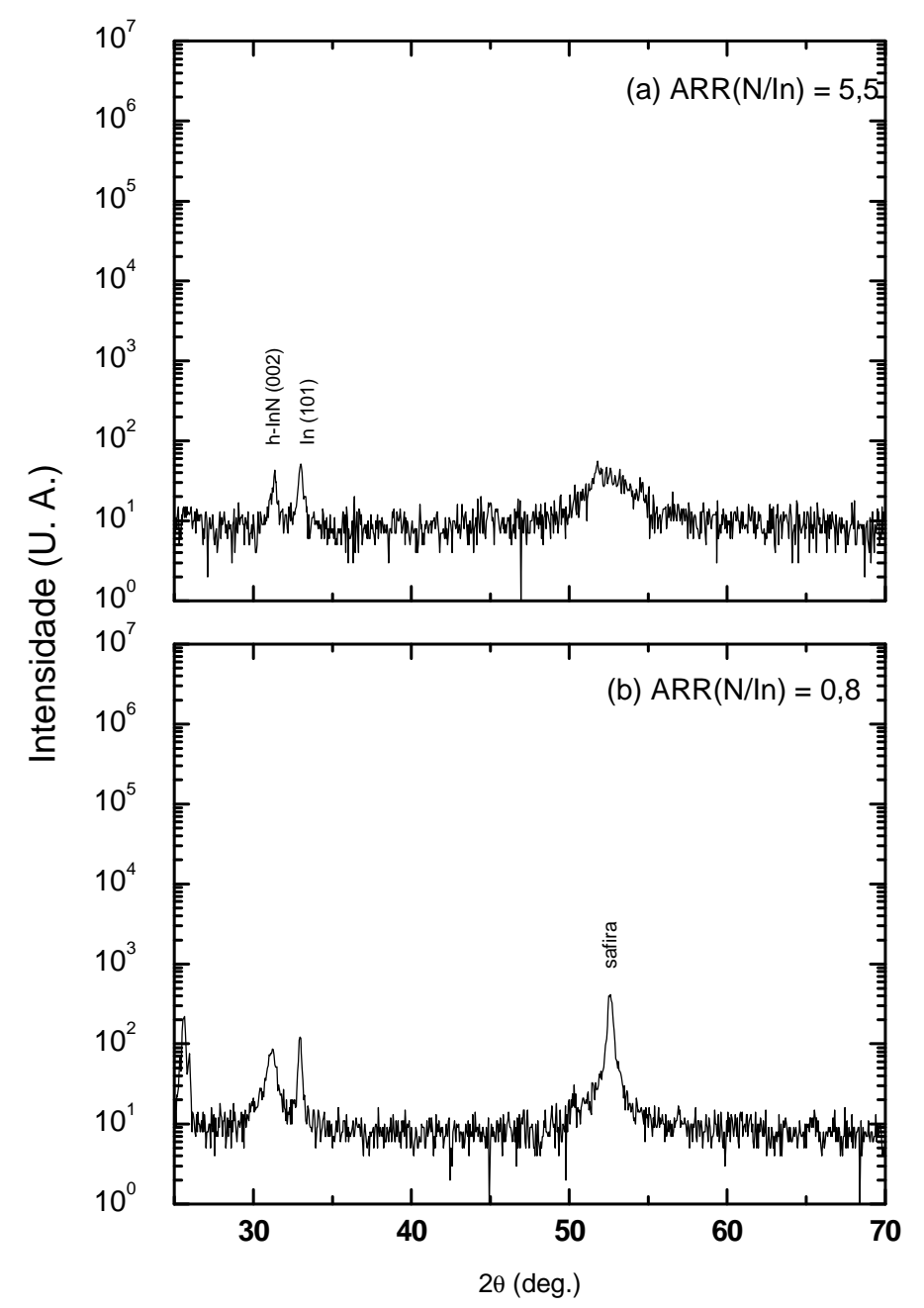

Figura 3.15. Difratogramas para amostras depositadas sobre safira-R em 300oC, com energia de íons de 100 eV e $\operatorname{ARR}(I / A)=(a) 5,5$ e (b) 0,8 .

\subsubsection{Amostras depositadas em substrato de GaN/safira}

(a) Dependência da TS

As figuras 3.16(a) - 3.16(e) apresentam difratogramas de amostras crescidas em 450, 300, 200, $100^{\circ} \mathrm{C}$ e $\mathrm{TA}$, respectivamente, $\operatorname{com} \mathrm{E}=100 \mathrm{eV}, \mathrm{ARR}(\mathrm{I} / \mathrm{A})=0,8$. As figuras 3.17(a) e 3.17(b) mostram difratogramas de amostras 
preparadas em 300 e $200^{\circ} \mathrm{C}$, respectivamente, com $\mathrm{E}=100 \mathrm{eV}$ e $\operatorname{ARR}(\mathrm{I} / \mathrm{A})=5,5$. Um pico em 53,0 , atribuído a InGaN (110), é observado distintamente na amostra formada em $450^{\circ} \mathrm{C}$. As amostras formadas acima de $300^{\circ} \mathrm{C}$ apresentam nitidamente dois picos novos, devido às reflexões dos planos (111) e (222) de cInN, em $31,1^{\circ}$ e $64,8^{\circ}$, respectivamente $[45,46]$. O aumento da TS facilita a formação dos compostos cristalinos de h-InN e cInN, junto com a dos compostos cristalinos de In, conforme afirmado nas seções anteriores; c-InN e In são orientados preferencialmente nas respectivas direções [111] e [101]. A amostra depositada em TA possui só o pico de h-InN cuja intensidade é bem menor que as dos picos relacionados ao substrato. 


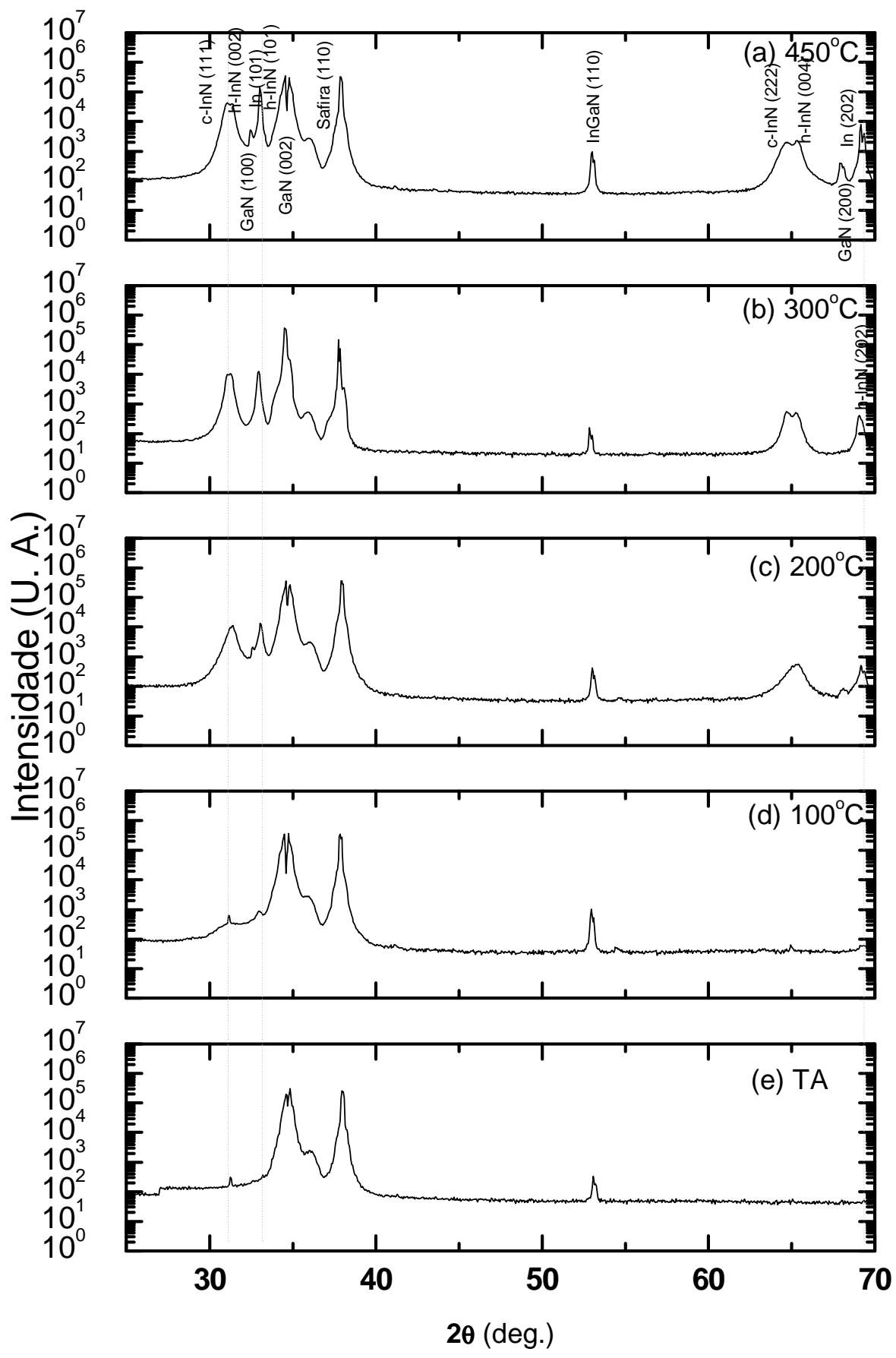

Figura 3.16. Difratogramas para amostras depositadas sobre GaN/safira em (a) 450oC, (b) $3000 \mathrm{C}$, (c) $2000 \mathrm{C}$, (d) $100 \mathrm{CC}$ e (e) TA, com $E=100 \mathrm{eV}$ e $\operatorname{ARR}(\mathrm{I} / \mathrm{A})=0,8$. 


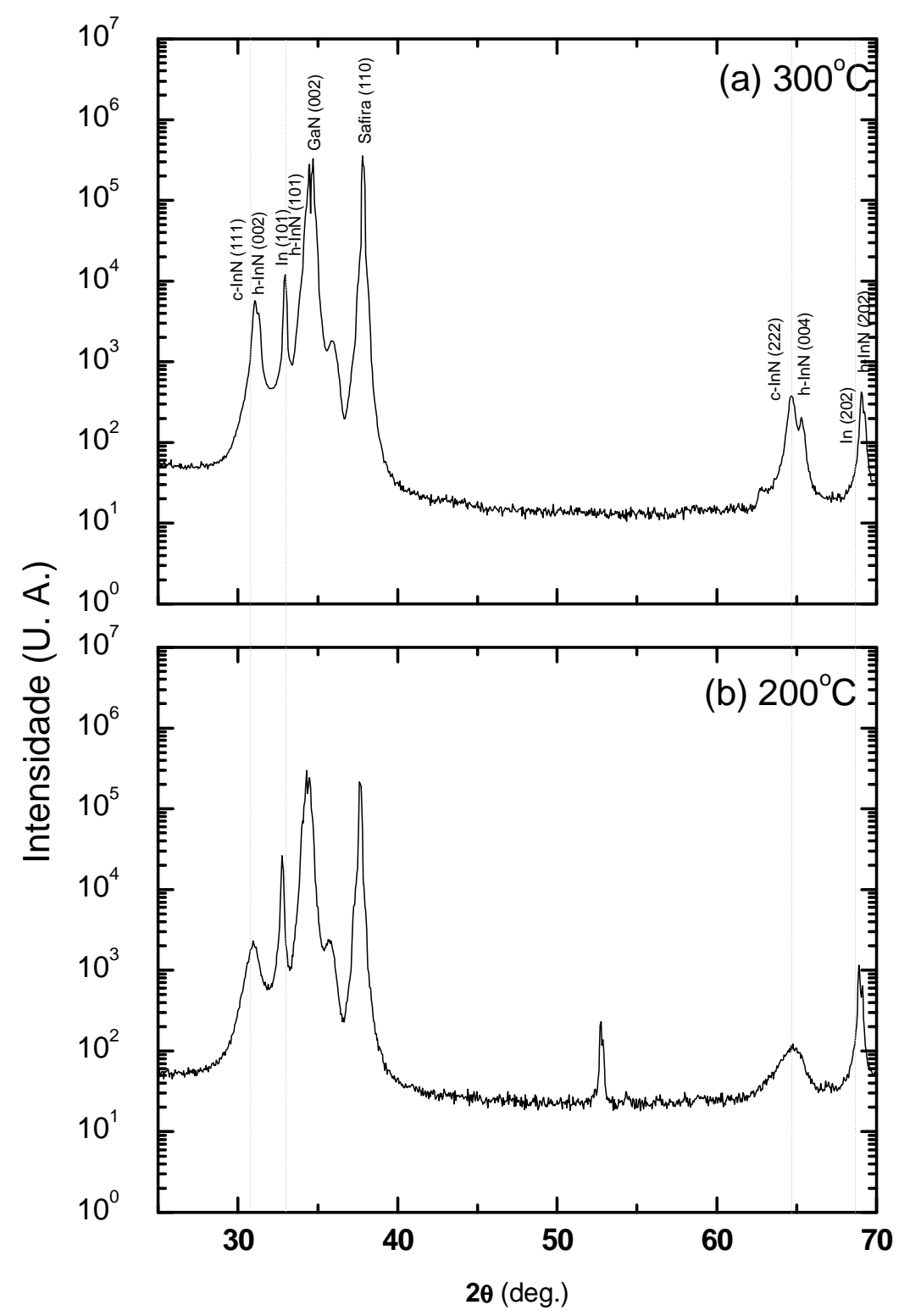

Figura 3.17. Difratogramas para amostras depositadas sobre GaN/safira em: (a) $300^{\circ} \mathrm{C}$ e (b) $2000 \mathrm{C}, \operatorname{com} E=100$ eV e $\operatorname{ARR}(\mathrm{I} / \mathrm{A})=5,5$.

\section{(b) Dependência de E}

As figuras $3.18(a)-3.18(d)$ mostram os difratogramas para os filmes depositados em $300^{\circ} \mathrm{C} \operatorname{com} \mathrm{ARR}(\mathrm{I} / \mathrm{A})=3,3$ e $\mathrm{E}=$ 200, 500, 800 e 1190 eV, respectivamente. As figuras 3.19(a) 3.19 (d) indicam os difratogramas para os filmes depositados 
com as mesmas condições de deposição citadas acima, exceto o valor de ARR(I/A) igual a 4,4.

Nas figuras 3.18 e 3.19 , pode-se perceber que a intensidade do pico de h-InN (002) e a de In (101) diminuem drasticamente à medida que aumenta a E de 200 para 500 eV. Este fenômeno devese ao fato de o crescimento da amostra se tornar mais difícil com o aumento da E por causa de sputtering. Essa evidência será comprovada através de observação da micrografia apresentada na figura 3.27, na seção 3.2. Em conseqüência de sputtering, é melhor escolher a E e a ARR(I/A) mais baixas (200 eV e 3,3, respectivamente) para formar a amostra cristalizada. 


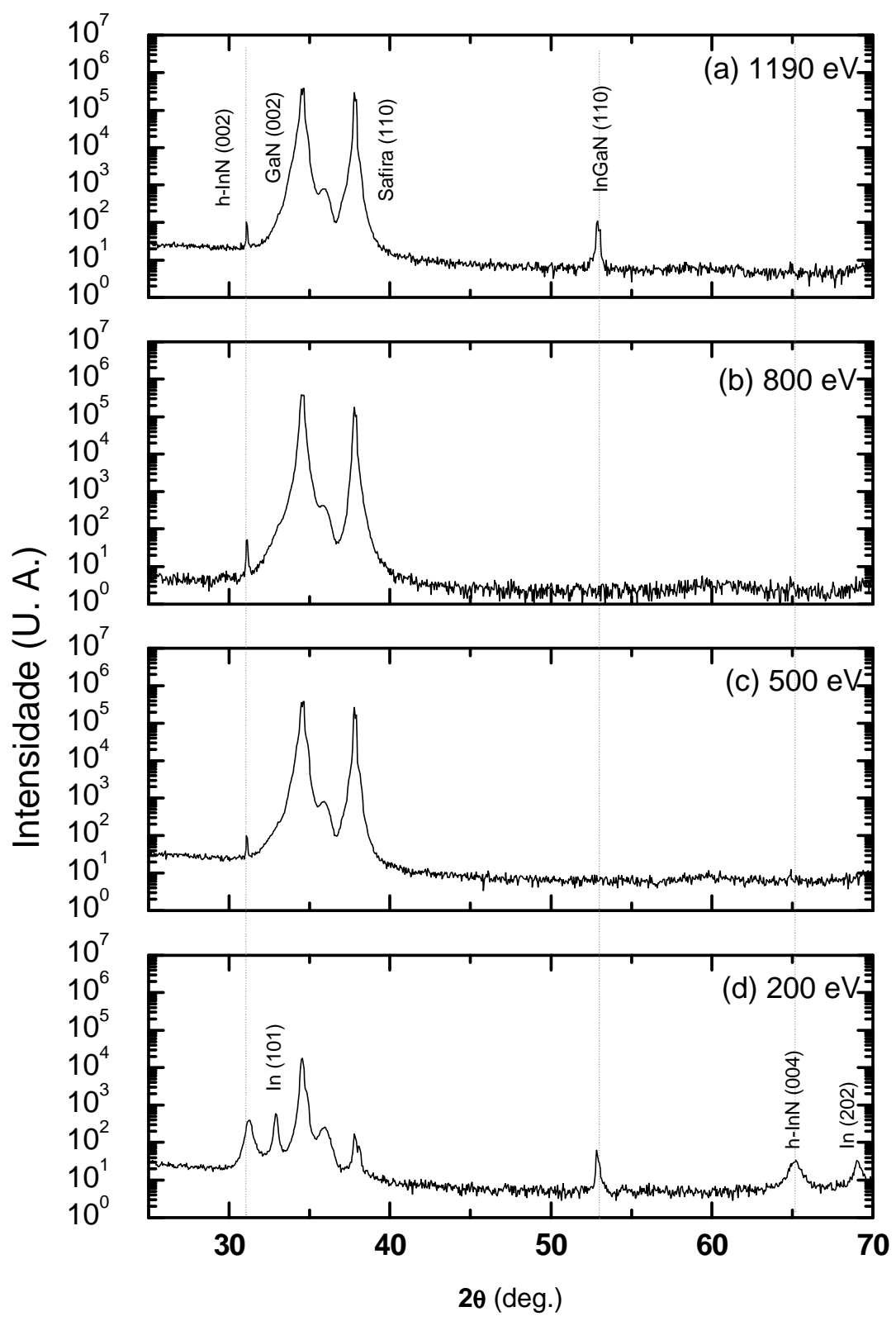

Figura 3.18. Difratogramas para amostras depositadas sobre GaN/safira em 300oC, com $\operatorname{ARR}(\mathrm{I} / \mathrm{A})=3,3 \mathrm{e} \mathrm{E}=$ (a) $1190 \mathrm{eV}$, (b) $800 \mathrm{eV}$, (c) 500 e (d) $200 \mathrm{eV}$. 


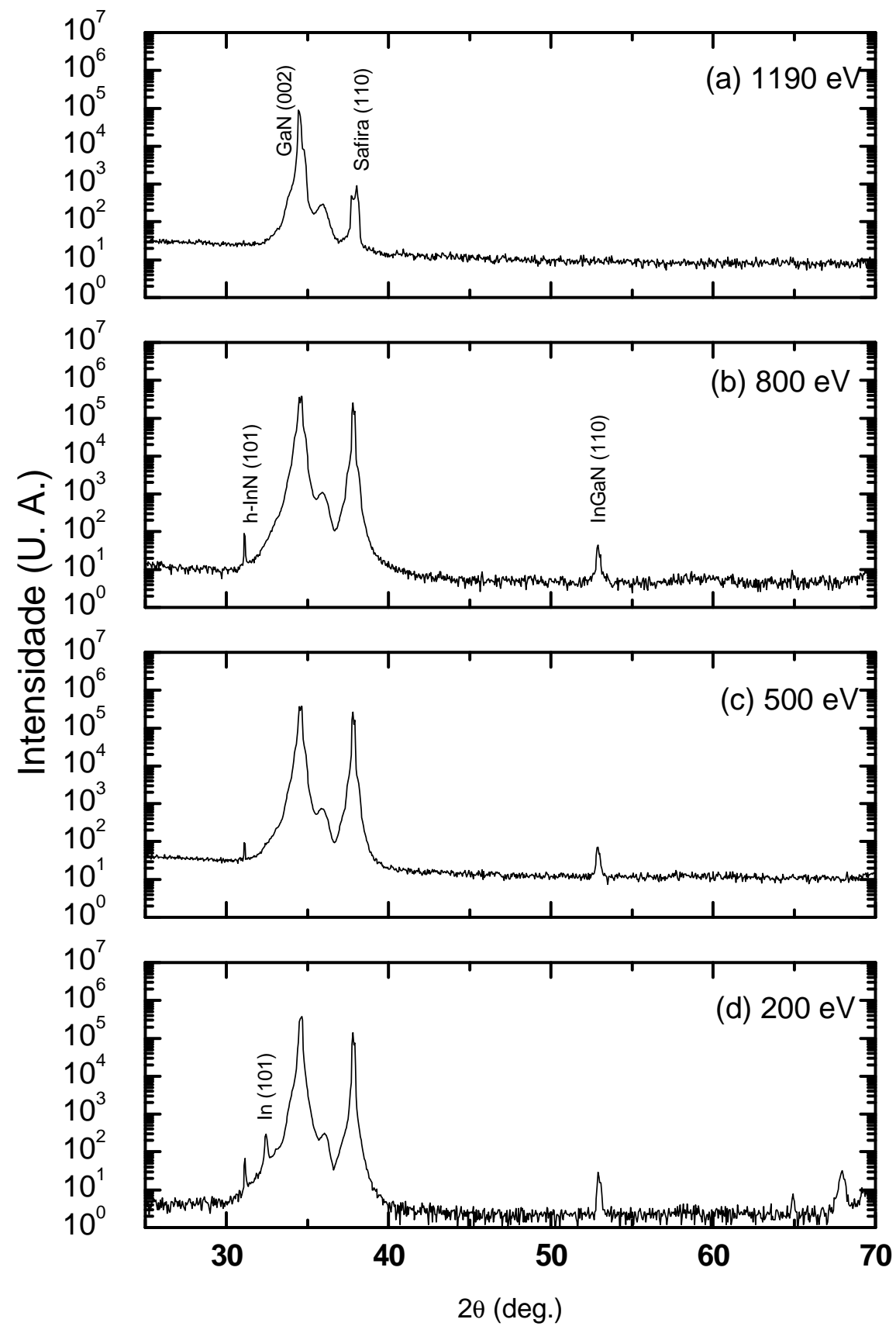

Figura 3.19. Difratogramas para amostras depositadas sobre GaN/safira em 300oC, com $\operatorname{ARR}(\mathrm{I} / \mathrm{A})=4,4 \mathrm{e} \mathrm{E}=$ (a) $1190 \mathrm{eV}$, (b) $800 \mathrm{eV}$, (c) 500 e (d) 200 eV.

\section{(c) Dependência de ARR(I/A)}

As amostras usadas nas figuras 3.20(a) e 3.20(b) foram crescidas em $200^{\circ} \mathrm{C} \operatorname{com} \mathrm{E}=100 \mathrm{eV}$ e $\mathrm{ARR}(\mathrm{I} / \mathrm{A})=5,5$ e 0,8 , respectivamente. As amostras utilizadas nas figuras 3.21(a) e 
3.21(b) foram preparadas com as mesmas condições de deposição usadas na figura 3.20 , exceto a TS, que foi de $300^{\circ} \mathrm{C}$. Nas figuras 3.20 e 3.21, observa-se que: (i) a fase cristalina de c-InN aparece mais distintamente na figura 3.21, pois essa fase é induzida e aumentada com o aumento de TS acima de $300^{\circ} \mathrm{C}$, como mencionado na seção 3.1 .4 (a); (ii) uma diminuição em intensidade dos picos de InN é observada em cada figura com o aumento de ARR(I/A). Este fato pode ser interpretado da seguinte maneira: quanto mais elevado o fluxo de íons, maior é a quantidade dos danos de radiação induzidos, impedindo o crescimento da fase cristalina.

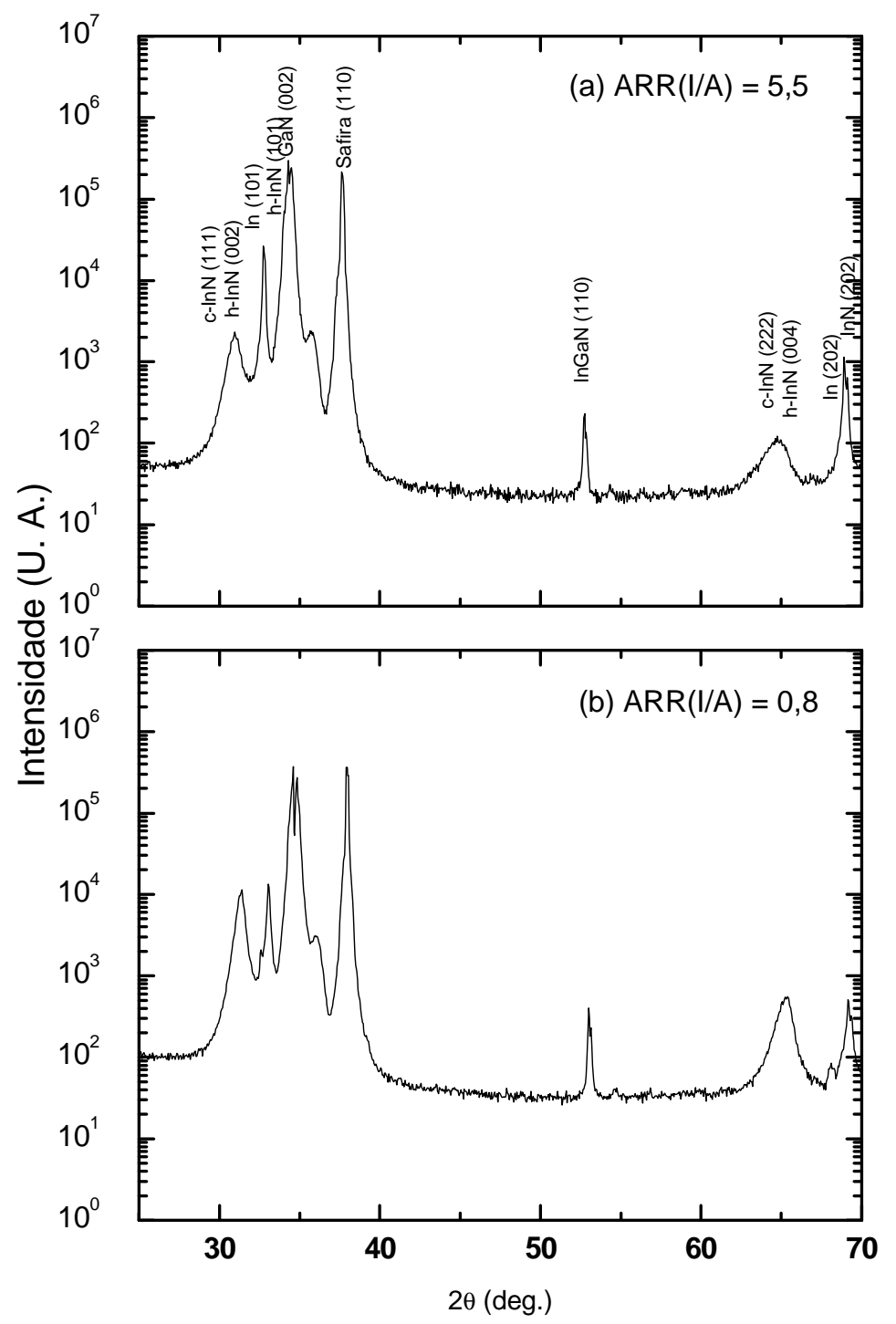

Figura 3.20. Difratogramas para amostras depositadas sobre GaN/safira em 200oC, com $E=100$ eV e $\operatorname{ARR}(I / A)=$ (a) 5,5 e (b) 0,8. 


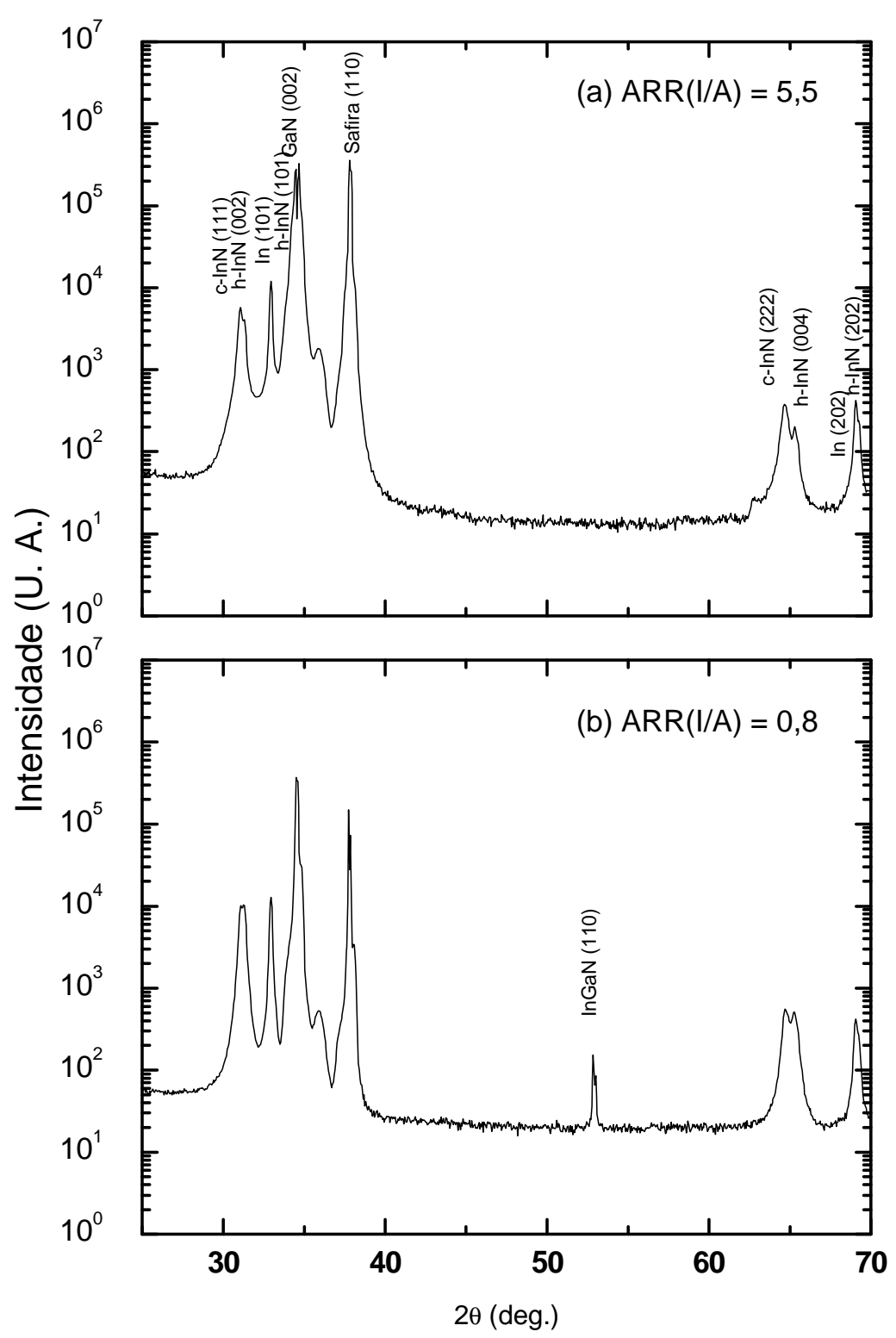

Figura 3.21. Difratogramas para amostras depositadas sobre GaN/safira em 300oC, com $E=100$ eV e $\operatorname{ARR}(I / A)=($ a) 5,5 e (b) 0,8 . 


\subsubsection{Amostras depositadas em substrato de vidro}

\section{(a) Dependência da TS}

As figuras a seguir apresentam amostras depositadas sobre substrato de vidro em $450,300,200^{\circ} \mathrm{C}$ e $\mathrm{TA}$, com $\mathrm{E}=100$ eV e ARR(I/A) =0,8 [figuras 3.22(a) - 3.22(d)] e 5,5 [3.23(a) e 3.23(b)]. Somente a amostra depositada em $450^{\circ} \mathrm{C}$ apresenta os picos de h-InN (002) e (004), e de In (101) e (202) [ver figura $3.22(\mathrm{a})]$. 


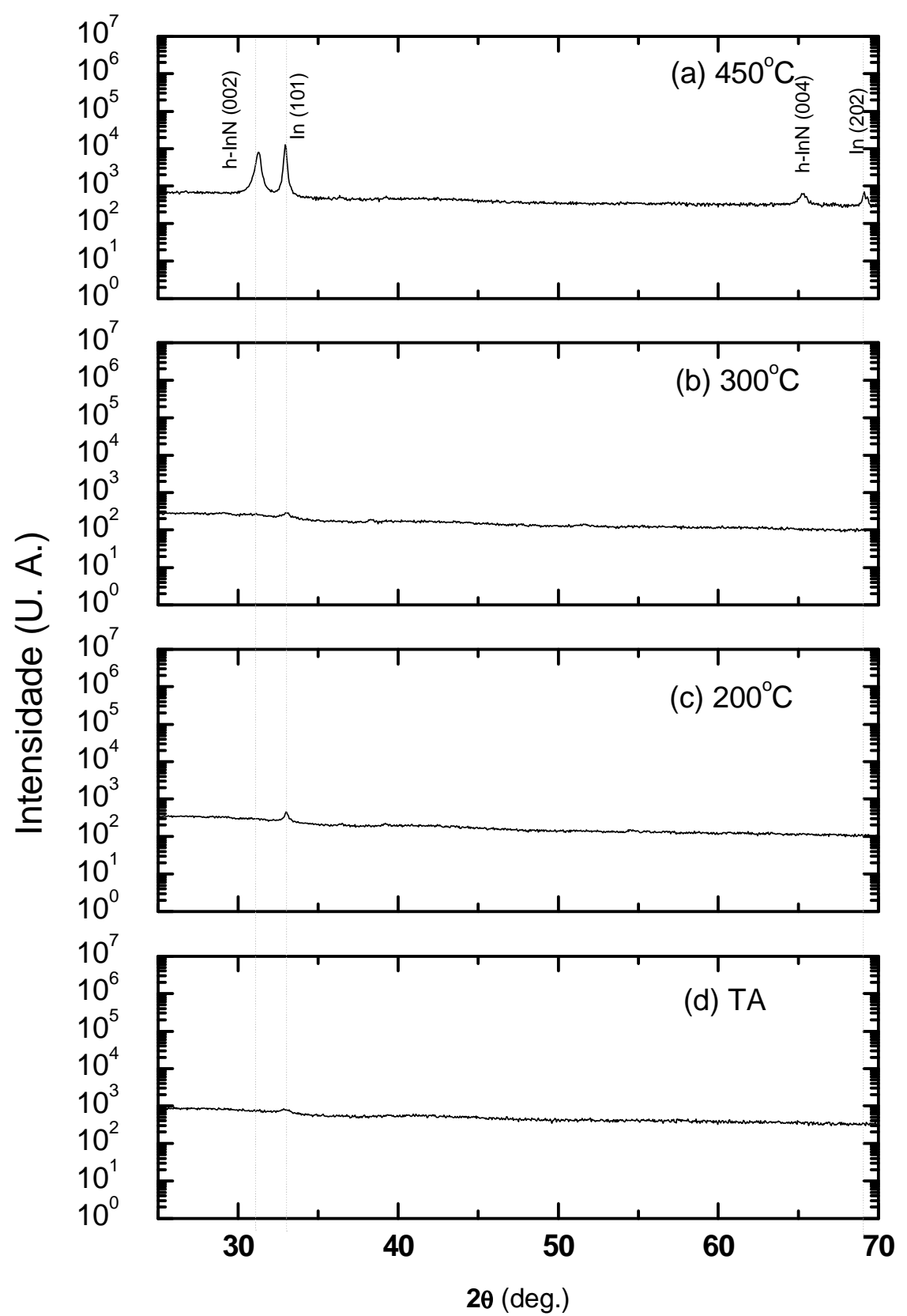

Figura 3.22. Difratogramas para amostras depositadas sobre vidro em: (a) $450^{\circ} \mathrm{C}$, (b) $3000 \mathrm{C}$, (c) $2000 \mathrm{C}$ e (d) TA, com $\mathrm{E}=100 \mathrm{eV}$ e $\operatorname{ARR}(\mathrm{I} / \mathrm{A})=0,8$. 


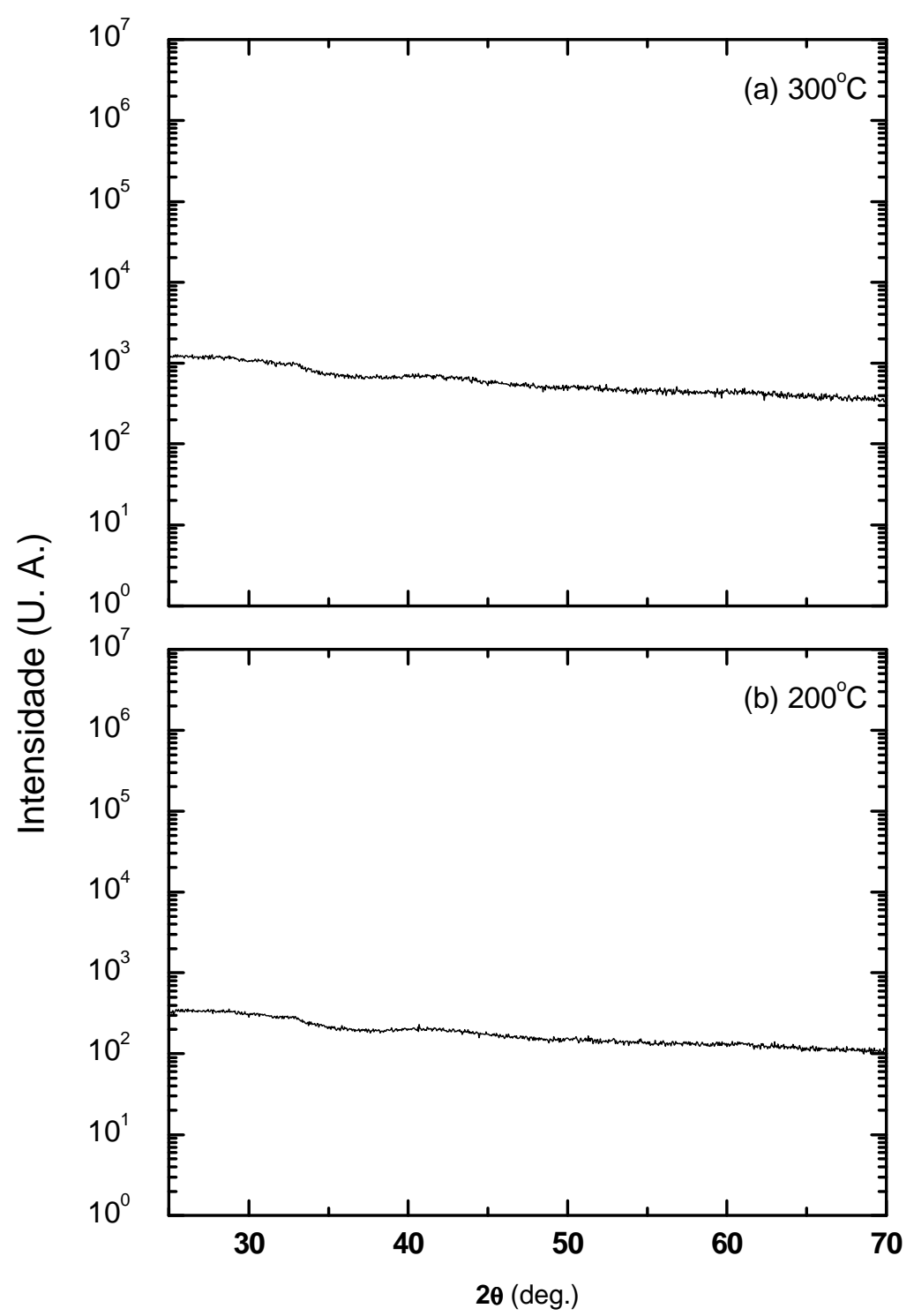

Figura 3.23. Difratogramas para amostras depositadas sobre vidro em: (a) $300^{\circ} \mathrm{C}$ e (b) $2000 \mathrm{C}, \operatorname{com} E=100$ eV e $\operatorname{ARR}(\mathrm{I} / \mathrm{A})=5,5$.

(b) Dependência de E

As figuras 3.24(a) e 3.24(b) apresentam os difratogramas das amostras depositadas em $300^{\circ} \mathrm{C} \operatorname{com} \mathrm{ARR}(\mathrm{I} / \mathrm{A})=4,0$ e $\mathrm{E}=$ 800 e 100 eV, respectivamente. Não se observa nenhum pico nos difratogramas, indicando, assim, caráter amorfo das amostras depositadas. 


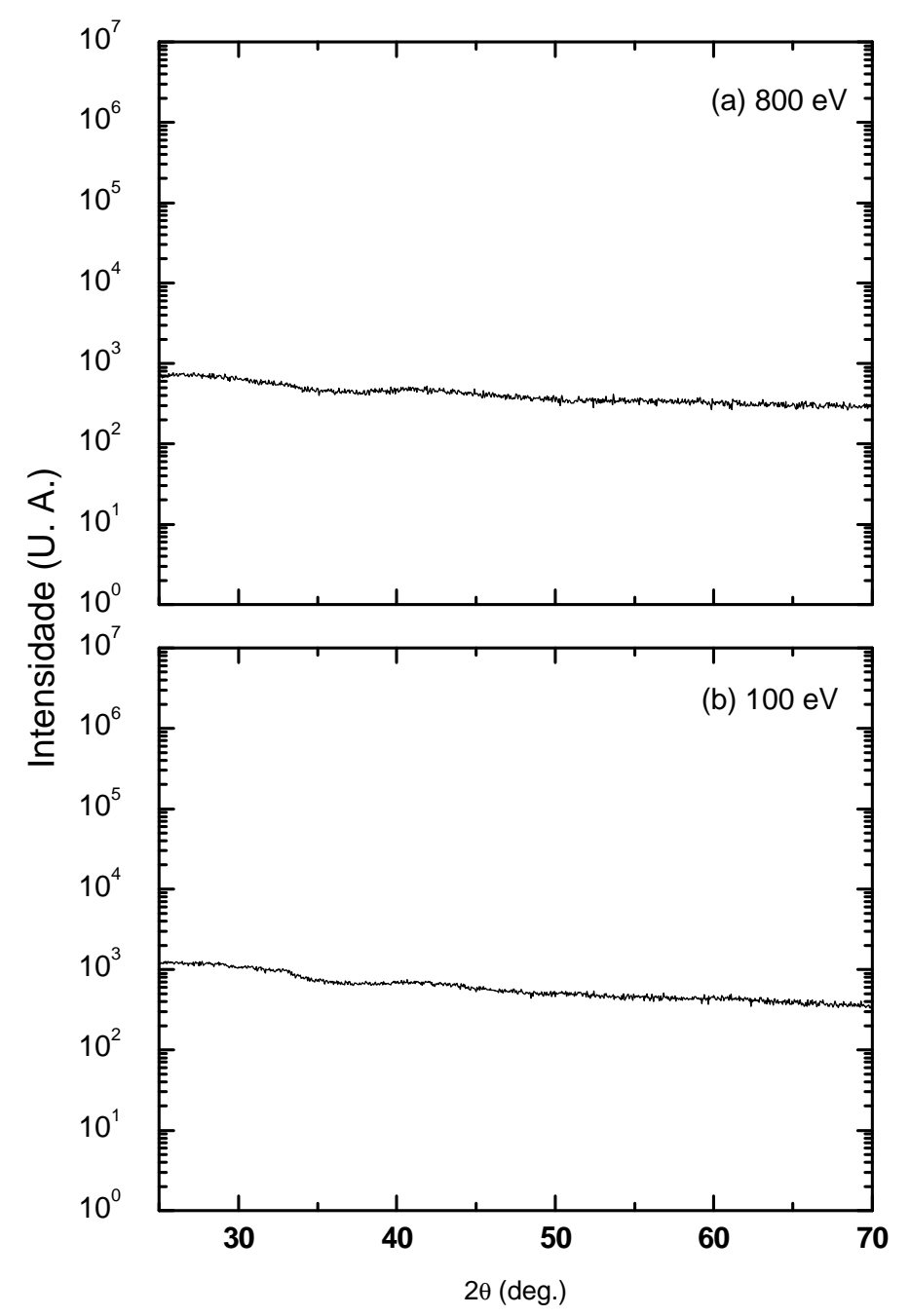

Figura 3.24. Difratograma para amostra depositada sobre substrato de vidro em 300oC, $\operatorname{ARR}(\mathrm{I} / \mathrm{A})=4,0, \operatorname{com} \mathrm{E}=$ (a) $800 \mathrm{eV}$ e (b) $100 \mathrm{eV}$.

\section{(c) Dependência de ARR(I/A)}

Para o estudo da influência da ARR(I/A) na formação de fases cristalinas, seria bom preparar uma amostra em $450^{\circ} \mathrm{C}$ com $\mathrm{E}=100 \mathrm{eV}$ e $\mathrm{ARR}(\mathrm{I} / \mathrm{A})$ diferente de 0,8 , cujo difratograma seria comparável com o da única amostra que havia apresentado dois compostos cristalinos [InN e In na figura 3.22(a)]; porém, a amostra em questão não foi crescida. As figuras 3.25(a) e 3.25(b) mostram os difratogramas das amostras depositadas em $300^{\circ} \mathrm{C}$ com $\mathrm{E}=100 \mathrm{eV}$ e $\mathrm{ARR}(\mathrm{I} / \mathrm{A})=5,5$ e 0,8 , respectivamente. As figuras 3.26(a) e 3.26(b) indicam os difratogramas das amostras crescidas em $200^{\circ} \mathrm{C}$ com $\mathrm{E}=100 \mathrm{eV}$ e $\mathrm{ARR}(\mathrm{I} / \mathrm{A})=5,5$ e 0,8, 
respectivamente. Como esses difratogramas não apresentam nenhum pico, as amostras são amorfas

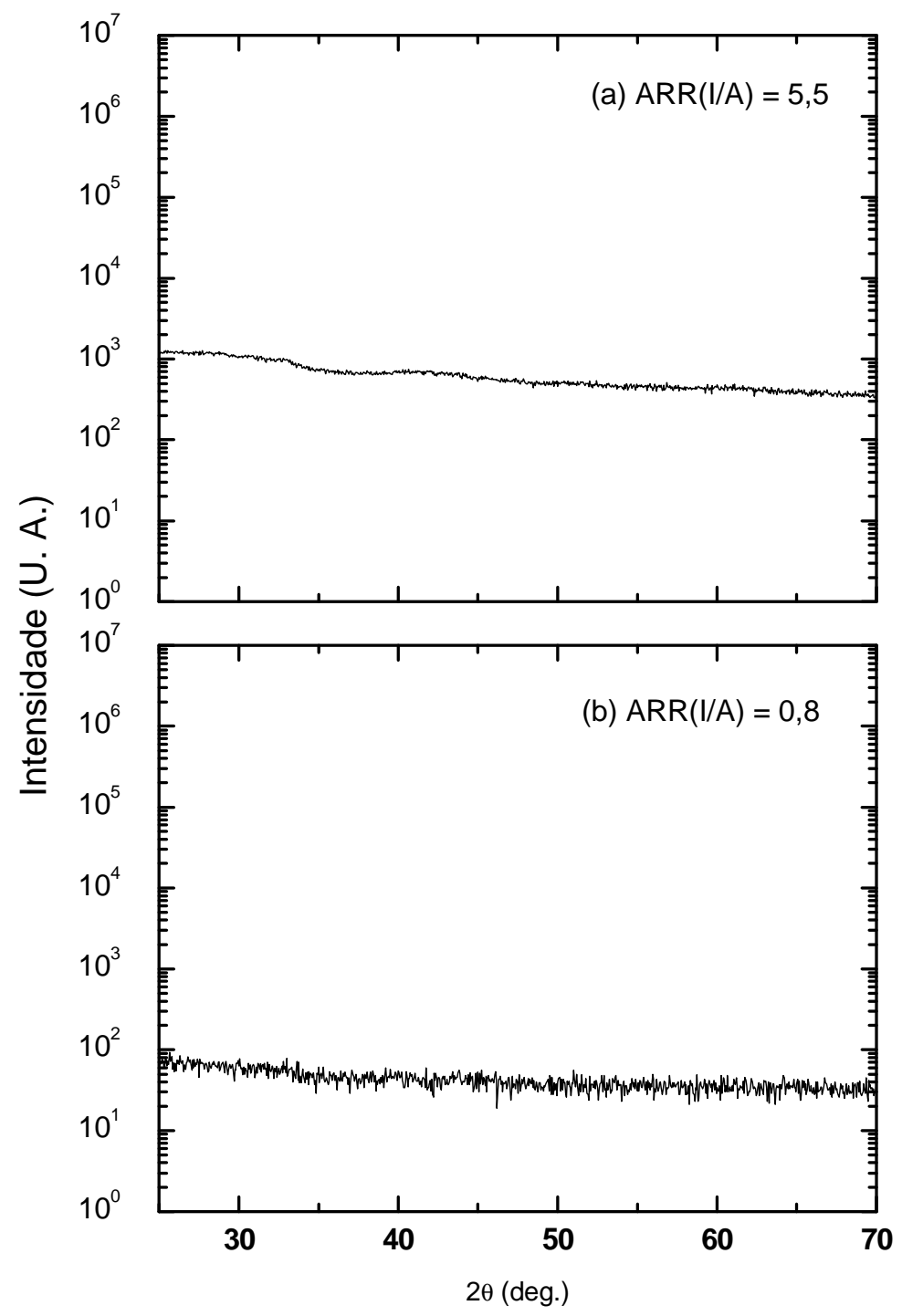

Figura 3.25 Difratogramas para amostras depositadas sobre vidro em $3000 \mathrm{C}$, com $E=100$ eV e $\operatorname{ARR}(I / A)=$ (a) 5,5 e (b) 0,8 . 


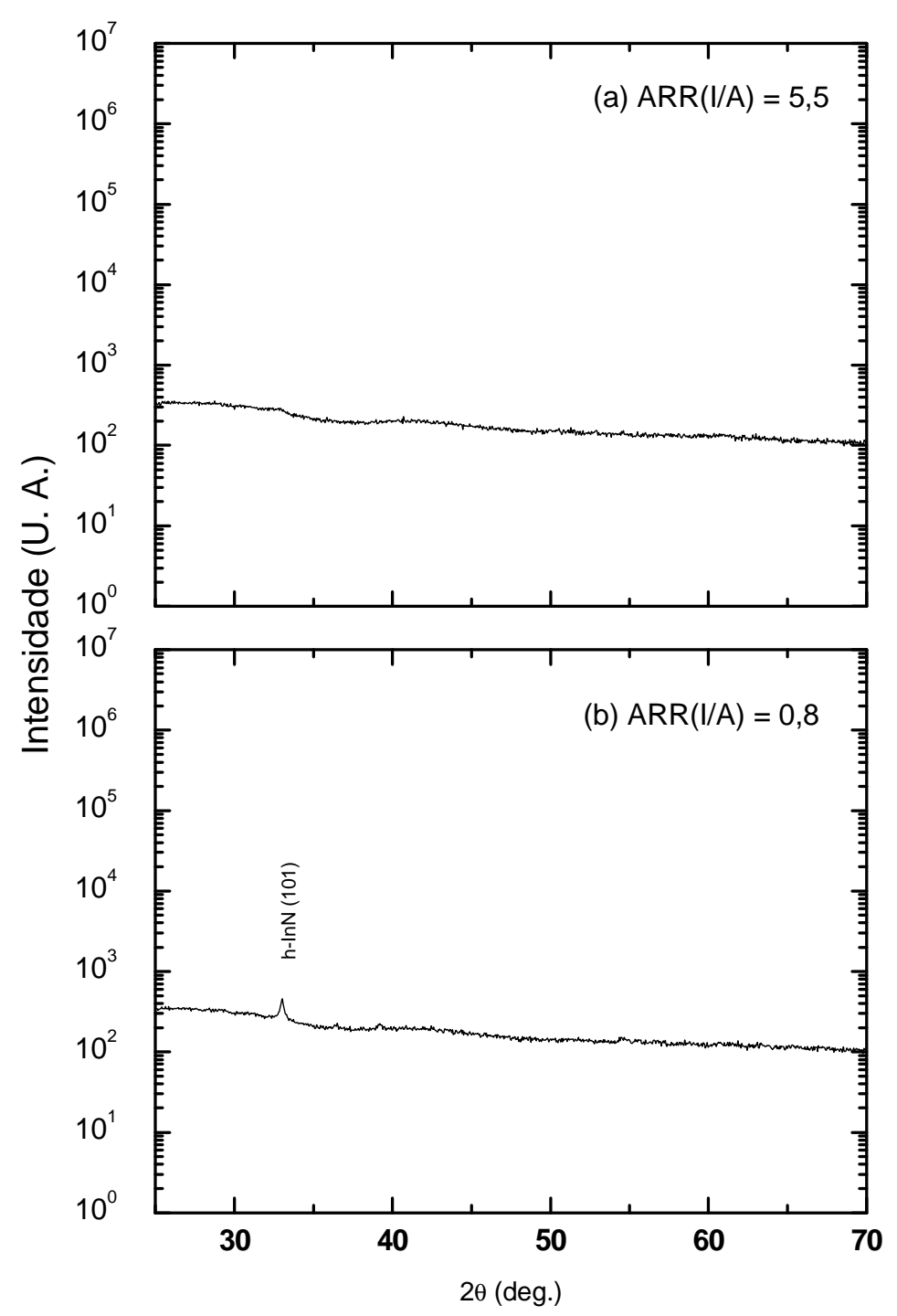

Figura 3.26. Difratogramas para amostras depositadas sobre vidro em $2000 \mathrm{C}$, com $E=100$ eV e $\operatorname{ARR}(\mathrm{I} / \mathrm{A})=$ (a) 5,5 e (b) 0,8 .

\section{(d) Dependência de Espessura}

Para observar o efeito de espessura da amostra, foram produzidas duas amostras em $\mathrm{TA}$ com $\mathrm{E}=100 \mathrm{eV}, \mathrm{ARR}(\mathrm{I} / \mathrm{A})=$ 0,8 e espessura nominal do filme de $3000 \AA$ [figura 3.27(a)] ou $500 \AA$ [figura 3.27(b)]. Observa-se mais nitidamente o pico de In(101) na figura 3.27(a), descartando-se a possibilidade de o 
processo de formação de InN ser dependente da espessura da amostra.

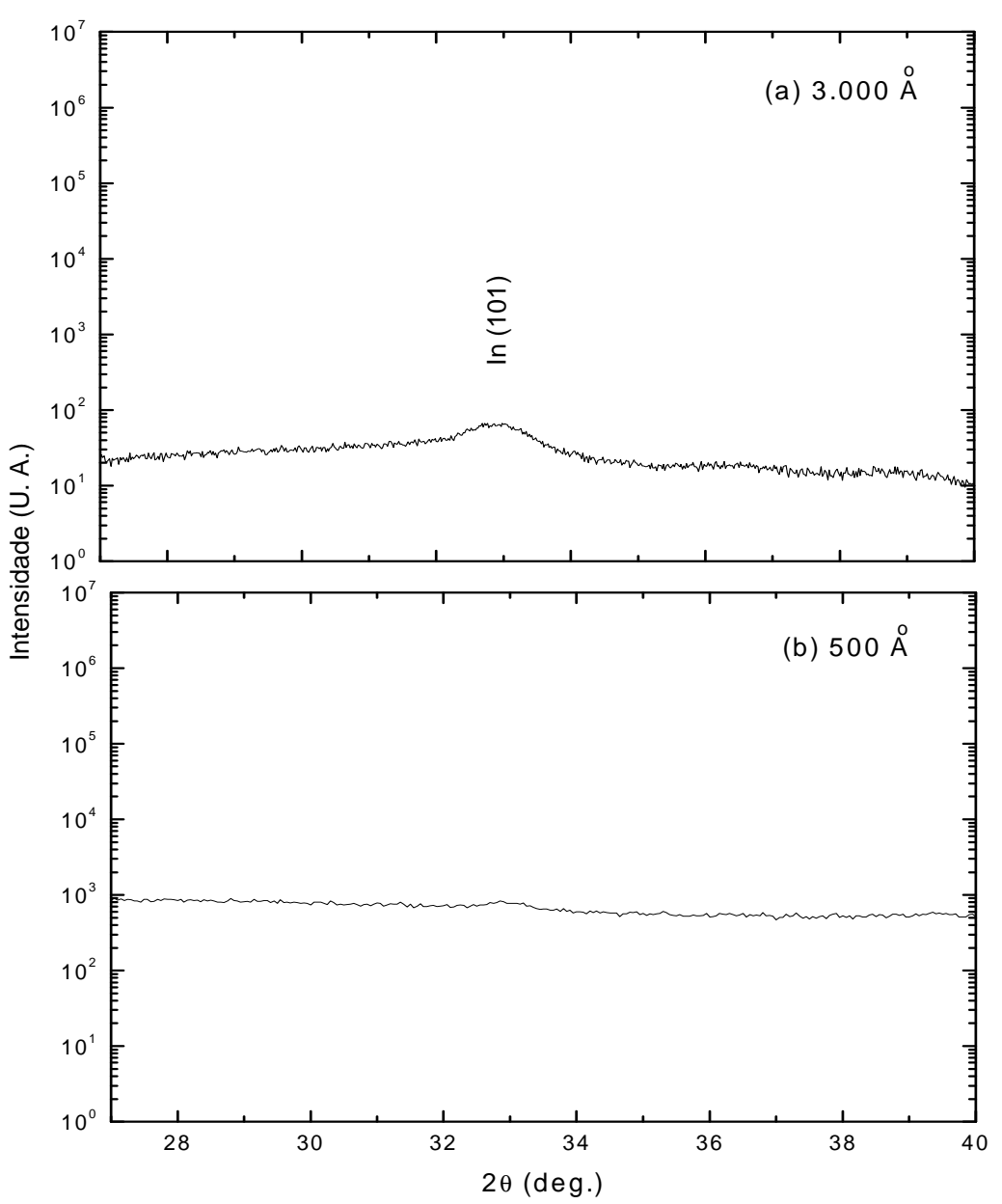

Figura 3.27. Difratograma para amostra depositada sobre vidro em TA, com $E=100 \mathrm{eV}$, $\operatorname{ARR}(\mathrm{I} / \mathrm{A})=0,8$ e espessura nominal de (a) 3000 $\AA$ e (b) 500 A. 


\subsection{SEM}

As medidas de SEM foram realizadas no intuito de observar a morfologia de algumas amostras já apresentadas neste capítulo e investigar a presença de agregados de In metálico nas amostras. A figura 3.28 apresenta a micrografia da amostra depositada em $300^{\circ} \mathrm{C}$ sobre o substrato de GaN/safira com $\mathrm{E}=500 \mathrm{eV}$ e $\operatorname{ARR}(I / A)=4,3$. Na figura, observa-se a presença de buracos na superfície do substrato pelo efeito de sputtering.Este fato foi verificado com a técnica de microssonda eletrônica (EPMA Electron Probe MicroAnalysis), que não foram detectados nessa superfície raios-x característicos de In, significando que não foi depositado nenhum filme na amostra.

As figuras 3.29(a) e 3.29(b) mostram as micrografias das amostras crescidas em $\mathrm{TA}$ e $450^{\circ} \mathrm{C}$, respectivamente, sobre os substratos de vidro, com $E=100 \mathrm{eV}$ e $\mathrm{ARR}(\mathrm{I} / \mathrm{A})=0,8$. A amostra crescida em TA apresenta a superfície lisa, enquanto que a amostra em $450{ }^{\circ} \mathrm{C}$, agregados de In metálico na superfície, em conseqüência da segregação do metal. Conclui-se que: (i) quando E é igual ou superior a $500 \mathrm{eV}$, a amostra não é depositada no substrato de GaN/safira por causa de sputtering; (ii) as amostras foram observadas nos outros substratos para todos os valores de E utilizados. 


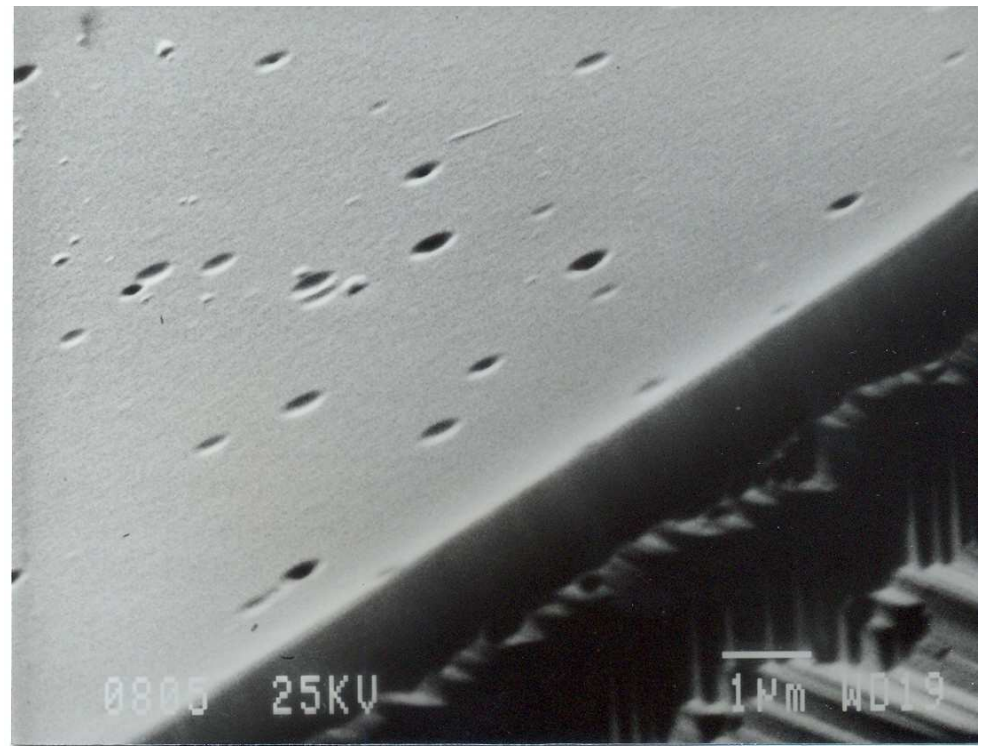

Figura 3.28. Micrografia da amostra gano6 depositado sobre safira/GaN em $300^{\circ} \mathrm{C}$ com energia de íons de 500 eV e $\operatorname{ARR}(I / A)=4,3$.

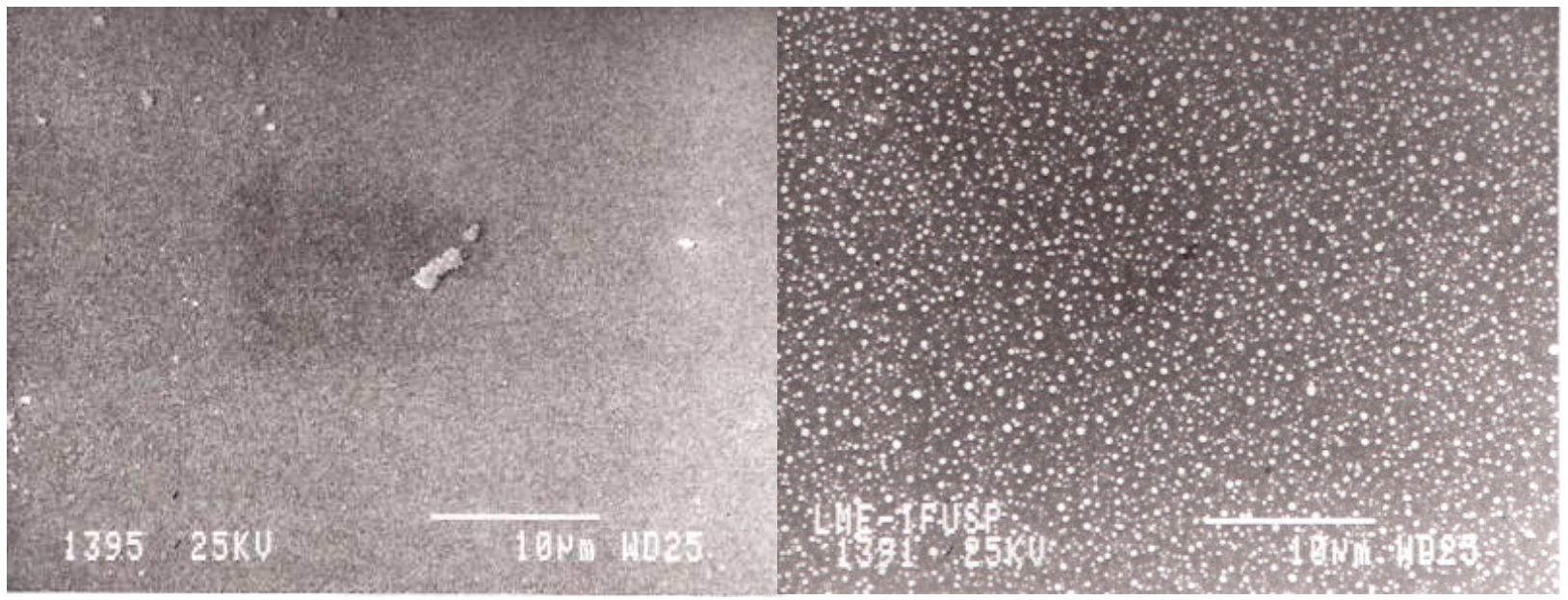

(a)

(b)

Figura 3.29. Amostras depositadas sobre substratos de vidro em (a) TA e (b) $450{ }^{\circ} \mathrm{C}$, com $\mathrm{ARR}(\mathrm{I} / \mathrm{A})=0,8$ e energia de íons de $100 \mathrm{eV}$. 


\subsection{Espectroscopia Raman}

As medidas de espectros Raman foram feitas na região de $400-700 \mathrm{~cm}^{-1}$ para avaliação da estrutura cristalina e qualidade cristalina de $\mathrm{InN}$ nas amostras. $\mathrm{O}$ h-InN pertence ao grupo espacial de $C_{6 V}^{4}$. A teoria de grupo prediz a seguinte representação para os modos vibracionais: $A_{1}+2 B_{1}+E_{1}+2 E_{2}$ $[1,2]$. Os modos $A_{1}$ e $E_{1}$ correspondem às vibrações axial e planar, respectivamente; eles separam-se em: modos acústico e ótico longitudinais (LA e LO) e modos acústico e ótico transversos (TA e TO), e os modos LO e TO podem ser ativos em Raman e Infravermelho. O modo $E_{2}$ é ativo somente em Raman e o $B_{1}$ é proibido, e cada modo tem dois modos marcados como high e low, conforme suas freqüências. Portanto, os modos ativos em Raman são $A_{1}(\mathrm{LO}), A_{1}(\mathrm{TO}), E_{1}(\mathrm{LO}), E_{1}(\mathrm{TO}), E_{2}(h i g h)$ e $E_{2}(l o w)$. No espectro Raman de h-InN na região de 400 a $700 \mathrm{~cm}^{-1}$, são observados os $A_{1}(\mathrm{TO}), E_{1}(\mathrm{TO}), E_{2}(\mathrm{high})$ e $A_{1}(\mathrm{LO})$ e $E_{1}(\mathrm{LO})$, respectivamente, em $448 \pm 13,469 \pm 7,488 \pm 4,556 \pm 20,588 \pm$ $4 \mathrm{~cm}^{-1}[48]$. Por outro lado, o c-InN pertence ao grupo especial de $T_{d}^{2}$, e há um modo LO e um TO. Os estudos de espalhamento Raman de c-InN são pouco relatados na literatura; Tabata et al. observaram os modos TO e LO localizados em 457 e $588 \mathrm{~cm}^{-1}$ [49].

As figuras 3.30-3.33 mostram os espectros Raman para as respectivas amostras depositadas em: $450^{\circ} \mathrm{C}$ sobre safira-C; $450^{\circ} \mathrm{C}$ sobre vidro; TA sobre vidro; TA sobre safira-R, com E $=100 \mathrm{eV}$ e $\operatorname{ARR}(I / A)=0,8$. Neles, são observados dois picos em 490 e 580 $\mathrm{cm}^{-1}$. Como observado somente h-InN nos difratogramas dessas amostras, dois picos são identificados como o modo $E_{2}$ (high) e o $A_{1}(\mathrm{LO})$. 
O Modelo de Correlação Espacial (SCM) assume que os fónons são confinados na região do comprimento $L$ onde são livremente propagados nesta região. A intensidade do pico do modo $A_{1}(\mathrm{LO})$ é dada por:

$$
I(w) \cong \int_{0}^{1} \frac{\exp \left(-q^{2} L^{2} / 4 a^{2}\right) d^{3} q}{[w-w(q)]^{2}+\left(\Gamma_{0} / 2\right)^{2}}
$$

onde $q$ é vetor de onda na unidade $2 \pi / a$, $a$ é o parâmetro de rede, $\Gamma_{0}$ é a largura do pico espalhado numa rede ideal e $\omega(q)$ é a curva de dispersão de fônon. Esta equação é integrada em uma zona de Brillouin esférica. E a relação de dispersão de fónon isotrópico é dada por:

$$
w(q)=A+B \cos (q \pi)
$$

onde as constantes $A=565 \mathrm{~cm}^{-1}$ e $B=20 \mathrm{~cm}^{-1}$ são determinadas pela curva de dispersão de fónon [50].

Os resultados da deconvolução estão indicados em cada espectro. O comprimento de correlação $L$ pode ser interpretado fisicamente como a distância média entre dois defeitos ou qualquer outro tipo de imperfeição no cristal. Portanto, o $L$ relaciona-se à qualidade cristalina do filme. O valor médio obtido nos resultados de deconvoluções para o parâmetro $L$ é igual a $28 \AA$ e este valor corresponde a densidade de defeitos existentes em cristalitos de InN de 4,6 x $10^{19} \mathrm{~cm}^{-3}$ ). 


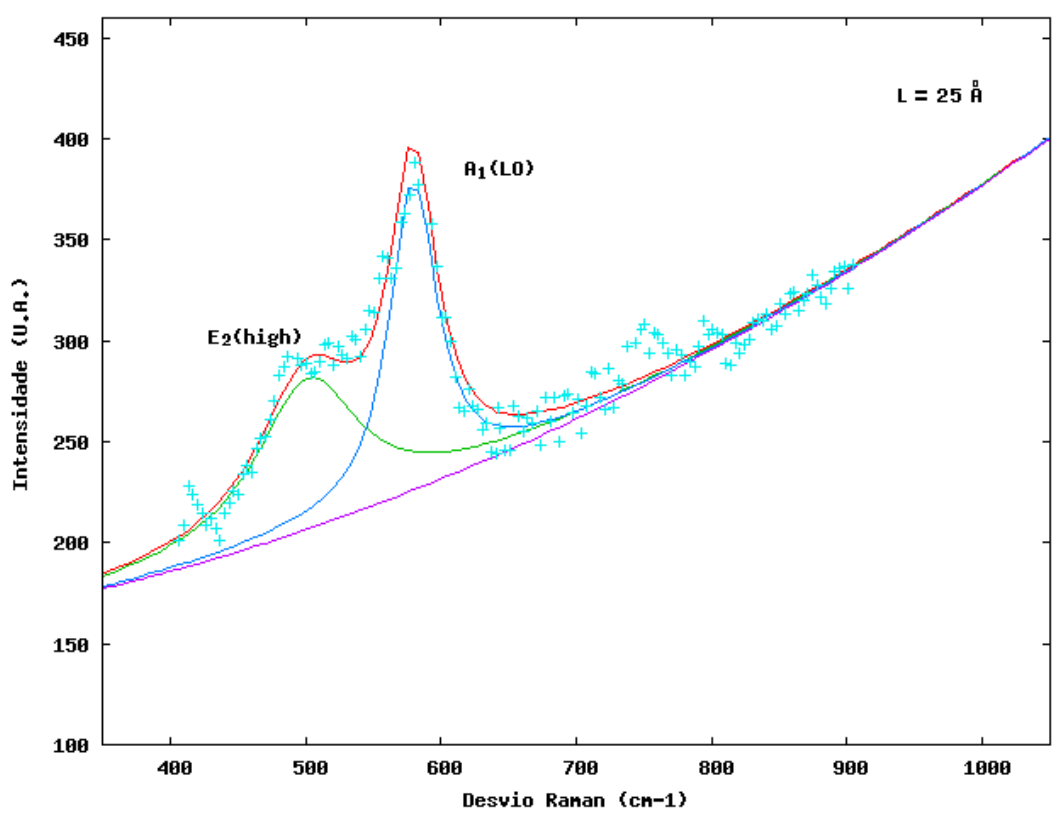

Figura 3.30. Espectro Raman para amostra depositada sobre substrato de safira- $\mathrm{C}$ em $450^{\circ} \mathrm{C} \operatorname{com} \mathrm{E}=100 \mathrm{eV}$ e $\operatorname{ARR}(\mathbf{I} / \mathrm{A})=\mathbf{0 , 8}$.

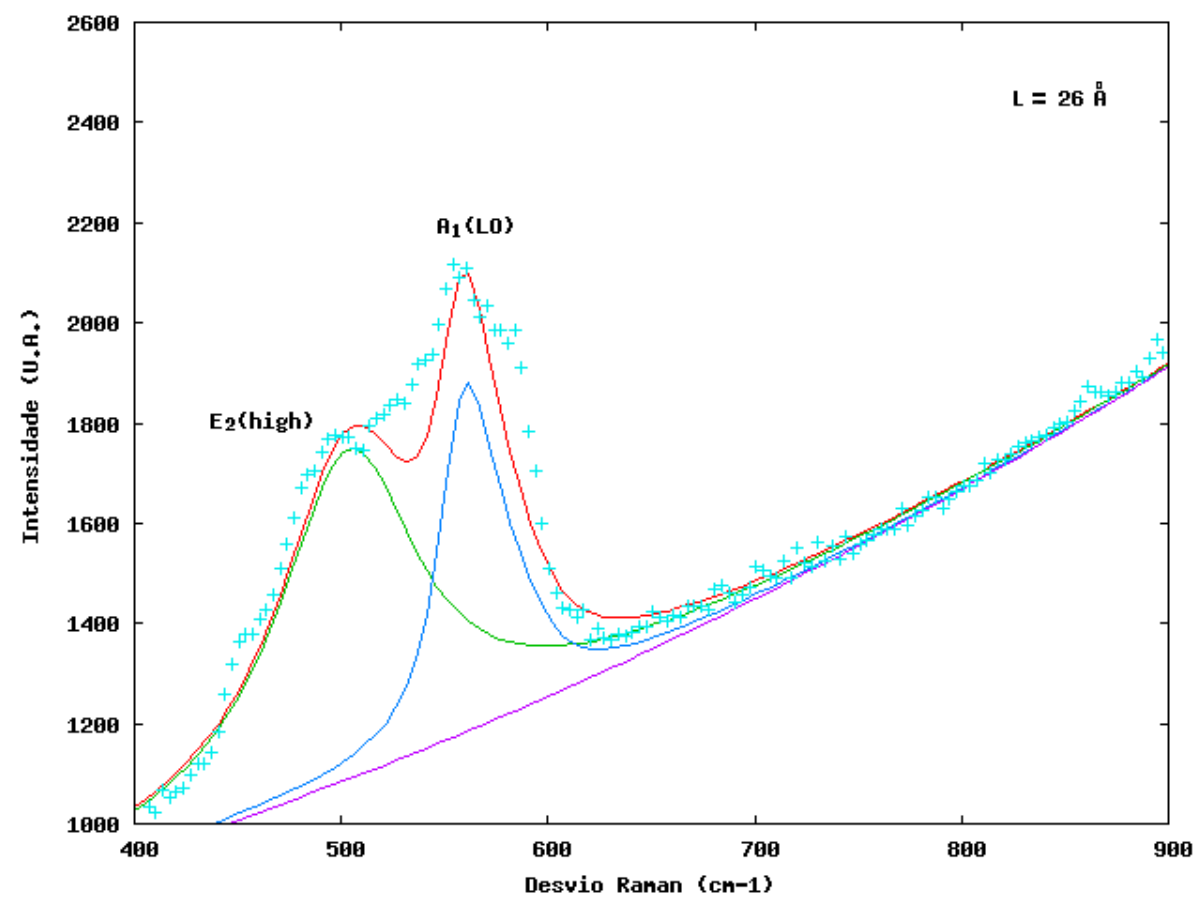

Figura 3.31. Espectro Raman para amostra depositada sobre vidro em $450^{\circ} \mathrm{C} \operatorname{com} E=100$ eV e $A R R(I / A)=0,8$. 


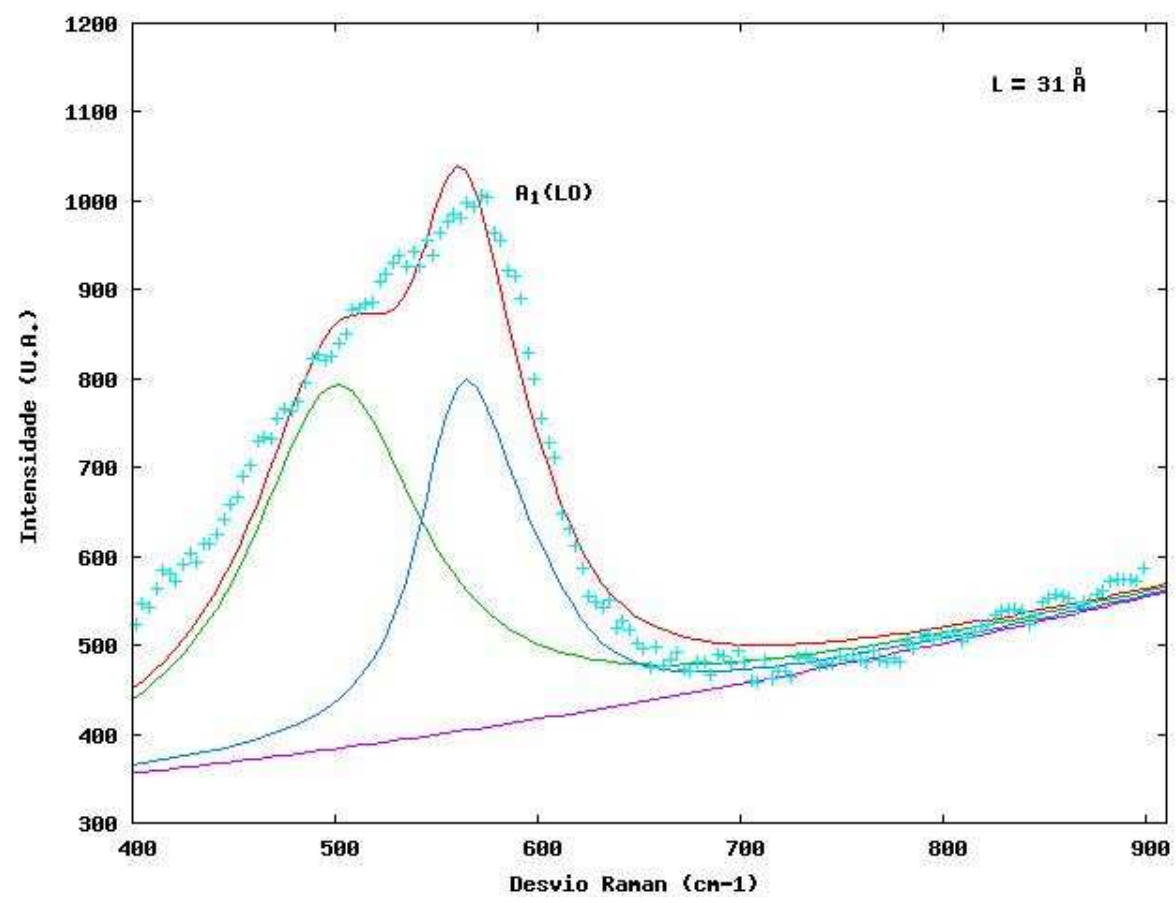

Figura 3.32. Espectro Raman para amostra depositada sobre vidro em TA com $E=100$ eV e $A R R(I / A)=0,8$.

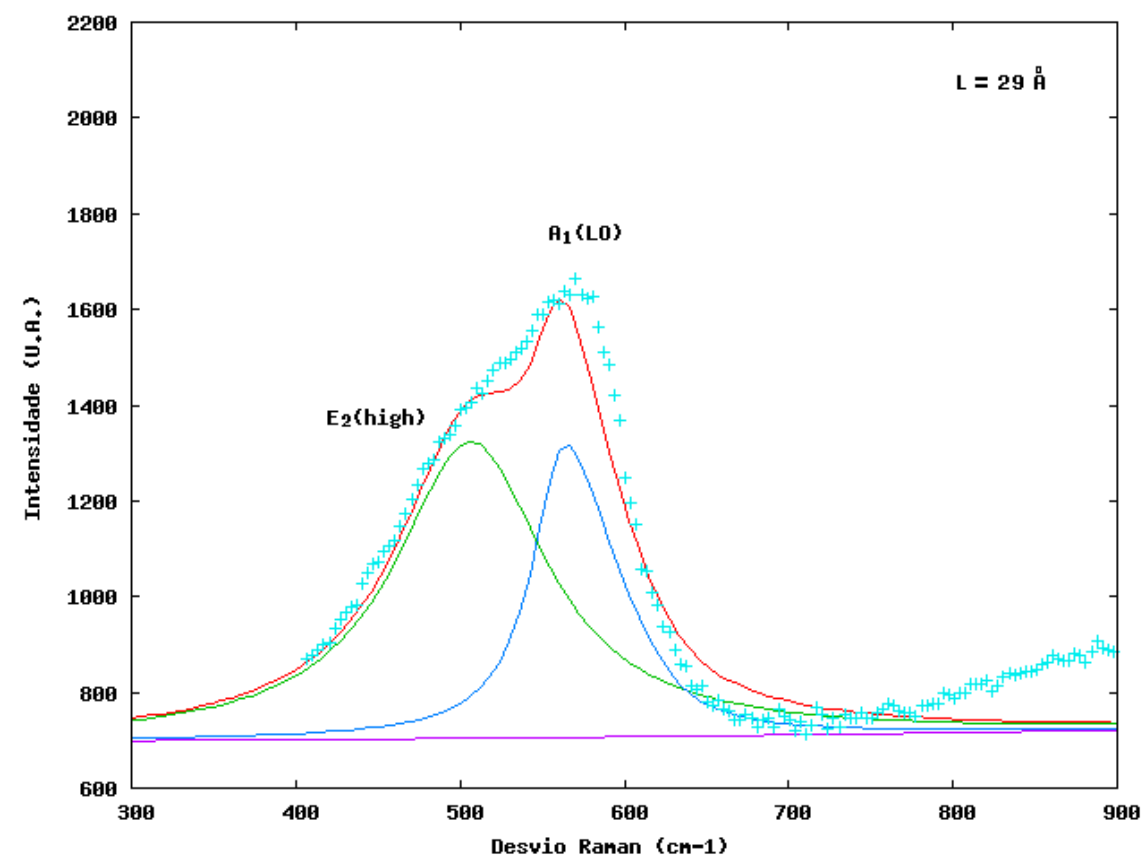

Figura 3.33. Espectro Raman para amostra depositada sobre safira-R em TA com $E=100$ eV e ARR(I/A) $=0,8$. 


\subsection{XPS}

As medidas de XPS foram feitas a fim de estudar o estado químico do átomo emissor e a composição química na superfície do filme. Para limpeza das amostras antes da medida, foi feito in situ sputtering da superfície de cada uma por íons de argônio a $3 \mathrm{keV}$.

Os estudos dos espectros XPS foram concentrados nos espectros de In $3 d$ e de $\mathrm{N} 1 s$. As deconvoluções dos picos foram feitas usando funções Voigt (convolução da função gaussiana e da lorentziana).

As figuras 3.34(a) e 3.34(b) são os espectros de $\mathrm{N} 1 s$ e de In $3 d$, respectivamente, para a amostra depositada em $450^{\circ} \mathrm{C}$ sobre o substrato de vidro $\operatorname{com} \mathrm{E}=100 \mathrm{eV}$ e $\mathrm{ARR}(\mathrm{I} / \mathrm{A})=0,8$, e as figuras 3.35(a) e 3.35(b) são os respectivos espectros de $\mathrm{N}$ $1 s$ e de In $3 d$ para a amostra depositada em TA sobre substrato $\mathrm{de} \mathrm{GaN} / \mathrm{safira}$ com $\mathrm{E}=100 \mathrm{eV}$ e $\mathrm{ARR}(\mathrm{I} / \mathrm{A})=0,8$.

$\mathrm{Na}$ figura 3.34(a), observam-se quatro picos em 396,8; 398,4; 400,0 e 404,0 eV de energia de ligação, que são associados a: InN, ligações $\mathrm{N}-\mathrm{N}, \mathrm{N}-\mathrm{H}$ e $\mathrm{N}-\mathrm{O}$, respectivamente. $\mathrm{Na}$ figura 3.34(b), são observados duas bandas na região da energia de ligação de 444 e na região de $\sim 452$ eV bem separadas, por causa da interação spin-órbita, que são caracterizados por In $3 d_{5 / 2}$ e In $3 d_{3 / 2}$, respectivamente. Na banda de In $3 d_{5 / 2}$, são deconvoluídos dois picos em 443,6 e 444,7 eV que são associados, respectivamente, à In metálico e InN [4,5]. A atribuição de InN e In é consistente com o resultado de XRD dessa amostra [ver a figura 3.25(a)]. 


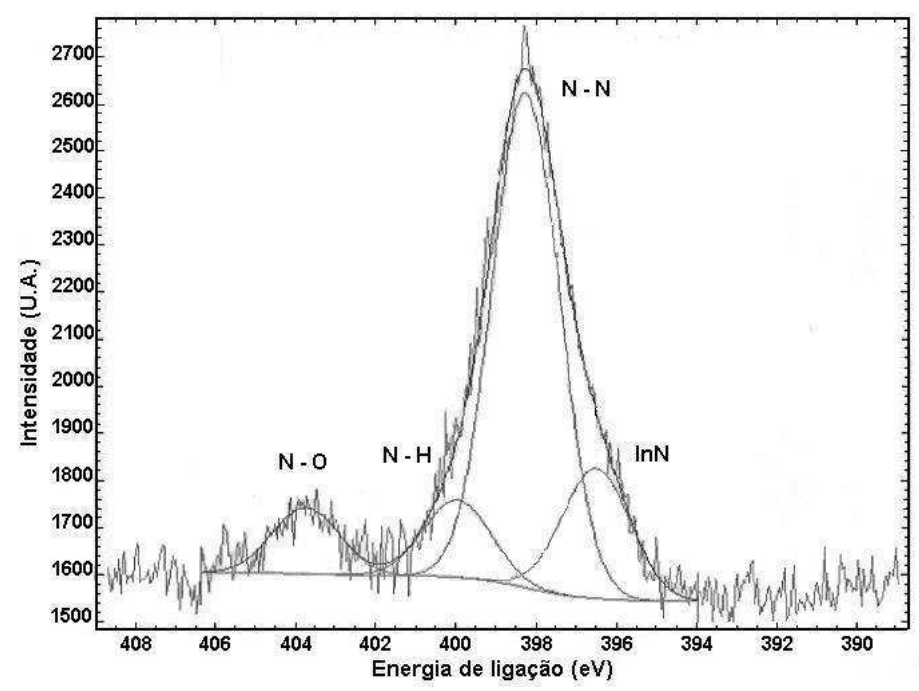

(a)

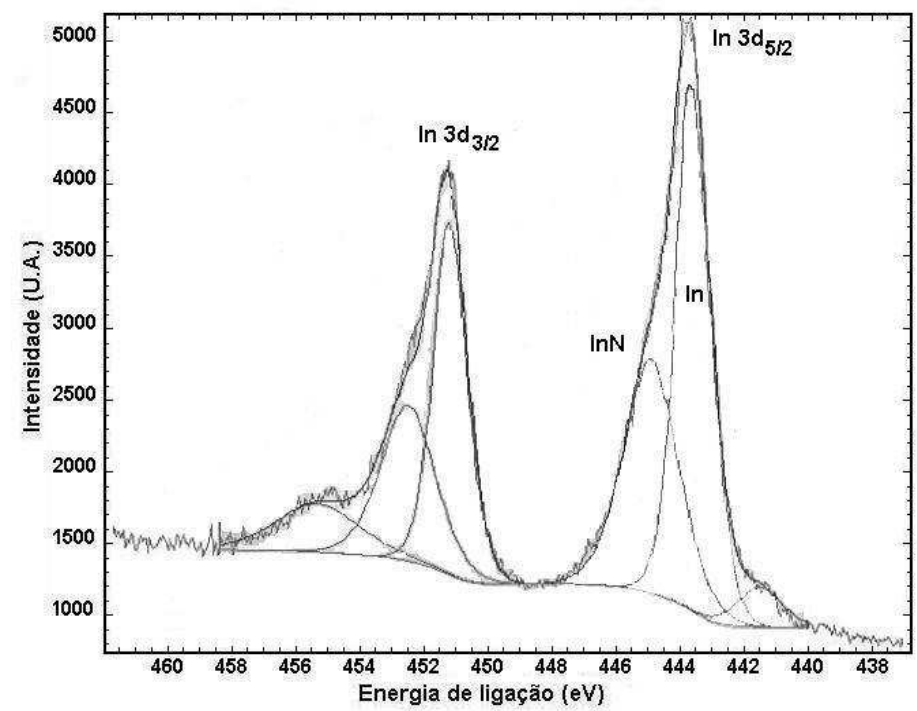

(b)

Figura 3.34. Espectros XPS de (a) N 1s e (b) In 3d para amostra depositada sobre vidro em $450^{\circ} \mathrm{C}$ com $\operatorname{ARR}(\mathrm{I} / \mathrm{A})=0,8 \mathrm{e} \mathrm{E}=100 \mathrm{eV}$.

Na figura 3.35(a), foram observados os três picos de $\mathrm{InN}$, N-H e N-O, além de: um pico em 397,2 eV que é devido a GaN do substrato e da contribuição de elétrons Auger oriundo de Ga $\left(L_{2} M_{4,5} M_{4,5}\right)$ na região de 389-395 eV. Na figura 3.35(b), observa-se somente um pico em 444,7 eV de energia de ligação, referente à InN. Este resultado indica que todos os átomos de índio da amostra estão ligados a átomos de nitrogênio nessa amostra. 


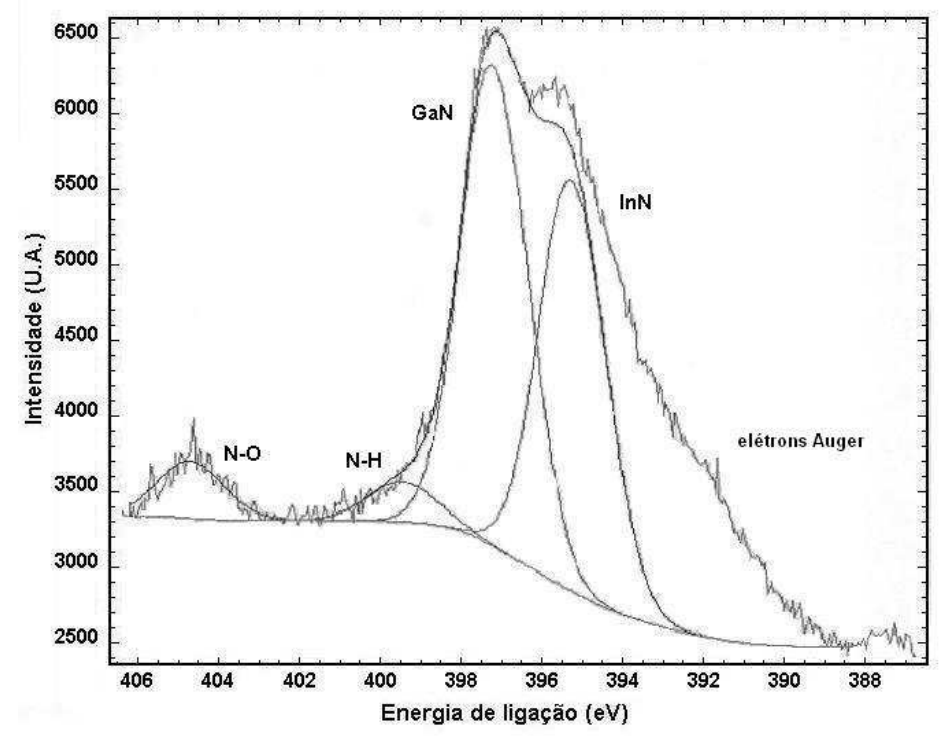

(a)

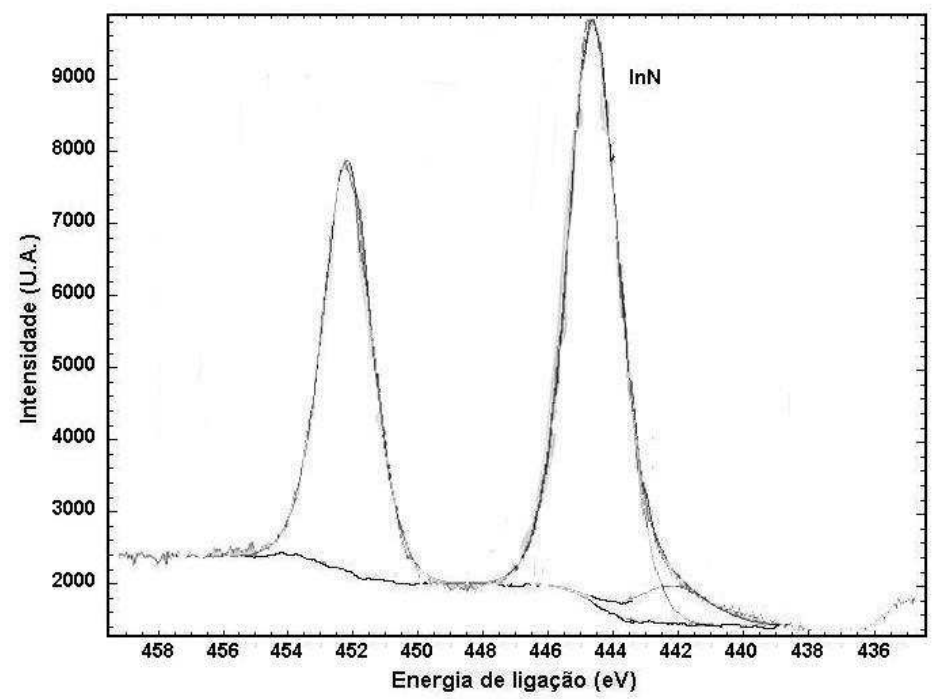

(b)

Figura 3.35. Espectros XPS de: (a) N 1s e (b) In 3d, para amostra depositada sobre GaN/safira na TA, com $\operatorname{ARR}(\mathrm{I} / \mathrm{A})=0,8 \mathrm{e} \mathrm{E}=100 \mathrm{eV}$.

A tabela 3.1 apresenta as concentrações de elementos detectados por XPS para as amostras analisadas. A presença de: $\mathrm{Si}, \mathrm{Ba}$ e uma parte de $\mathrm{O}$ na amostra depositada em vidro (borosilicato de bário); Ga na amostra em GaN/safira; Al e uma parte de $\mathrm{O}$ na amostra em safira-C, é atribuída às composições dos respectivos substratos, significando que o tempo de sputtering por íons de Ar foi suficiente para que íons atingissem cada substrato. 
Note que todas as amostras analisadas possuem ao menos C como um contaminante.

Tabela 3.1. Composições ( $\%$ at.).

\begin{tabular}{ccccccccc}
\hline \hline Amostra & $\mathbf{N}$ & $\mathbf{I n}$ & $\mathbf{G a}$ & $\mathbf{S i}$ & $\mathbf{C}$ & $\mathbf{O}$ & $\mathbf{B a}$ & Al \\
\hline vidro07 & 7,86 & 15,69 & - & 11,38 & 18,30 & 45,21 & 1,58 & - \\
$\operatorname{vidro02}$ & 8,86 & 6,77 & - & 16,97 & 24,76 & 41,38 & 1,24 & - \\
$\operatorname{gan} 16$ & 25,48 & 15,36 & 23,34 & 2,96 & 11,60 & 21,26 & - & - \\
$\operatorname{safC07}$ & 9,50 & 19,01 & - & 4,63 & 13,78 & 41,77 & - & 11,31 \\
\hline \hline
\end{tabular}

\subsection{Absorção Ótica}

Para determinar o band gap ótico, foram medidos os espectros de absorção de algumas amostras preparadas em substrato de vidro. Usando esses espectros e a referência [47], foram construídos os gráficos do quadrado do produto entre o coeficiente de absorção e a energia da luz incidente, em função da energia da luz incidente. Fazendo um ajuste linear em cada gráfico, o valor do band gap ótico foi obtido através do valor correspondente ao ponto de intersecção da reta ajustada com o eixo da energia da luz incidente.

Os gráficos são apresentados nas figuras 3.36-3.38 para as amostras depositadas, respectivamente, em: $450^{\circ} \mathrm{C} \operatorname{com} \mathrm{E}=100$ $\mathrm{eV}$ e $\mathrm{ARR}(\mathrm{I} / \mathrm{A})=0,8 ; 300^{\circ} \mathrm{C} \operatorname{com} \mathrm{E}=100 \mathrm{eV}$ e $\mathrm{ARR}(\mathrm{I} / \mathrm{A})=5,5$; $300^{\circ} \mathrm{C}$ com $\mathrm{E}=100 \mathrm{eV}$ e $\mathrm{ARR}(\mathrm{I} / \mathrm{A})=0,8$, e os valores do band gap ótico obtidos são, respectivamente, 1,71, 1,64 e 2,06 eV. Existe divergência a respeito do valor do band gap ótico. A maioria dos valores experimentais do band gap ótico é cerca de 1,9-2,0 eV; mas, recentemente são relatados valores de 0,7-1,1 eV para amostras consideradas de alta qualidade e crescidas com as técnicas de MBE e MOVPE. Acredita-se que o valores de 1,9-2,0 eV sejam para as amostras policristalinas [32]. Os valores do 
band gap ótico estimados no presente trabalho estão mais próximos aos valores típicos das amostras policristalinas, concordando com os resultados de Raman; entretanto, a quantidade dos resultados obtidos é insuficiente para alguma conclusão. A investigação sobre o band gap ótico para InN está em andamento.

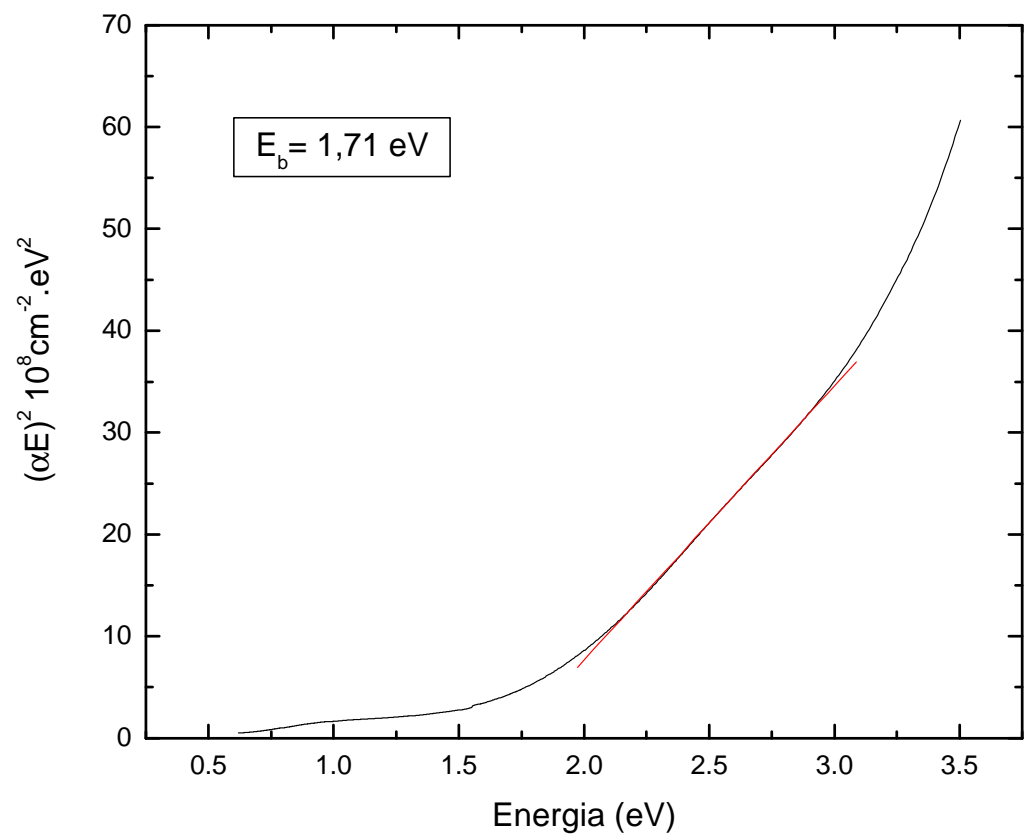

Figura 3.36. $(\alpha \mathbf{E})^{2}$ vs. Energia para amostra depositada em $450^{\circ} \mathrm{C}$ sobre vidro, $\operatorname{com} \mathrm{E}=100 \mathrm{eV}$ e $\mathrm{ARR}(\mathrm{I} / \mathrm{A})=0,8$. 


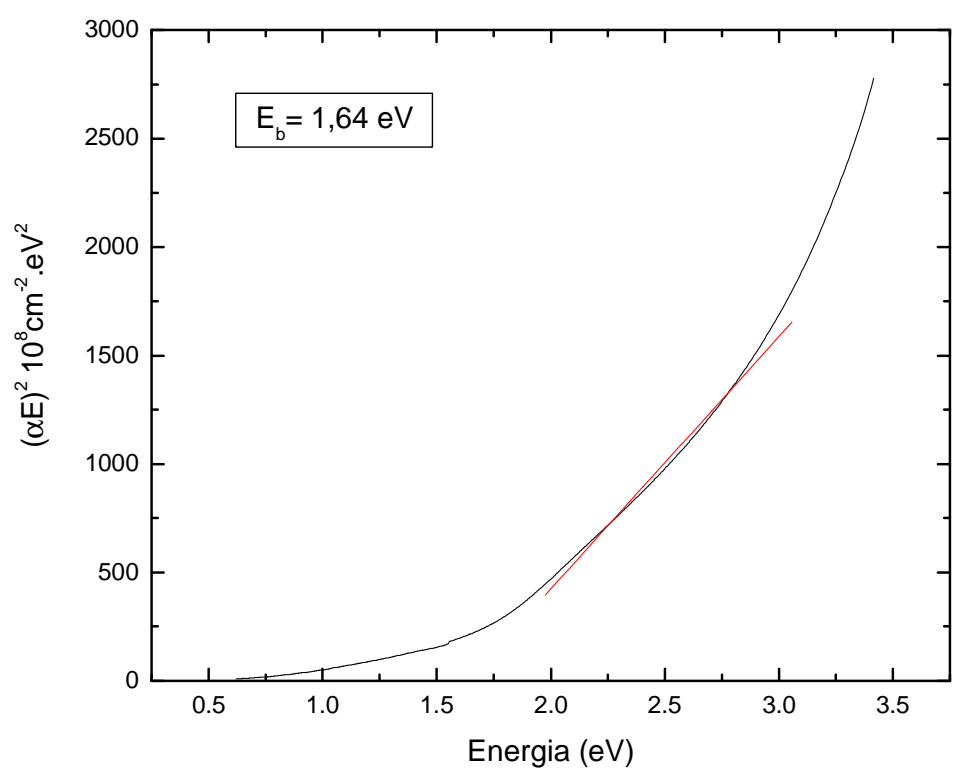

Figura 3.37. $(\alpha \mathbf{E})^{2}$ vs. Energia para amostra depositada em $300^{\circ} \mathrm{C}$ sobre vidro, com $\mathrm{E}=100 \mathrm{eV}$ e $\operatorname{ARR}(\mathrm{I} / \mathrm{A})=5,5$.

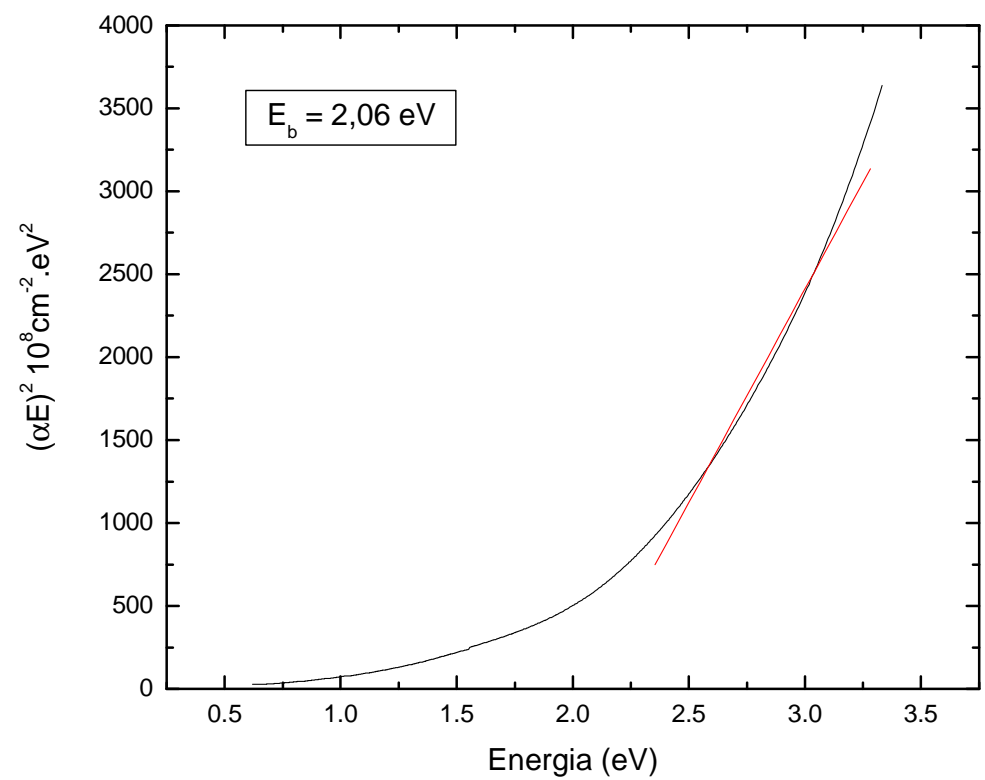

Figura 3.38. $(\alpha \mathbf{E})^{2}$ vs. Energia para amostra depositada em $300^{\circ} \mathrm{C}$ sobre vidro, $\operatorname{com} \mathrm{E}=100 \mathrm{eV}$ e $\mathrm{ARR}(\mathrm{I} / \mathrm{A})=0,8$. 


\section{Capítulo 4}

\section{Conclusão}

Esta dissertação teve como objetivo principal depositar os filmes de InN com o método IBAD e caracterizá-los usando as técnicas de XRD, SEM, espectroscopia Raman, XPS e absorção ótica.

Os resultados obtidos em termos dos parâmetros de deposição foram os seguintes:

\section{(1) Tipo de Substrato}

Foram encontrados dois picos de difração principais, um de h-InN(002) em 31,3o e o outro de In(101) em 32,9o. Observando-se a variação da intensidade do pico de h-InN(002), foi verificado que, para formar o h-InN cristalino, é melhor usar substratos de safira-C, safira-A e GaN/safira (ver as figuras $3.1,3.7,3.12,3.15,3.16$ e 3.22 ). Este fato indica que a formação de InN cristalino é influenciada fortemente pela estrutura cristalina no plano superficial de substrato em que a formação ocorre e pela inibição de formação de InN devido à suposta presença de SiN na superfície de Si(111). Note-se que: (a) a fase cristalina de In metálico acompanha sempre a de $\operatorname{InN}$; (b) a fase cristalina de $c-\operatorname{InN}$ aparece nitidamente quando a amostra é depositada acima de $3000 \mathrm{C}$ sobre o substrato de $\mathrm{GaN} / \mathrm{safira}$. 


\section{(2) Energia de íons, E}

Os dois picos de difração de h-InN(002) e $\operatorname{In}(101)$ mostram uma tendência de diminuírem em intensidade com o aumento de $\mathrm{E}$ (figuras 3.3, 3.9, 3.13, 3.18, 3.19,). Este fato significa que o bombardeamento por íons energéticos fornece energia requerida para a formação e crescimento da fase cristalina; porém, ao mesmo tempo, esse bombardeamento pode destruir a fase cristalina já formada criando grande quantidade de danos de radiação. Com E acima de 500 eV, as amostras não foram depositadas sobre os substratos de GaN/safira, em conseqüência do sputtering por íons mais energéticos (figura 3.28). Foi verificado também no presente estudo, que o melhor valor da energia de íons foi $100 \mathrm{eV}$ para a formação de InN cristalino.

\section{(3) Temperatura de substrato, TS}

As amostras formadas em TA são encontradas principalmente amorfas e, com o aumento de TS, os dois picos de $h-\operatorname{InN}(002)$ e $\operatorname{In}(101)$ aparecem e crescem em intensidade junto. Foi verificado que, quanto mais alta a TS, melhor é a cristalização da amostra. A imagem de SEM indica agregados de In metálico na superfície de InN da amostra depositada em $450 \mathrm{oC}$ [figura $3.29(\mathrm{a})$ ]. Este fato ocorre em virtude da mobilidade mais alta dos átomos depositados na superfície do substrato quando a TS é aumentada, facilitando a formação e cristalização de InN e, segregação de In metálico. Foi confirmado através dos resultados obtidos com XPS que a amostra depositada em TA sobre o substrato de GAN/safira é amorfa de InN (figura 3.35). 


\section{(4) $\operatorname{ARR}(\mathbf{I} / \mathrm{A})$}

Infelizmente, não houve perceptível dependência desse parâmetro nas formações cristalinas de h-InN e In metálico.

(5) Mistura com íons de argônio no feixe de íons de nitrogênio

Esperava-se que, em uma mesma energia de íons, íons mais pesados transferissem à amostra mais energia necessária para a formação da fase cristalina, melhorando a cristalinidade da amostra. Entretanto, o resultado obtido foi contrário (figura 3.6), significando que o bombardeamento por íons mais pesados destrói a fase cristalina já formada ou inibe essa formação.

Todos os espectros Raman para as amostras preparadas sobre os substratos de safira-C $(\mathrm{E}=100 \mathrm{eV}, \mathrm{ARR}(\mathrm{I} / \mathrm{A})=0,8 \mathrm{e}$ TS $=450 \mathrm{oC}$; figura 3.30), de vidro $(\mathrm{E}=100 \mathrm{eV}, \operatorname{ARR}(\mathrm{I} / \mathrm{A})=$ 0,8 e TS $=$ TA, 450oC; figuras 3.32 e 3.31 , respectivamente) e de safira-R $(E=100 \mathrm{eV}, \operatorname{ARR}(\mathrm{I} / \mathrm{A})=0,8$ e $\mathrm{TS}=\mathrm{TA}$; figura $3.33)$ apresentam dois modos de vibração [ $E_{2}(h i g h)$ e $\left.A_{1}(L O)\right]$ característicos de h-InN cristalino e, através das análises dos espectros, foi possível determinar o tamanho de cristalitos de InN igual a 2,8 $\pm 0,3 \mathrm{~nm}$. Esse resultado sobre o tamanho de cristalitos não é contraditório à afirmação de que os valores de band gap ótico obtidos pelas análises dos espectros de absorção ótica (1,6-2,1 eV) são típicos das amostras policristalinas.

Espera-se que alguns problemas aqui levantados possam ser resolvidos através de pesquisas futuras. Ao se concluir este capítulo, sugere-se a realização de tratamentos químico com $\mathrm{HCl}$ para remover os agregados de In metálico na superfície de In $\mathrm{N}$ da amostra crescida. 


\section{Capítulo 5}

\section{Bibliografia}

[1] S.C.Jain, M.Willander, J.Narayan, R.V.Overstraeten, J.Appl. Phys. 87, 965 (2000).

[2] S.Strite, H.Morkoc, J.Vac.Sci.Technol. B 10, 1237 (1992).

[3] S.N.Mohammad, H.Morkoc, Prog.Quantum Electron. 20, 361 (1996).

[4] O.Ambacher; J. Phys.D: Appl. Phys., 312653 (1998).

[5] I.Akasaki, H.Amano, N.Koide, M.Kotaki, K.Manabe, Physica B 185, 428 (1993)

[6] S.Nakamura, M.Senoh, S.Nagahama, N.Yamada, T.Matsushita, H.Kiyoku, Y.Sugimoto, Jpn J. Appl. Phys., Part 2 35, L74 (1996).

[7] A.G.Bhuiyan, A.Hashimoto, A.Yamamoto, J. Appl. Phys. 94, 2779 (2003).

[8] C.Nörenberg, M.G.Martin, R.A.Oliver, M.R.Castell, G.A.D. Briggs, J.Phys. D 35, 615 (2002).

[9] A.Koukito, N.Takahashi, H.Seki, Jpn. J. Appl. Phys.,Part 2 36, L1136 (1997).

[10] R.Juza, H.Hahn, Z. Anorg. Allg. Chem. 239, 282 (1938).

[11] R.Juza, A.Rabenau, Z. Anorg. Allg. Chem. 285, 212 (1956).

[12] T.Renner, Z. Anorg Allg. Chem., 298, 28 (1958).

[13] J.Pastrnak, L.Souckova, Phys. Status Solidi 3, K71 (1963).

[14] G.V.Samsonov, Nitridy Kiev, 1969. 
[15] J.B.McChesney, P.M.Bridenbaugh, P.B.O'Connor, Mater. Res. Bull. 5, 783 (1970).

[16] H.J.Hovel, J.J.Cuomo; Appl. Phys. Lett. 20, 71 (1972).

[17] J.W.Trainor, K.Rose; J.Electron. Matter., 3, 821 (1974).

[18] K.Osamura, K.Nakajima, Y.Murakami, H.P.Shingu, A.Ohtsuki; Solid State Commun., 11, 617 (1972).

[19] K.Osamura, S.Naka, Y.Murakami; J. Appl. Phys. 46, 3432 (1975).

[20] L.A.Marasina, I.G.Pichugin, M.Tlaczala, Krist. Tech. 12, 541 (1977).

[21] T.L.Tansley, C.P.Foley, Electron. Lett. 20, 1066 (1984).

[22] C.P.Foley, T.L.Tansley, Appl. Surf. Sci. 22/23, 663 (1985)

[23] P.Foley, T.L.Tansley, Phys. Rev. B 33, 1430 (1986).

[24] B.T.Sullivan, R.R.Parsons, K.L.Westra, M.J.Brett, J. Appl. Phys. 64, 4144 (1988).

[25] K.Kubota, Y.Kobayashi, K.Fujimoto, J. Appl. Phys. 66, 2984 (1989).

[26] A.Yamamoto, T.Tanaka, K.Koide, A.Hashimoto, Phys. Status Solidi A 194, 510 (2002).

[27] T.Yodo, H.Ando, D.Nosei, Y.Harada, Phys. Status Solidi B 228, 21 (2001).

[28] Z.G.Qian, W.Z.Shen, H.Ogawa, Q.X.Guo, J. Phys.: Condens. Matter. 16, R381 (2004)

[29] W.K.Chen, H.C.Lin, Y.C.Pan, J.Ou, C.K.Shu, W.H.Chen, M.C.Lee, Jpn J. Appl. Phys., Part1 37, 4870 (1998).

[30] Q.X.Guo, A.Okade, H.Kidera, T.Tanaka, M.Nishio, H.Ogawa, J. Cryst. Growth 237-239, 1032 (2002).

[31] A.G.Rubhuiyan, A.Hashimoto, A.Yamamoto; J. Appl. Phys., 942779 (2003).

[32] T.Yodo, H.Yona, H.Ando, D.Nosei, Y.Harada, Appl. Phys. Lett. 80, 968 (2002).

[33] T.E.Lamas, Epitaxia por feixe molecular de camadas dopadas do tipo p para a construção de dispositivos optoeletrônicos, Tese (Doutorado) IFUSP, (2004). 
[34] J.F.D.Chubaci, Formação e caracterização de filmes finos de nitreto de carbono, Tese (Doutorado) IFUSP, (1996).

[35] W.A.S.Mamani, Formação e caracterização de filmes finos de nitreto de carbono por IBAD, Tese (Doutorado) IFUSP, (2007).

[36] S.C.Brown, Basic Data of Plasma Physics, MIT Press, Cambridge, MA, 67 (1967).

[37] B.D.Cullity; Elements of x-Ray Diffraction; AddisonWesley Publishing Company Inc., Reading, Massachusetts, (1967).

[38] C.Kittel, Introdução à Física do Estado Solido, Ed. Guanabara Dois RJ, (1978).

[39] F.F.Ferreira, Eletrocromismo em filmes finos compósitos, Tese (Doutorado) IFUSP, (2003).

[40] P.Kiyohara, M.Silveira, Disciplina Introdução à Microscopia Eletrônica, notas de aula, (1998).

[41]http://carbon.cudenver.edu/public/chemistry/classes/chem 4 538/raman.htm

[42] O.Sala, Fundamentos da espectroscopia Raman e no infravermelho, Unesp, São Paulo, (1995).

[43] P.A.P.Nascente, Caracterização de Materiais por Técnicas de Análise de Superfícies, notas de aula, (2001).

[44] M.L.F.Nascimento, Condutividade Elétrica de Vidros de Boratos, Silicatos e Sílico-Sulfatos de Íons Alcalinos, Tese (Doutorado) IFUSP, (2000).

[45] T.Yodo, Y.Kitayama, K.Miyaki, H.Yona, Jpn. J. Appl. Phys.43, L139 (2004).

[46] Z.Bi, J. Crys. Gr.300, 123 (2007).

[47] K.S.A.Butcher, T.L.Tansley, Sup. Mic. 38, 1 (2005).

[48] G.Kaczmarczyk, A.Kaschner, S.Reich, A.Hoffmann, C.Thomsen, Appl. Phys. Let.76, 15 (2000)

[49] A.Tabata et al, App1.74, 362 (1999)

[50] Z.G.Qian, W.Z.Shen, J. Appl. Phys.93, 5 (2003) 